Luiz Tadeu de Moura Fachine

\title{
ULTRA-SONOMETRIA ÓSSEA
}

\section{PARA DETERMINAÇÃO DO RISCO DE}

\author{
FRATURA DO FÊMUR
}

Dissertação apresentada ao Programa de PósGraduação das Interunidades de Bioengenharia - Escola de Engenharia de São Carlos, Faculdade de Medicina de Ribeirão Preto e Instituto de Química de São Carlos - da Universidade de São Paulo, como parte dos requisitos para a obtenção do título de Mestre em Bioengenharia.

Orientador: Prof. Dr. João Manuel Domingos de Almeida Rollo

SÃO CARLOS

2006 
AUTORIZO A REPRODUÇÃO E DIVULGAÇ̃̃O TOTAL OU PARCIAL DESTE TRABALHO, POR QUALQUER MEIO CONVENCIONAL OU ELETRÔNICO, PARA FINS DE ESTUDO E PESQUISA, DESDE QUE CITADA A FONTE.

Ficha catalográfica preparada pela Seção de Tratamento da Informação do Serviço de Biblioteca - EESC/USP

F139u

Fachine, Luiz Tadeu de Moura

A ultra-sonometria óssea para determinação do risco de fratura do femur / Luiz Tadeu de Moura Fachine; orientador João Manuel Domingos de Almeida Rollo. -- São Carlos, 2006.

Dissertação (Mestrado-Programa de Pós-Graduação Interunidades em Bioengenharia. Área de Concentração: Bioengenharia) -- Escola de Engenharia de São Carlos, Faculdade de Medicina de Ribeirão Preto e Instituto de Química de São Carlos da Universidade de São Paulo, 2006.

1. Ultra-sonometria óssea. 2. 0steoporose. 3. Fratura do femur. 4. Mulheres de baixa renda. I. Título. 


\section{AGRADECIMENTOS}

A Deus, por mais esta oportunidade de crescimento e conquista. 
Ao Prof. Dr. João Manuel Domingos de Almeida Rollo, pela confiança, ajuda e paciência durante a orientação desta pesquisa.

Aos funcionários da Bioengenharia de São Carlos, especialmente à Janete, pelos auxílios prestados durante a realização deste trabalho.

Aos professores da Bioengenharia, especialmente ao Prof. Dr. Orivaldo Lopes da Silva pelo apoio, incentivo e avaliações realizados. 
A minha esposa Agnes, pelo apoio incondicional que me dispensou durante todo o período de realização deste trabalho e incentivo para que pudesse realizá-lo com dedicação e competência.

Aos meus filhos Bruno e Laura, pela compreensão dos bons momentos a que foram privados de usufruir para que pudesse me dedicar a esta pesquisa e pelo incentivo que recebi ao ser alvo de admiração. 
FACHINE, L.T.M. Ultra-sonometria óssea para determinação do risco de fratura do fêmur . 2006, 126 fls. (Dissertação) - Interunidades em Bioengenharia - Escola de Engenharia de São Carlos, Faculdade de Medicina de Ribeirão Preto e Instituto de Química de São Carlos, Universidade de São Paulo, São Carlos.

\section{RESUMO:}

A osteoporose é uma doença que afeta o tecido ósseo diminuindo sua resistência, que é determinada pela sua densidade, arquitetura e velocidade de remodelamento. O método padrão atualmente utilizado para seu diagnóstico e monitoramento é a densitometria óssea, que utiliza radiação ionizante, e que, por ser caro, é inacessível à maioria da população de baixa renda. Tem, ainda, o inconveniente de não avaliar adequadamente a massa óssea e nem a sua resistência. Vários estudos têm sido publicados discutindo o uso de técnicas complementares ou alternativas para tornar essa avaliação mais confiável. Uma dessas técnicas é a ultra-sonometria óssea do calcâneo, que se baseia na análise da propagação do ultra-som através do osso traduzindo informações de sua qualidade e, com isso, predizendo o risco de fratura, principalmente do colo do fêmur. Esse método não utiliza radiação ionizante, é de fácil aplicação e de baixo custo. Atualmente é utilizado para rastreamento populacional de indivíduos candidatos à densitometria óssea. Como os resultados desse método têm uma melhor correlação com o indivíduo idoso e na avaliação do colo do fêmur, propôs-se a sua utilização para avaliar pacientes de baixa renda cadastrados em serviços públicos de saúde, a 
maioria com doenças concomitantes, rastreando-os para que sejam submetidos a programas de prevenção de fraturas do fêmur, conseqüência de maior morbidade e mortalidade da osteoporose. Como método, um grupo de 757 mulheres idosas foi submetido à avaliação pela ultra-sonometria óssea do calcâneo. Destas, $71 \%$ foram considerados com risco aumentado de fratura (24\% com osteoporose e 47\% com osteopenia, de acordo com os critérios da OMS para a densitometria óssea) e $29 \%$ normais, dados importantes pelo elevado número de indivíduos em risco. Outros parâmetros também foram analisados em função de um questionário respondido pelas examinadas, que mostrou, entre outras informações, a concomitância de moléstias.

Palavras-chave: Ultra-sonometria óssea; osteoporose; fratura do fêmur; mulheres de baixa renda. 
FACHINE, L.T.M. Bone Ultra-sonometry for the assesment of the fêmur fracture risk . 2006, 126 fls. (Dissertação) - Interunidades em Bioengenharia - Escola de Engenharia de São Carlos, Faculdade de Medicina de Ribeirão Preto e Instituto de Química de São Carlos, Universidade de São Paulo, São Carlos.

\section{ABSTRACT:}

Osteoporosis is a disease which affects the bone tissue reducing its resistance that is determined by its density, architecture and speed of remodeling. Currently, the pattern method used for its diagnosis and monitoring is the bone densitometry which makes use of ionizing radiation and because of its high costs, it is not available to the majority of the low-income population. It also has the inconvenience of neither assessing adequately the bone mass nor its resistance. Several studies have been published discussing the use of complementary or alternative techniques to make this evaluation more reliable. One of these techniques is the bone ultra-sonometry of the calcaneus which is based on the analysis of the ultrasound propagation thought the bone translating information about its quality and therefore predicting mainly the fracture risk in the femoral collum this method do not use ionizing radiation, it is easy to apply and has low costs. Nowadays, it is used for populational screening of individuals who are candidates for bone densitometry. As its results have a better correlation with this method in the old individual and in the assessment of the femoral neck, its utilization its proposed to evaluate low-income patients registered at the public health, most of them suffering from concomitant diseases, screening them in the order to be submitted to preventive programs of femoral fractures, the consequence of increased morbity and mortality related to osteoporosis. 
As a method, a group of 757 old women was submitted to the evaluation by the bone ultra-sonometry of the calcaneus. $71 \%$ or the women were considered with increased fracture risk (24\% with osteoporosis and $47 \%$ with osteopenia according to the WHO criteria for densitometry) and $29 \%$ were normal, important data because of the high number of individuals at risk. Other parameters were also analyzed in terms of a questionnaire answered by the evaluated women showing the concomitance of diseases besides other information.

The obtained data are not coincident with those from the literature that observes old individuals who were randomly chosen within the population in general. Such a fact is related to the criterion used for the choice of the studied universe constituted by patients and not simply by individuals who were already registered at the health treatment service. For these reasons, it was concluded that the method in question is valuable to screen low-income old women with the facture risk increased by the reduction of the bone resistance and conduct them to preventive programs of femoral fractures.

Keywords: Ultra-sonometry; osteoporosis; fêmur fracture; low-income women. 


\section{LISTA DE FIGURAS}

\begin{tabular}{|c|c|c|}
\hline Figura 1 & $\begin{array}{l}\text { Representação dos quatro componentes da microestrutura } \\
\text { óssea }\end{array}$ & 29 \\
\hline Figura 2 & $\begin{array}{l}\text { Representação dos dois componentes da macroestrutura } \\
\text { óssea }\end{array}$ & 31 \\
\hline Figura 3 & $\begin{array}{l}\text { Esquema ilustrativo do processo de remodelamento no } \\
\text { osso esponjoso }\end{array}$ & 32 \\
\hline Figura 4 & $\begin{array}{l}\text { Microscopia Eletrônica de Varredura: estrutura do osso } \\
\text { esponjoso }\end{array}$ & 37 \\
\hline Figura 5 & $\begin{array}{l}\text { Curva representativa da mudança na massa óssea em } \\
\text { relação à idade em homens e mulheres, mostrando padrões } \\
\text { de perda óssea }\end{array}$ & 43 \\
\hline Figura 6 & $\begin{array}{l}\text { Incidência de fraturas de quadril, vértebra e rádio distal } \\
\text { relacionadas com a idade em homens e mulheres }\end{array}$ & 45 \\
\hline Figura 7 & $\begin{array}{l}\text { Gráfico demonstrativo resultante da densitomeria óssea da } \\
\text { coluna lombar realizada em aparelho Densitômetro DPX-IQ } \\
\text { Lunar, mostrando densidade mineral óssea de } 1.30 \mathrm{~g} ; \mathrm{cm} 2 \\
\text { num individuo de } 50 \text { anos }\end{array}$ & 58 \\
\hline Figura 8 & $\begin{array}{l}\text { Gráfico demonstrativo resultante da densitomeria óssea do } \\
\text { fêmur proximal realizada em aparelho Densitômetro DPX- } \\
\text { IQ Lunar, mostrando densidade mineral óssea de } 1.19 \\
\mathrm{~g} / \mathrm{cm} 2 \text { num individuo de } 49 \text { anos. }\end{array}$ & 59 \\
\hline Figura 9 & $\begin{array}{l}\text { Fluxograma mostrando elementos responsáveis pela } \\
\text { fratura }\end{array}$ & 62 \\
\hline Figura 10 & Esquema ilustrativo do mecanismo da piezoeletricidade & 66 \\
\hline Figura 11 & $\begin{array}{l}\text { Fotografia localizando o osso calcâneo com ampliação da } \\
\text { área mostrando as características estruturais do tecido } \\
\text { ósseo esponjoso }\end{array}$ & 76 \\
\hline Figura 12 & $\begin{array}{l}\text { Parâmetros determinados pela ultra-sonometria do } \\
\text { calcâneo }\end{array}$ & 77 \\
\hline Figura 13 & Ilustração esquemática das medidas da USO & 78 \\
\hline Figura 14 & $\begin{array}{l}\text { Gráfico exibido no resultado da ultra-sonometria óssea do } \\
\text { calcâneo do aparelho GE-Aquilles, mostrando a correlação } \\
\text { do stiffness e do t-score com a idade do examinado em } \\
\text { anos. }\end{array}$ & 81 \\
\hline Figura 15 & $\begin{array}{l}\text { Número e porcentagem de mulheres examinadas em função do } \\
\text { resultado obtido }\end{array}$ & 88 \\
\hline Figura 16 & Porcentagem de examinados com maior risco de fratura & 88 \\
\hline Figura 17 & $\begin{array}{l}\text { Porcentagem de doenças concomitantes entre as mulheres } \\
\text { examinadas de acordo com questionário respondido }\end{array}$ & 89 \\
\hline Figura 18 & $\begin{array}{l}\text { Porcentagem de mulheres examinadas que afirmaram ter algum } \\
\text { conhecimento sobre osteoporose através de qualquer método } \\
\text { citado no questionário }\end{array}$ & 90 \\
\hline Figura 19 & $\begin{array}{l}\text { Porcentagem de mulheres examinadas que tiveram acesso à } \\
\text { densitometria óssea }\end{array}$ & 90 \\
\hline Figura 20 & $\begin{array}{l}\text { Porcentagem de mulheres medicadas pelo menos uma vez para } \\
\text { osteoporose }\end{array}$ & 91 \\
\hline
\end{tabular}


\begin{tabular}{|l|l}
\hline Figura 21 & Porcentagem das mulheres que tiveram fratura do quadril em
\end{tabular}

\section{LISTA DE TABELAS}

\begin{tabular}{|l|l|l|}
\hline Tabela 1 & $\begin{array}{l}\text { Custos da alternativa tradicional (sem interençao } \\
\text { específica) }\end{array}$ & 49 \\
\hline Tabela 2 & Métodos não-invasivos para a avaliação do esqueleto & 51 \\
\hline Tabela 3 & $\begin{array}{l}\text { Técnicas de medida de densidade óssea segundo os } \\
\text { sítios medidos e a utilidade clínica }\end{array}$ & 55 \\
\hline Tabela 4 & $\begin{array}{l}\text { Técnica de avaliação quantitativa que não mede a } \\
\text { densidade óssea }\end{array}$ & 55 \\
\hline
\end{tabular}




\section{LISTA DE ABREVIATURAS E SIGLAS}

\begin{tabular}{|l|l|}
\hline IBGE & Instituto Brasileiro de Geografia e Estatística \\
\hline NIH & $\begin{array}{l}\text { Consensus Statement on Osteoporosis Prevention, } \\
\text { diagnosis and Therapy }\end{array}$ \\
\hline DEXA & Absorciometria Radiológica de Energia Dupla \\
\hline DMO & Densidade Mineral Óssea \\
\hline SUS & Sistema Único de Saúde \\
\hline QUS & Ultra-Som Quantitativo \\
\hline RA & Radiografia por Absorciometria ou Fotodensitometria \\
\hline SPA & Absorciometria por Foton Unico \\
\hline SXA & Absorciometria por Raios X \\
\hline DPA & Absorciometria por Foton Duplo \\
\hline QCT & Tomografia Computadorizada Quantitativa \\
\hline PQCT & Tomografia Computadorizada Quantitativa Periférica \\
\hline QMR & Ressonância Magnética Quantitativa \\
\hline SOS & Velocidade do som \\
\hline BUA & Atenuação do som \\
\hline
\end{tabular}




\section{SUMÁRIO}

RESUMO

ABSTRACT

LISTA DE FIGURAS

LISTA DE TABELAS

LISTA DE ABREVIATURAS E SIGLAS

Pág.

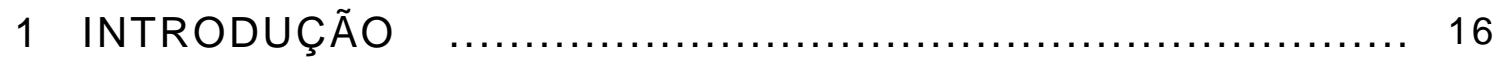

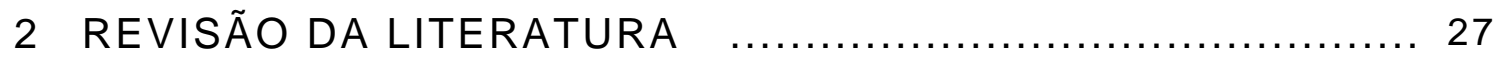

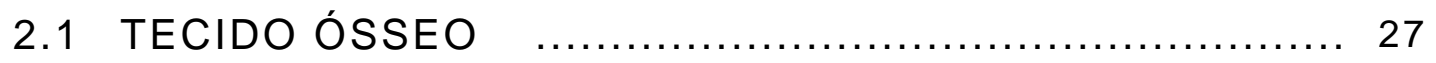

2.1.1 As funções do tecido ósseo $\ldots \ldots \ldots \ldots \ldots \ldots \ldots \ldots 27$

2.1.2 Hierarquia estrutural: micro e $\ldots \ldots \ldots \ldots \ldots \ldots .28$ macroestrutura do tecido ósseo

2.1.3 Remodelamento do tecido ósseo $\ldots \ldots \ldots \ldots \ldots \ldots . \ldots 31$

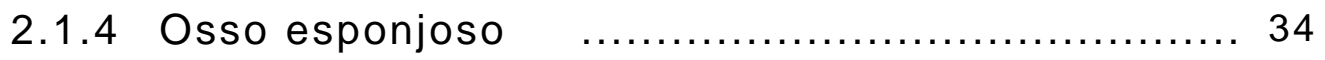

2.1.5 A estrutura do osso esponjoso ................ 36

2.2 DOENÇAS OSTEOMETABÓliCAS E .................. 41

O RISCO DE FRATURAS

2.2.1 Definição de osteoporose e .................. 41 grupo de risco

2.2.2 O impacto social da ocorrência ................ 44 das fraturas osteoporóticas

2.2.3 Características gerais do femur ............... 47 proximal e suas fraturas

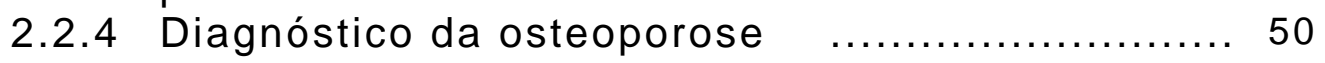

2.2.5 O exame de densitometria óssea $\ldots \ldots \ldots \ldots \ldots \ldots . \ldots 6$

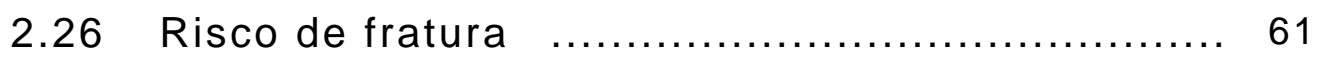

2.2.7 Contribuição da resistência óssea $\ldots \ldots \ldots \ldots \ldots \ldots . \ldots 3$ na fratura 
2.2.8 Contribuição do traumatismo na $\ldots \ldots \ldots \ldots \ldots \ldots . . . \ldots 4$ fratura

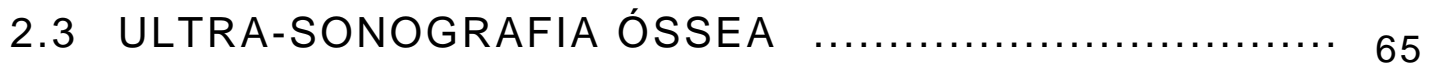

2.3.1 Aspectos teóricos do ultra-som …............... 65

2.3.2 Parâmetros do ensaio ultra- .................. 67

sônico em osso

2.3.2. A alteração da velocidade 67

1 da onda ultra-sônica $\quad \ldots \ldots \ldots \ldots \ldots \ldots \ldots \ldots$

2.3.2. A atenuação da energia 68

$\begin{array}{llll}2 & \text { transmitida pela onda } & \ldots \ldots \ldots \ldots \ldots \ldots \ldots & \\ 2 & \end{array}$

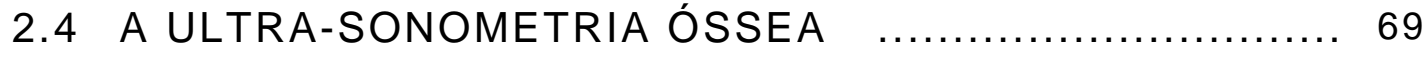

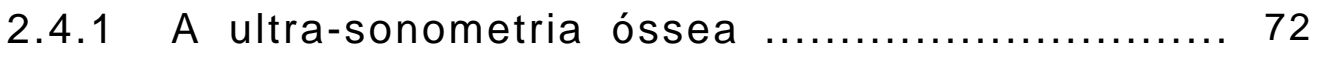

e o risco de fratura

2.4.1. A ultra-sonometria óssea 72

1 e a densidade mineral óssea

2.4.1. A ultra-sonometria óssea ................. 73

2 e a qualidade óssea

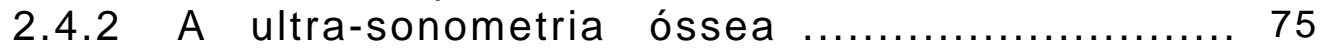
do calcâneo

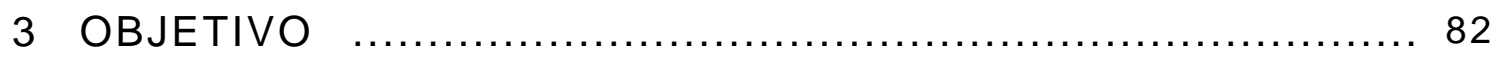

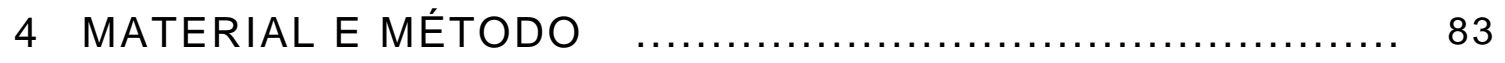

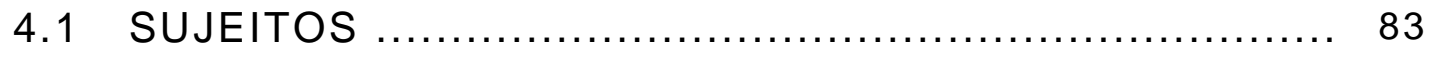

4.2 MATERIAL E EQUIPAMENTO $\ldots \ldots \ldots \ldots \ldots \ldots \ldots \ldots \ldots \ldots \ldots \ldots \ldots \ldots \ldots \ldots \ldots \ldots$

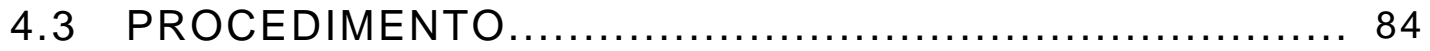

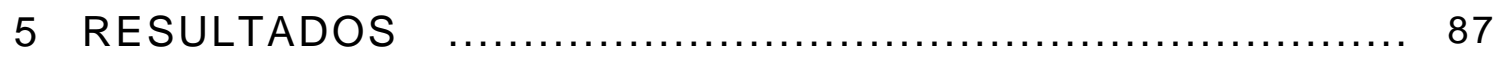

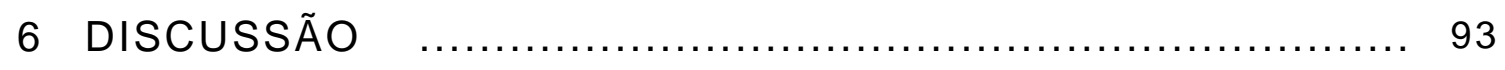

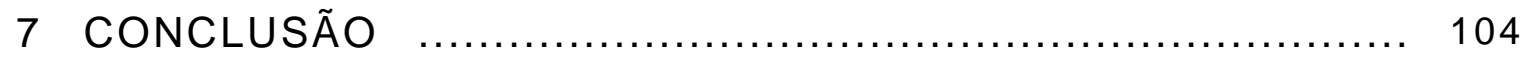

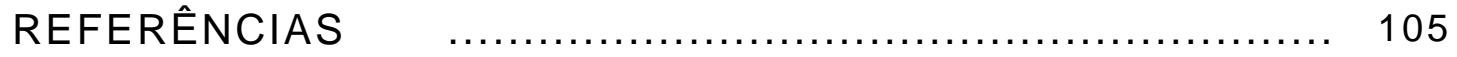

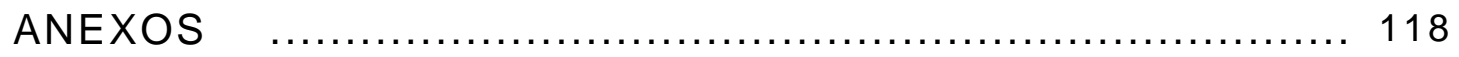




\section{INTRODUÇÃO}

studos realizados nos últimos anos têm mostrado que a expectativa média de vida aumentou dramaticamente para todas as idades e para ambos os gêneros (GURALNIK; HAVLIK, 2000). Segundo a Organização das Nações Unidas (ONU), no ano 2000, por exemplo, a população considerada idosa, de faixa etária acima de 60 anos, era formada por cerca de 610 milhões de pessoas, e estima-se que, em 2025, será contabilizada uma população de 1,1 bilhões de idosos (WHO, 1994). Uma vez que os custos individuais de serviços de saúde para idosos são muito elevados, o crescimento desse segmento da população afetará notadamente os custos relacionados com a saúde desses indivíduos (BEERS; BERKOW, 2000).

Estudando a população americana, Beers e Berkow (1997) mostraram que, enquanto a expectativa de vida de uma criança do sexo masculino nascida em 1900 era de 46 anos, hoje essa notação se estenderia além dos 72 anos. Para o gênero feminino, a expectativa de vida passou de 48 anos para aproximadamente 79 anos, ou seja, hoje as mulheres têm probabilidade de viver 30 anos ou mais após a chegada da menopausa. 
No censo do ano 2000, do Instituto Brasileiro de Geografia e Estatística (IBGE), o Brasil contabilizava 14,5 milhões de pessoas com idade superior a 60 anos - 36\% a mais do que no ano de 1991 e o correspondente a $8,2 \%$ da população nacional. Em duas décadas, essa população deverá dobrar. Até 2020, essa população poderá chegar a 40 milhões de pessoas, classificando-se, provavelmente, como a sexta maior população de idosos do mundo (IBGE, 2000).

De acordo com Guralnik e Havlik (2000), há um grande número de doenças típicas de pessoas idosas. Esses problemas afetam notadamente o funcionamento geral do organismo, comprometendo a independência pessoal desses indivíduos e exigindo um cuidado permanente e diferenciado por um longo período de tempo. As circunstâncias crônicas que conduzem à incapacidade incluem aquelas que geralmente também causam a morte (por exemplo, doença de coração, doença pulmonar e diabetes) e aquelas menos prováveis de provocar uma morte, mas que afetam a capacidade de movimentação do indivíduo (por exemplo, artrite e osteoporose).

Para Brundtland (2000), as doenças músculo-esqueléticas aparecem, em todas as partes do mundo, como a maior causa de morbidade. Essas doenças têm uma substancial influência na saúde e na qualidade de vida das pessoas e ocasionam um enorme custo aos sistemas de saúde. Observa-se ainda que, junto com o aumento do número de mulheres que passam da menopausa, há também um aumento do número de fraturas decorrentes de doenças como, por exemplo, a osteoporose, principal e mais comum doença 
osteometabólica que atinge pessoas idosas de ambos os sexos, especialmente a mulher (MERCK, 2006)

Segundo Cooper, Campion e Melton III (1992), as fraturas osteoporóticas de fêmur surgem como a terceira causa de internação hospitalar e a segunda causa de óbito entre a população feminina americana e européia com mais de 50 anos. No Brasil, há indícios de que as fraturas osteoporóticas de qualquer segmento do esqueleto atingem cerca de $20 \%$ a $25 \%$ do total de mulheres pós-menopausadas, todas vítimas da osteoporose involucional.

A osteoporose involucional é definida como síndrome de perda acelerada de massa óssea durante o envelhecimento, incluindo a osteoporose pós-menopausa e a senil. Constitui-se na mais comum das doenças ósseas metabólicas, caracterizada por deterioração microarquitetural do tecido ósseo, redução da massa óssea e elevado risco de fraturas. Doença silenciosa, por vezes tem seu diagnóstico realizado apenas após a ocorrência de fraturas, com repercussões significativas, em termos de saúde pública, devido à morbidade e à mortalidade associadas notoriamente às fraturas osteoporóticas instala-se, dessa maneira, o diagnóstico precoce no intuito de minimizar as conseqüências dessa entidade clínica. Assim, a identificação de pacientes de risco e os métodos de quantificação da massa óssea realizados têm sido rotineiramente pesquisados pelo clínico; porém, essa abordagem, um verdadeiro paradigma na investigação da osteoporose, tem sido revista ao longo dos anos (HEANEY, 2003) e, atualmente, encontra-se numa fase de expectativa 
até que surjam métodos clínicos que contemplem, simultaneamente, a medida da massa óssea, o status da sua microarquitetura e a velocidade de sua remodelação, informando o quanto essa estrutura osteometabólica é resistente.

Há alguns anos a osteoporose era definida como um "distúrbio do metabolismo ósseo que comprometia a sua "quantidade", porém não a sua "qualidade", diferentemente do registrado na definição da osteomalácia, que o considerava somente qualitativamente anormal. Até então, a medida da densidade óssea era apropriada para a predição de fratura osteoporótica, a qual mantinha uma correlação linear entre densidade e resistência óssea baseada em testes biomecânicos (LOTZ; CHEAL;HAYES, 1991)

Entretanto, quando se tratava de associar esse conceito ao monitoramento de tratamentos com drogas que pretendiam aumentar a massa óssea, essa correlação mostrava-se pobre e confusa(BLACK et al., 1996), pois a correlação linear deixava de existir - incrementos na densidade óssea nem sempre se relacionavam à diminuição do risco de fratura.

A partir de 1991, após o estabelecimento de um consenso entre especialidades afins que estudam o tratamento e a prevenção da osteoporose (CONSENSUS DEVELOPMENT CONFERENCE, 1991), esta passou a ser definida como "uma doença esquelética sistêmica caracterizada por massa óssea baixa e deterioração da microarquitetura do tecido ósseo, concomitante a um aumento da fragilidade óssea e do risco de fratura", isto é, um distúrbio da 
quantidade e da qualidade óssea (BORAH et al., 2002). A partir do NIH Consensus Statement on Osteoporosis Prevention, diagnosis and Therapy (NIH CONSENSUS ESTATEMENT, 2000), sua definição passou a ser "um distúrbio do esqueleto caracterizado pelo comprometimento da resistência óssea aumentando o risco de fratura". O termo resistência passou a integrar as variáveis conhecidas: densidade e qualidade óssea. A qualidade óssea refere-se à arquitetura, à remodelação, ao dano acumulado (microfraturas) e à mineralização.

Atualmente, sabe-se que a qualidade óssea não é passível de medição e que a procura por métodos que a avaliem tem sido constante (CHESNUT; ROSEN, 2001). Além disso, a atual diretriz para diagnóstico e monitoramento da osteoporose, a Absorciometria Radiológica de Energia Dupla (DEXA), encontra-se inclusa nesse impasse, deixando os profissionais da área apreensivos quanto à necessidade de substituí-la e, assim, poder beneficiar profilaticamente indivíduos que hoje têm Densidade Mineral Óssea (DMO) normal, porém sem risco de fratura definido, e outros que, sem acesso facilitado ao DEXA, não são avaliados ou aguardam impacientemente para se submeterem a um método incapaz de refletir a realidade.

Apesar de muitas pessoas idosas apresentarem perda de massa óssea, expressa, atualmente, por um decréscimo da densidade mineral óssea medida pelo DEXA, nem todas chegam às fraturas. Estudos mostram que há uma dissociação da DMO entre grupos com e sem fraturas osteoporóticas e que a sua medida isolada é insuficiente para 
avaliar a resistência do osso osteoporótico. Para predizer o risco de fratura osteoporótica em pacientes idosos, é essencial a caracterização biomecânica desse osso (LUCAS; EINHORN, 1993). As propriedades mecânicas do osso podem ser examinadas em diferentes níveis de estrutura óssea, abordando desde escalas macroscópicas até nanométricas, quanto à sua heterogenicidade ou homogenicidade e sua condição isotrópica ou anisotrópica (CUREY, 1964; KATZ,1971;KATZ, YOON, 1984).

A densidade mineral óssea, a geometria óssea, a microarquitetura do osso, a qualidade do tecido ósseo e a velocidade de remodelação são os componentes que determinam a resistência óssea (WEINSTEIN et al., 2000). Em média, 70\% a 80\% da variação da resistência óssea, in vitro, são determinados pela densidade. A literatura (CUMMINGS et al., 2002) revela também que o prognóstico a respeito da resistência do osso trabecular pode ter sua acuidade notavelmente aumentada se forem incluídas certas características arquiteturais. Isso pode ser verificado nos resultados de uma revisão sistemática da literatura que relacionou o aumento de DMO à redução de fraturas (CRANNEY, 2002) e apresentou como conclusão que, considerando-se todas as variáveis, menos de $30 \%$ da redução do risco de fratura é atribuível ao aumento da DMO.

Além disso, a resistência óssea não é o único fator determinante do risco de fratura; a função neuromuscular e os perigos do ambiente também influenciam; o risco de queda, a força de impacto e a resistência do osso são igualmente fatores importantes (WHO, 1994). 
Todas essas situações relatam as dificuldades de se encontrar métodos de avaliação da resistência óssea que contemplem, na população, os indivíduos que necessitam de cuidados preventivos quanto à osteoporose, às fraturas e às quedas. Além disso, tais métodos teriam de ser acessíveis à população quanto ao custo e à disponibilidade.

Métodos que pretendem contemplar essas variáveis estão em estudo, porém, pela sua complexidade, são caros e de difícil acesso. Entre eles estão a microtomografia computadorizada e a ressonância magnética de alta definição (FAULKNER; POCOCK, 2001), técnicas que associam imagens estruturais, inclusive volumétricas, a análises por elemento finito desenvolvidas em vários modelos (FAULKNER; CANN; HASEGAWA, 1991); são métodos que avaliam a densidade mineral óssea, a orientação trabecular e sua microestrutura, além da condição de anisotropia e heterogenicidade do osso. Um resumo dos métodos em desenvolvimento pode ser avaliado na Tabela 2.

A DEXA convencional avalia, pela Densitometria Óssea, a densidade mineral óssea em dois sítios do esqueleto previamente conhecidos, para que possa, além das medidas quantitativas, comparar os resultados com um banco de dados. É um método que avalia a densidade óssea somente, porém, analogamente, eficaz para materiais isotrópicos e homogêneos. Mesmo com suas importantes limitações para essa finalidade, ainda é o método de eleição para o diagnóstico e o monitoramento da osteoporose. 
A DEXA (Absorciometria por Raio X de Dupla Energia) pode ser considerada de médio custo quando comparada à Microtomografia Computadorizada ou à Microrressonância Magnética.

Os usuários de planos complementares de saúde têm acesso a ele com razoável facilidade. Porém, para a maioria da população que utiliza somente o SUS - Sistema Único de Saúde - para assistência médica, esse acesso é restrito. Mesmo assim é o critério utilizado pelo Ministério da Saúde para incluir indivíduos no protocolo de tratamento e distribuição de medicamentos (Anexo B - Portaria n. 470 de 24/7/2002).

O QUS (Ultra-Som Quantitativo), hoje, é aceito, por consenso, como método de predição de risco de fratura, principalmente do colo do fêmur (MEUNIER et al., 1995), sem, porém, medir densidade óssea, o que o coloca como eficaz para a determinação do perfil (screening) populacional e não para diagnóstico e monitoramento da osteoporose (FDA, 2001; PORTER, 1990; HANS et al., 1995; WHO, 1994). Tendo em vista a relação custo-benefício, é um método barato pelo qual muitos exames podem ser realizados em curto espaço de tempo com equipamentos de fácil manuseio e mais baratos. Outros benefícios são atribuídos aos QUS, como sua portabilidade e a ausência de radiação ionizante como no DEXA (GLUER, 1997). Do ponto de vista quantitativo, uma boa correlação foi encontrada entre QUS e resistência óssea mediante ensaios mecânicos de compressão (RODRIGUES, 2003; GLUER et al., 1997). Além disso, o método prediz o risco de fratura contemplando, também, a anisotropia óssea 
(orientação das trabéculas do osso esponjoso), parâmetros que não podem ser separados (MINAKUSH et al., 1997). Para se medir a DMO isoladamente, é necessário abordagem com outro método de avaliação. O produto dessas duas medidas avalia e reflete as propriedades mecânicas do osso esponjoso com comportamento anisotrópico.

Como todo esforço para encontrar um método que contemple as variáveis citadas tem por objetivo prevenir fraturas, diminuindo a morbidade e a mortalidade dos indivíduos e os custos financeiro e social de seu tratamento, e seqüelas, faz-se necessário identificar quais fraturas são mais freqüentes e de maior repercussão, de uma maneira geral. Pode-se considerar que as fraturas osteoporóticas do fêmur proximal são as de maior impacto financeiro (SAKAKI et al., 2004) e de morbi-mortalidade (DIETER; LINDSKOG; BAUMGAERTNER, 2004), além de que o aumento de seu limiar de fratura tem uma relação direta com a idade (FREITAS et al., 1998).

Assim, com a nova abordagem que se deve dar à compreensão da osteoporose e de suas conseqüências, e considerando que seu diagnóstico técnico pode levar muito tempo para ser alcançado enquanto os indivíduos continuam sofrendo fraturas, o risco de fratura obtido a baixo custo (MAJUNDAR et al.,1998) associado a dados clínicos conhecidos pode ser útil como parâmetro para eleger indivíduos a serem submetidos a programas de prevenção das fraturas do fêmur proximal. Deve-se considerar, também, a realidade que se apresenta em relação à condição dos indivíduos que têm acesso ao DEXA pela utilização dos serviços oferecidos por planos de saúde 
complementares e à de indivíduos que necessitam fazer uso dos serviços oferecidos pelo Sistema Único de Saúde. Estes têm, em geral, dificuldades de acesso ao exame pela demanda excessiva e pelos poucos serviços credenciados. Aqueles têm acesso facilitado inclusive para monitoramento anual. Quanto ao programa oferecido pelo Ministério da Saúde para distribuição de medicamentos para prevenção e tratamento da osteoporose, como um dos critérios de elegibilidade dos beneficiários é o resultado da DEXA, a população de baixa renda que não faz uso de planos de saúde complementares acaba não sendo contemplada pelo programa (FELICIANO et al., 2004).

Outro aspecto a ser considerado é a constatação de que os métodos atualmente utilizados para diagnóstico e tratamento de osteoporose são dispendiosos o suficiente para tornar a prevenção das fraturas osteoporóticas do fêmur cerca de cinco vezes mais caras do que seu tratamento. Essa constatação vem de uma extensa revisão sistemática da literatura pela qual a avaliação tecnológica em saúde é realizada envolvendo critérios como o custo e a efetividade das intervenções que se propõe realizar, visando contribuir de forma simples e eficaz com as políticas públicas de assistência à saúde do idoso e, principalmente, com eficácia na conduta médica a ser instituída (FELICIANO et al., 2004). Faz-se necessário, então, minimizar o custo a ponto de tornar viável e eficaz qualquer programa de saúde pública para essa finalidade, quando o custo da DEXA colabora para aumentá-lo e para o que outros métodos mais baratos de diagnóstico ou rastreamento podem contribuir. 
Neste contexto, e utilizando-se ferramentas técnicas e sociais, realizou-se uma revisão da literatura e uma pesquisa de campo com 757 mulheres com idade acima de 60 anos submetidas a um exame de ultra-sonometria óssea do osso calcâneo e a um questionário com alternativas de múltipla escolha com a finalidade de fundamentar uma proposta de utilização do método atualmente disponível para selecionar mulheres idosas de baixa renda e cadastradas em serviço público de saúde para programas de prevenção de fraturas em fêmur proximal. 


\section{REVISÃO DA LITERATURA}

\subsection{TECIDO ÓSSEO}

\subsubsection{AS FUNÇÕES DO TECIDO ÓSSEO}

Segundo Martin e Dempster (1998), o esqueleto é constituído na sua maior parte de tecido ósseo, o mais resistente tecido do corpo humano, que desempenha as seguintes funções em um organismo sadio: a) fornece uma estrutura resistente à gravitação, a qual serve como uma armadura protetora das partes mais moles e dos órgãos vitais (como os contidos nas caixas craniana e toráxica e no canal raquidiano); b) age como um reservatório extracelular para os íons, tais como o cálcio, o fósforo e outros; c) aloja e protege a medula óssea, formadora das células do sangue; d) proporciona apoio aos músculos esqueléticos, transformando contrações musculares em movimentos úteis e formando um sistema de alavancas que amplia as forças geradas na contração muscular.

O osso armazena e libera os íons de maneira controlada e, para que haja um funcionamento normal do organismo, a concentração de íons no sangue deve ser mantida constante. Há um intercâmbio contínuo entre o cálcio do plasma sangüíneo e o do osso. O cálcio absorvido da alimentação e que faria aumentar a concentração 
sangüínea desse íon é depositado rapidamente no tecido ósseo e, inversamente, o cálcio do osso é mobilizado quando diminui sua concentração no sangue (JUNQUEIRA; CARNEIRO, 1999).

\subsubsection{HIERARQUIA ESTRUTURAL: MICRO E MACRO- ESTRUTURA DO TECIDO ÓSSEO}

O osso é um tecido extremamente bem organizado, de surpreendente baixo peso, e fornece uma excelente estrutura de suporte. Sua composição varia dependendo da sua localização, da idade, do histórico de alimentação do indivíduo e da existência de doenças (KAPLAN et al., 1985). Categoriza-se o osso em quatro componentes microestruturais: células, matriz orgânica, matriz inorgânica e fatores solúveis (Figura 1), e em dois componentes macroestruturais integrados em hierarquias macroestruturais distintas: osso cortical e esponjoso (Figura 2) (HOLLINGER; BUCK; BRUDER, 1999). A proporção de osso cortical e de trabecular difere nas várias regiões do esqueleto. 


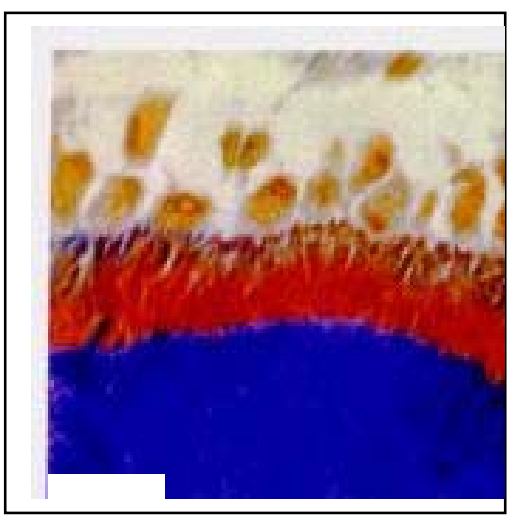

(Hollinger, 1999)

O osso cortical (Figura 2) corresponde a $80 \%$ do esqueleto, é duro, denso, e forma a parte externa de vários ossos e o corpo dos ossos longo As unidades constituintes são os ósteons e as regiões ósseas intersticiais ou sistema haversiano. Os ósteons possuem formato cilíndrico (diâmetro de $200 \mu \mathrm{m}-250 \mu \mathrm{m}$ e comprimento de $10 \mu \mathrm{m}-20 \mu \mathrm{m})$ e são compostos de lamelas ou camadas concêntricas (3 $\mu \mathrm{m}-7 \mu \mathrm{m}$ de espessura) paralelamente dispostas ao longo do eixo do oss "AARTIN; DEMPSTER, 1998; EINHORN, 1996; ATHANASIOU et al., ${ }^{4}$ 0). Os sistemas haversianos estão localizados no centro dos ósteons e acomodam vasos sanguíneos para facilitar o suprimento de nutrientes para as células ósseas (osteócitos). O osso cortical possui uma porosidade considerada baixa, de $5 \%$ a $30 \%$, sendo rígido e capaz de suportar um valor razoável de tensão antes de fraturar quando submetido a um carregamento.

O osso esponjoso (Figura 2) compõe $20 \%$ do esqueleto e é uma estrutura altamente porosa encontrada nos corpos vertebrais e na parte final dos ossos longos. Formado por numerosas e pequenas trabéculas interconectadas (100 $\mu \mathrm{m}-300 \mu \mathrm{m}$ de espessura com espaçamento de $300 \mu \mathrm{m}-1.500 \mu \mathrm{m}$ entre as trabéculas adjacentes) (MARTIN; DEMPSTER, 1998; EINHORN, 1996), que tendem a se orientar ao longo da direção da tensão principal, em adaptação ao carregamento externo do ambiente. Tem-se que $75 \%-95 \%$ do volume do osso 
esponjoso é constituído por poros interconectados e é preenchido com medula óssea. O osso esponjoso possui uma porosidade considerada alta, de $30 \%$ a $90 \%$, sendo capaz de suportar alongamentos e deformações antes de fraturar quando submetido a um carregamento.

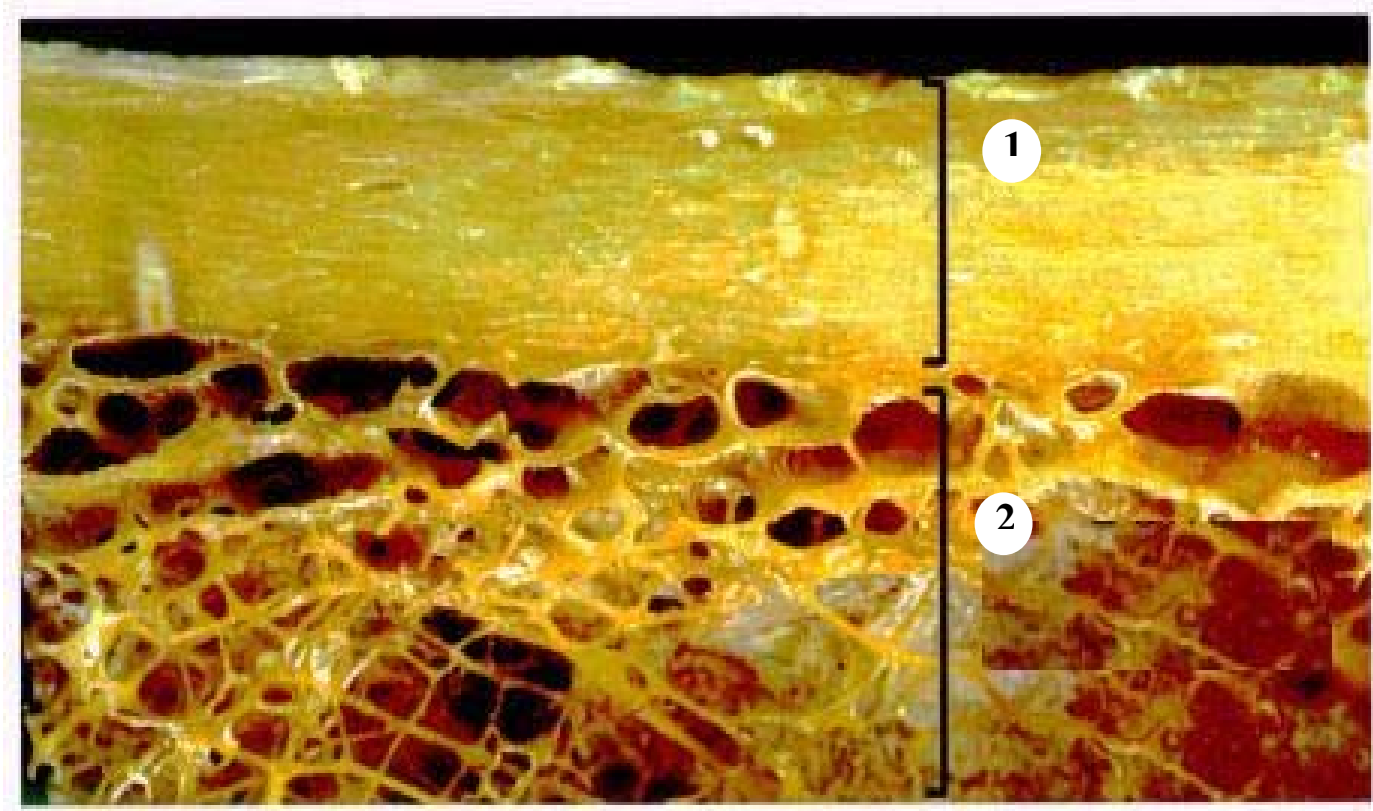

FGURA 2 - Representação dos dois componentes da macroestrutura óssea 1) Osso cortical: forma $80 \%$ do esqueleto, duro e denso, parte externa e o corpo de ossos longos.

2) Osso trabecular: forma os outros 20\%, rede 3D de trabéculas, vértebras e diáfise de ossos longos.

\subsubsection{O REMODELAMENTO DO TECIDO ÓSSEO}

Segundo Francis, Sutcliffe e Scane (1998), o osso é um tecido vivo que está continuamente em ação. As atividades celulares do tecido ósseo são de três tipos: Atividade de Modelamento - associada ao crescimento, transformando osso do recém-nascido em osso adulto; Atividade de Reparo - relacionada com a reparação contínua da micro e da macroestrutura do esqueleto quando danificadas por fadiga ou 
trauma devido a tensões físicas recebidas; Atividade de Remodelamento - atividade que faz a manutenção da homeostasia mineral no sangue por meio de reabsorção de material e neoformação óssea.

O remodelamento ósseo ocorre tanto no osso cortical quanto no esponjoso. Os osteoclastos, os osteoblastos e os osteócitos são as células mais importantes envolvidas nesse processo (Figura 3). Essas células ósseas respondem a vários sinais do meio, a induções químicas, mecânicas, elétricas e a estímulos magnéticos. Inicialmente ocorre a ativação da célula óssea, o local de ativação sofre reabsorção osteoclástica e depois ocorre a reposição óssea pelos osteoblastos (EINHORN, 1996).

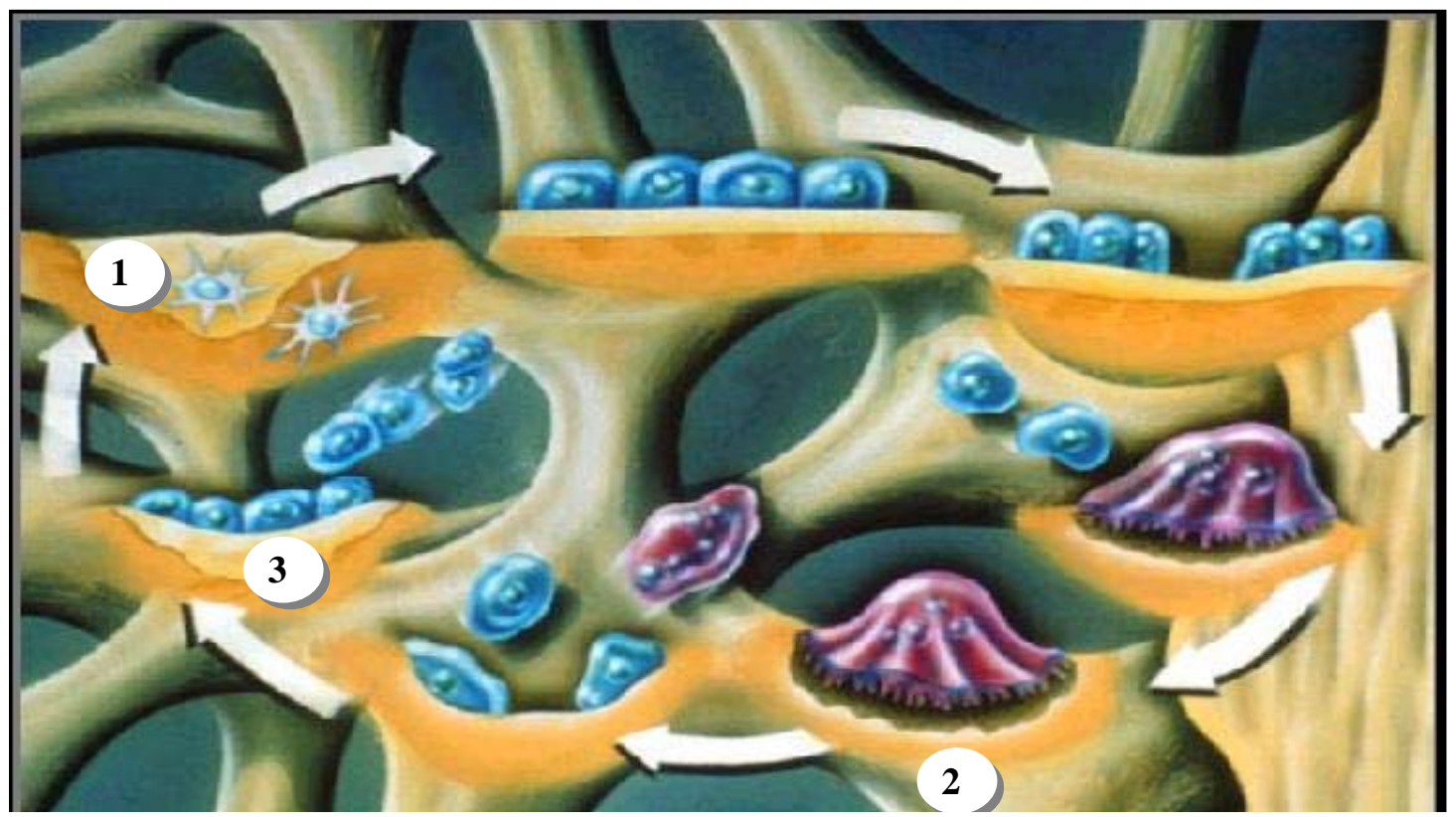

FIGURA 3 - Esquema ilustrativo do processo de remodelamento no osso esponjoso. As células envolvidas no remodelamento ósseo são osteócitos, osteoclastos e osteoblastos. 1) Osteócitos: células encontradas no interior da matriz óssea que se mineraliza posteriormente.

2) Osteoclastos: células que corroem uma área do osso, iniciando a reabsorção óssea.

3) Osteoblastos: células que são atraídas para a cavidade de reabsorção, iniciando a formação óssea.

PAVÓN; ZANCHETTA, [s.d]. CD-ROM. 
Os osteócitos são osteoblastos maduros aprisionados dentro do osso calcificado. Eles são interconectados por longos filamentos e fornecem uma rede de comunicação para transmitir ao tecido informações referentes às solicitações mecânicas, que são usadas para modificar o osso por processos de reabsorção e formação (FRANCIS, SUTCLIFFE; SCANE, 1998). Os osteoclastos são células multinucleadas que reabsorvem o osso e que removem materiais orgânicos degradados, ou seja, provocam a desmineralização do tecido e a degradação do colágeno, destruindo o tecido ósseo. Os osteoblastos são células sintetizadoras da matriz óssea ou osteóide e são subseqüentemente mineralizados pelo crescimento do cristal em formação (FRANCIS;SUTCLIFFE; SCANE, 1998).

Os osteoblastos são células ativas que sintetizam e liberam o colágeno para o espaço extracelular adjacente. As fibrilas de colágeno alinham-se em arranjos regulares e produzem uma matriz orgânica, os osteóides. No interior do osteóide, o íon cálcio é depositado como massas amorfas de fosfato de cálcio. A seguir, íons hidróxido e bicarbonato são gradualmente adicionados à fase mineral, e cristais de hidroxiapatita maduros são formados lentamente. Os mediadores que agem sobre os osteoclastos têm sua ação realizada pelos osteoblastos (LIAN; STEIN, 1996).

A matriz calcificada do osso não é metabolicamente inerte, e células (osteócitos) são encontradas incrustadas profundamente dentro 
do osso em pequenas lacunas. Elas são originalmente osteoblastos aprisionados no interior da célula para produzir a matriz óssea que depois se calcifica. O osteoclasto é uma célula que possui mobilidade. Ela reabsorve osso para formar uma lacuna e então se move atravessando a superfície do osso para reabsorver outra área (MUNDY, 1993).

Os processos de reabsorção e formação são intimamente ligados, provavelmente através de fatores humorais locais, e a formação óssea excede a reabsorção durante o crescimento do esqueleto até que a reabsorção ultrapasse a formação óssea após o crescimento. O remodelamento ósseo pode ser influenciado por forças mecânicas aplicadas ao esqueleto, por fatores humorais locais, fatores transformadores de crescimento, por tumores necrosados e por hormônios circulantes como o estrógeno, a testosterona, a calcitonina, o hormônio paratireóide $(\mathrm{PTH})$ e a vitamina D (FRANCIS; SUTCLIFFE; SCANE, 1998).

\subsubsection{OSSO ESPONJOSO}

Segundo Rho et al., (1993) é importante definir que o termo "osso esponjoso" refere-se à estrutura esponjosa, enquanto o termo "osso trabecular" refere-se ao material trabecular (tecido ósseo encontrado no osso esponjoso). A palavra trabécula significa "pequena trave" em 
latim. Uma trabécula individual é um único suporte do osso esponjoso (GIBSON; ASHBY, 1998).

A necessidade social do entendimento do comportamento mecânico do tecido é ilustrada por estudos epidemiológicos realizados desde a década de 60 - que documentaram a alta incidência de fraturas nesse tecido em pessoas idosas. Visando prevenir ou reduzir fraturas, um conhecimento maior das características de resistência do osso esponjoso deve ser buscado, assim como deve ser feita uma maior pesquisa sobre métodos que avaliem a integridade do tecido ósseo de modo pouco oneroso e pouco invasivo (COWIN, 1989). A importância de se desenvolver mais estudos sobre as mudanças estruturais do osso esponjoso está no fato de a perda da conectividade estrutural ser um processo irreversível, observando-se que somente um novo osso lamelar pode ser adicionado às superfícies já existentes. Os problemas clínicos mais importantes em ortopedia envolvem locais do esqueleto que são dominados pelo osso trabecular (KEAVENY; HAYES; 1993; PARFITT, 1984).

As pesquisas sobre o osso trabecular têm crescido exponencialmente nos últimos 30 anos, motivadas por problemas clínicos e científicos tais como fraturas ósseas relacionadas com a idade, desligamento de próteses e remodelamento ósseo. Os esforços têm sido focalizados sobre as medidas das propriedades mecânicas de trabéculas individuais, o melhoramento de métodos para ensaios mecânicos e a quantificação tridimensional do osso trabecular (KEAVENY; HAYES, 1993). 


\subsubsection{A ESTRUTURA DO OSSO ESPONJOSO}

O osso esponjoso é uma estrutura mecânica e biológica cujas propriedades mecânicas são impossíveis de serem entendidas sem se considerar a sua biologia. A atividade celular desse osso ocorre pelo transporte de metabólitos entre o tecido duro trabecular e a medula. As trabéculas ósseas humanas são raramente servidas internamente por suprimento de sangue, sugerindo que os mecanismos de transporte sejam difusão e transporte ativo de metabólitos, podendo explicar: a) a íntima relação entre a superfície e o volume ósseo e b) o declínio exponencial da fração do volume ósseo durante períodos de desuso mecânico (FYRIE; KIMURA, 1999).

O osso trabecular é mais bem descrito como sendo um material esponjoso formado por células abertas. Ignorando os detalhes microanatômicos de cada fase, o osso trabecular pode ser considerado um material com duas fases: tecido duro e medula (FYHRIE; KIMURA, 1999).

Como foi citado anteriormente, o remodelamento ósseo é um evento que ocorre na superfície do osso trabecular, que tem uma área superficial maior que a área do osso cortical. O osso trabecular apresenta um remodelamento ósseo cerca de 8 vezes maior, apesar de possuir 4 vezes menos massa do que o cortical (KAPLAN et al., 1985). 
A estrutura do osso esponjoso é formada por uma rede interconectada de longas, finas e rugosas traves cilíndricas e placas (trabéculas), rodeadas por tecido medular. Uma rede formada somente por traves produz baixa densidade, enquanto uma outra formada por traves e placas fornece densidades mais altas. Em uma amostra, à medida que a densidade aumenta, as traves progressivamente se espalham e se achatam, formando placas e, por fim, se fundem, formando uma estrutura com aspecto de células fechadas (Figura 4) (GIBSON; ASHBY,1997).
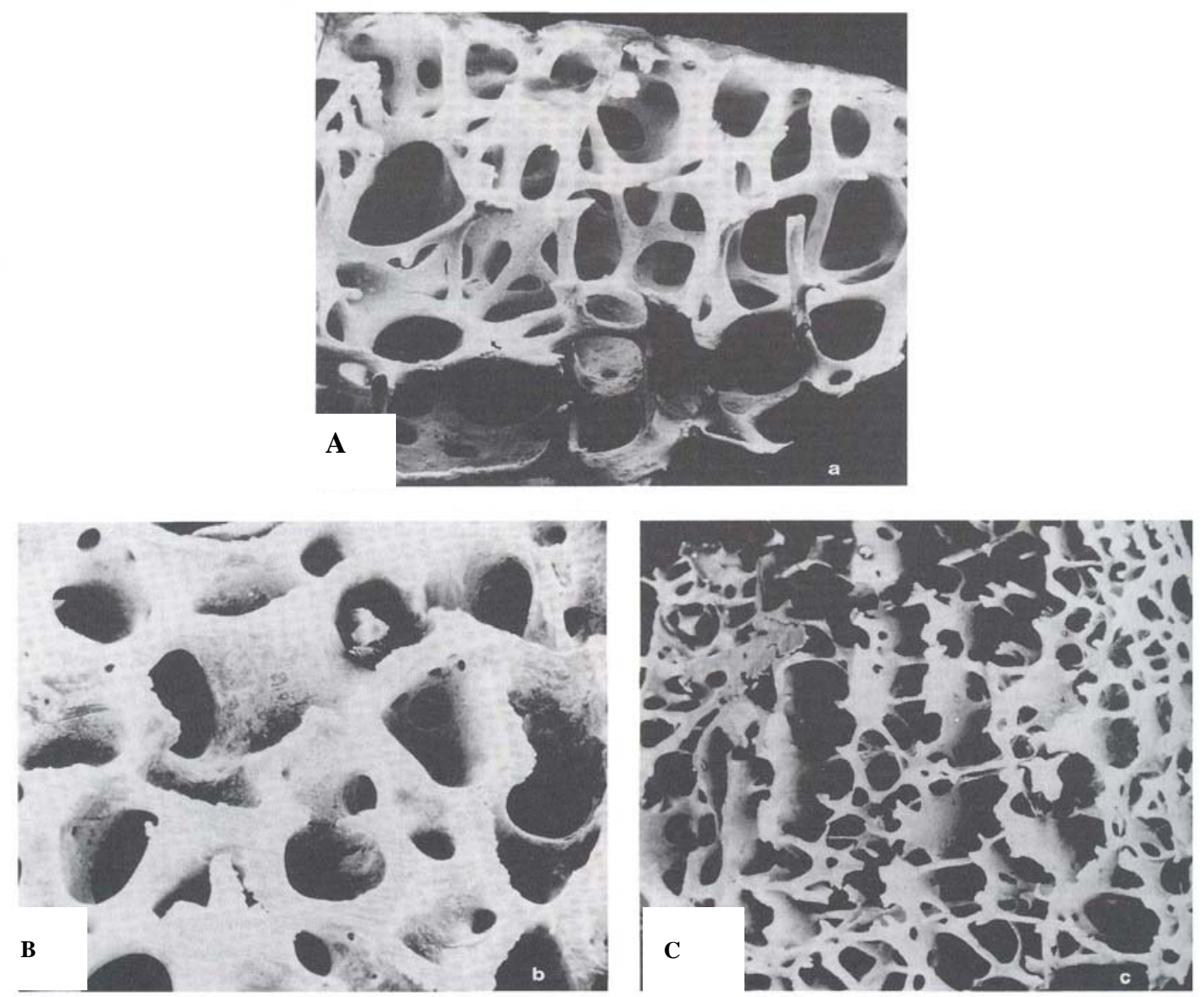

FIGURA 4- Microscopia Eletrônica de Varredura: estrutura do osso esponjoso.

a) Amostra da cabeça do fêmur, estrutura formada por traves com baixa densidade.

b) Amostra da cabeça do fêmur, estrutura rugosa e prismática com densidade mais alta.

c) Amostra do côndilo femoral, mostrando uma estrutura orientada pela tensão, formada por placas paralelas e traves perpendiculares de densidade intermediária. 
FONTE: GIBSON; ASHBY, 1997.

Enquanto o osso cortical tem uma densidade estrutural com cerca de $1,8 \mathrm{~g} / \mathrm{cm}^{3}$, a estrutura porosa do osso esponjoso apresenta uma estrutura na qual duas densidades podem ser medidas: a densidade do material trabecular (densidade relativa) e a densidade da estrutura esponjosa (densidade aparente). A densidade do material trabecular é medida de modo que somente o volume ósseo é considerado no cálculo da densidade, sendo seu valor similar ao do osso cortical, variando de $1,6 \mathrm{~g} / \mathrm{cm}^{3}$ a $1,9 \mathrm{~g} / \mathrm{cm}^{3}$. A densidade da estrutura esponjosa leva em conta a porosidade do osso trabecular (é medida usando o volume total de toda a dimensão física da amostra), seu valor varia de 0,15 g/cm ${ }^{3}$ a $1 \mathrm{~g} / \mathrm{cm}^{3}$, com porosidade de mais de 75\% (ASHMAN et al., 1984). A densidade relativa é a característica mais importante da estrutura de um material. Para o osso esponjoso, varia de 0,05 a 0,07. Tecnicamente, qualquer osso com valor de densidade relativa menor que 0,7 é classificado como "esponjoso" (GIBSON; ASHBY, 1997)

A já citada lei de Wolff, que foi postulada há mais de 100 anos, declara que, quando as cargas sobre um osso são alteradas, o remodelamento funcional reorienta as trabéculas de modo que elas se alinham com a nova trajetória da tensão principal. As trabéculas são dispostas segundo as orientações que correspondem às linhas de força que o osso suporta. Por exemplo, as trabéculas da cabeça do fêmur alinham-se nas direções principais da tensão gerada durante a aplicação de uma carga (HELMINEN et al., 1987). 
Hoje se sabe que o osso trabecular é um material altamente complexo. Sua estrutura heterogênea é um sítio anatômico, simultaneamente dependente e anisotropicamente direcional da sua arquitetura e de propriedades mecânicas, sendo a sua densidade baseada na maximização estrutural com a mínima massa óssea possível (GOLDSTEIN; GOULET; McCUBBREY, 1993). A estrutura do osso esponjoso muda com o tempo em virtude das reduções na massa óssea em função da idade. Por exemplo, ocorre uma redução de 50\% na densidade do osso trabecular da vértebra entre os 20 e 80 anos de idade (MOSEKILDE, 1989). Assim, pode-se afirmar que as características da arquitetura do osso trabecular são muito similares.

No entanto, fatores tais como local anatômico, amostra, idade, direção de carregamento e estados da doença devem ser especificados na descrição das propriedades mecânicas do osso trabecular (KEAVENY; HAYES, 1993). As propriedades estruturais de uma amostra trabecular variam para cada região anatômica, dependendo da densidade do osso esponjoso e da orientação trabecular, ou seja, é um material anisotrópico, apresentando diferentes propriedades em diferentes direções (TURNER; BURR, 1993).

A arquitetura do osso trabecular descreve a forma do osso e a sua orientação. A estrutura básica descreve a conectividade geral da trabécula, a espessura das trabéculas principais, o espaçamento entre as trabéculas e o número de trabéculas (KAPLAN, 1994). As diferentes arquiteturas existentes no osso trabecular resultam de uma anisotropia das propriedades elásticas do tecido. 
Kleerekoper et al. (1985) estudaram cadáveres investigando as relações existentes entre a arquitetura de ossos esponjosos e a resistência óssea, concluindo que:

- o declínio relacionado com a idade na massa óssea do osso esponjoso na coluna, no fêmur proximal e no ílio está associado a mudanças relacionadas com a idade em toda a arquitetura do osso esponjoso;

- a principal mudança estrutural na arquitetura do osso esponjoso relacionada com a idade é uma redução no número de trabéculas com uma aumentada separação e conectividade diminuída entre elas;

- o declínio na competência mecânica do osso esponjoso relacionado com a idade é mais pronunciado do que seria esperado apenas na massa, mas pode ser melhor explicado pelo declínio da massa e pelas alterações na arquitetura;

- a capacidade limitada das medidas de massa óssea, in vivo e in vitro, para distinguirem entre pacientes com e sem fraturas osteoporóticas, pode, em parte, ser explicada pela alteração na arquitetura óssea trabecular, a qual não pode ser detectada pela simples medida de massa do osso esponjoso. 


\subsection{DOENÇAS OSTEOMETABÓLICAS E O RISCO DE FRATURAS}

As doenças osteometabólicas incluem os distúrbios generalizados do esqueleto e são causadas por influências humorais (KRANE et al., 1996). Qualquer alteração na taxa de formação ou reabsorção do remodelamento resulta não só na alteração da massa óssea total, como também na forma e na distribuição óssea. Os hormônios, especialmente o PTH, o calcitonina e a tamina $\mathrm{D}$, têm profundo e complexo efeito sobre o remodelamento, o modelamento e o crescimento ósseo. Segundo Junqueira e Carneiro (1999), a concentração de cálcio no sangue deve ser mantida constante, e a carência alimentar desse mineral causa descalcificação dos ossos, predispondo-os a fraturas. Sendo assim, as patologias do tecido ósseo podem ser muito sérias, afetando uma larga faixa de funções corporais.

Neste estudo detalhar-se-á a osteoporose por ser essa patologia o foco de atenção do presente estudo.

\subsubsection{DEFINIÇÃO DE OSTEOPOROSE E GRUPO DE RISCO}

A osteoporose é a mais freqüente das doenças osteometabólicas.

É a principal causa de fraturas ósseas em mulheres pós-menopausadas e pessoas idosas em geral. Trata-se de uma condição crônico- 
degenerativa e incapacitante, resultante de uma fragilidade generalizada do esqueleto pela redução da quantidade de osso e de um distúrbio da microarquitetura esquelética a ponto de aumentar a vulnerabilidade em relação a fraturas (FERNANDES et al., 2001).

Como se viu, a osteoporose é um distúrbio do esqueleto caracterizado pelo comprometimento da resistência óssea aumentando o risco de fratura. Embora ela resulte de um conjunto de processos bioquímicos e fisiológicos ainda incompreendidos de modo completo, a manifestação clínica (fratura ou deformação) é puramente mecânica (NJEH; LANGTON, 1997).

Segundo Fernandes et al. (2001), a osteoporose não é uma patologia fatal, mas é uma doença com alta morbidade, freqüentemente associada a fraturas de quadril e de vértebra. Trata-se de uma patologia menos ocorrente em homens por estes apresentarem esqueletos mais densos, com início de perda óssea mais tardia e progressão mais lenta, não havendo período de rápida mudança hormonal com perda óssea associada, como pode ser evidenciado na Figura 5. 


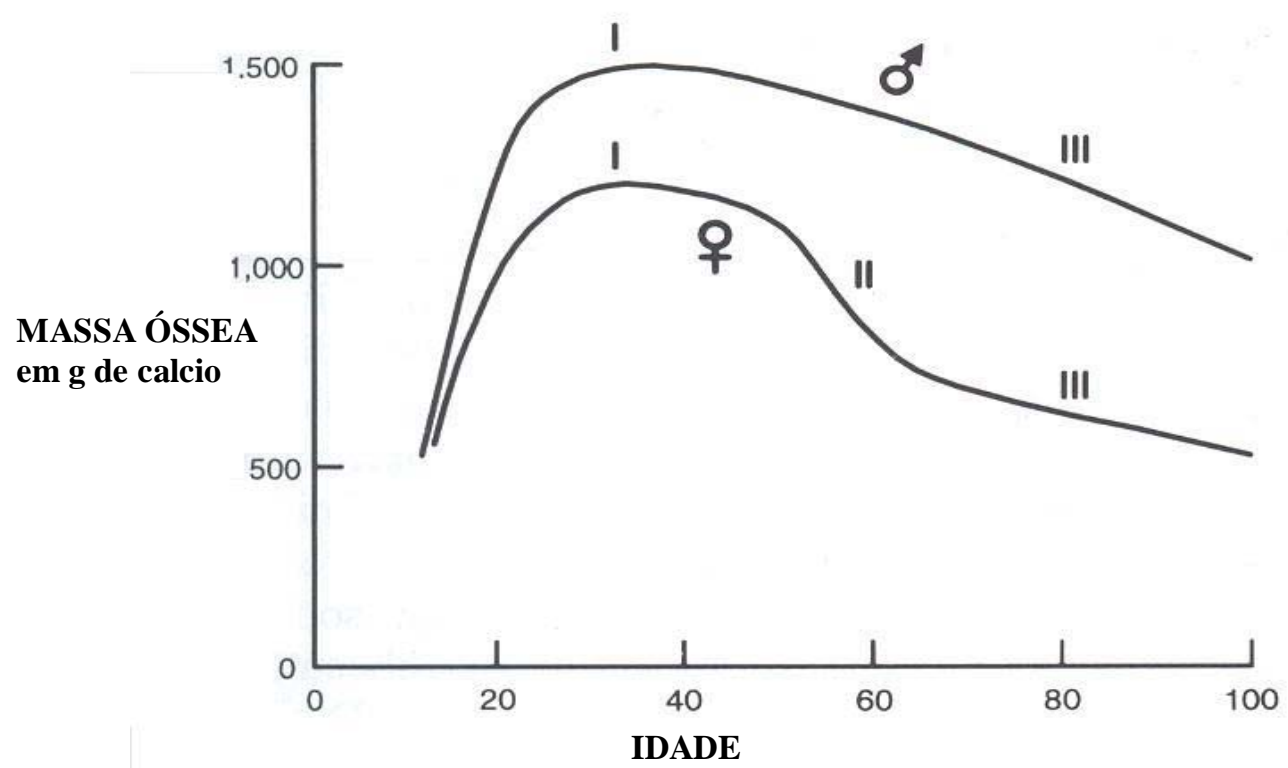

FIGURA 5 - Curva representativa da mudança na massa óssea em relação à idade em homens e mulheres, mostrando padrões de perda óssea.

I) Pico de massa óssea; II) Fase rápida de perda óssea nas mulheres próximas da menopausa

III) Perda óssea relacionada com a idade quase similar entre homens e mulheres

RIGGS; MELTON III, 1992.

Quando o metabolismo ósseo está em condições normais, existe um equilíbrio entre a formação e a reabsorção óssea (remodelamento). Na pós-menopausa e na velhice, em ambos os gêneros, há uma menor tendência à formação óssea. Nessa fase da vida, os osteoblastos têm a sua capacidade produtora diminuída gradativamente, enquanto os osteoclastos permanecem ativos. A redução progressiva do conteúdo mineral ósseo caracteriza a osteopenia e, em fases mais avançadas, a osteoporose (GASPERINO, 1995).

Apesar de a osteoporose ser geneticamente determinada, aquelas mulheres que se enquadram no grupo de risco apresentam uma maior chance de desenvolver a doença: caucasianas, asiáticas, tabagistas, 
alcoolistas, pessoas que apresentam longos períodos de imobilização e inatividade física, portadores de insuficiência renal crônica, menopausa precoce (idiopática ou ooforectomia) e usuários de determinados tipos de drogas como corticóides e anticonvulsionantes.

Hemert et al. (1987), em pesquisa americana, realizaram um estudo em 1.267 mulheres entre 45 e 64 anos, observadas por um período médio de 4 anos em relação à ocorrência de fraturas. Após a coleta de informações sobre todas as fraturas ocorridas, foi concluído que não é eficiente usar somente os fatores de risco para a seleção de mulheres em programas de prevenção de fraturas.

\subsubsection{O IMPACTO SOCIAL DA OCORRÊNCIA DAS FRATURAS OSTEOPORÓTICAS}

As principais manifestações clínicas da osteoporose são as fraturas, sendo mais freqüentes as de vértebra, fêmur e antebraço e em qualquer região do esqueleto com alto porcentual de osso trabecular (LINDSAY et al., 2001). As fraturas causadas pela osteoporose e as incapacidades dela resultantes têm impacto importante na saúde das populações idosas do mundo ocidental e requerem freqüentemente hospitalização, reabilitação e cuidados domiciliares. Elas têm especial importância na sociedade brasileira se considerado o envelhecimento progressivo da sua população, com conseqüências físicas, financeiras e psicossociais, afetando os indivíduos, as famílias e a comunidade. As 
fraturas atingem homens e mulheres, predominantemente pessoas do sexo feminino com deficiência estrogênica e indivíduos idosos.

$\mathrm{Na}$ maioria das populações, a taxa de incidência aumenta exponencialmente com a idade, como pode ser evidenciado na Figura 6. Em todas as idades após os 50 anos, a incidência nas mulheres é duas vezes maior do que no homem. De qualquer forma, cerca de $80 \%$ de todas as fraturas de quadril ocorrem nas mulheres (COOPER; MELTON III, 1992).

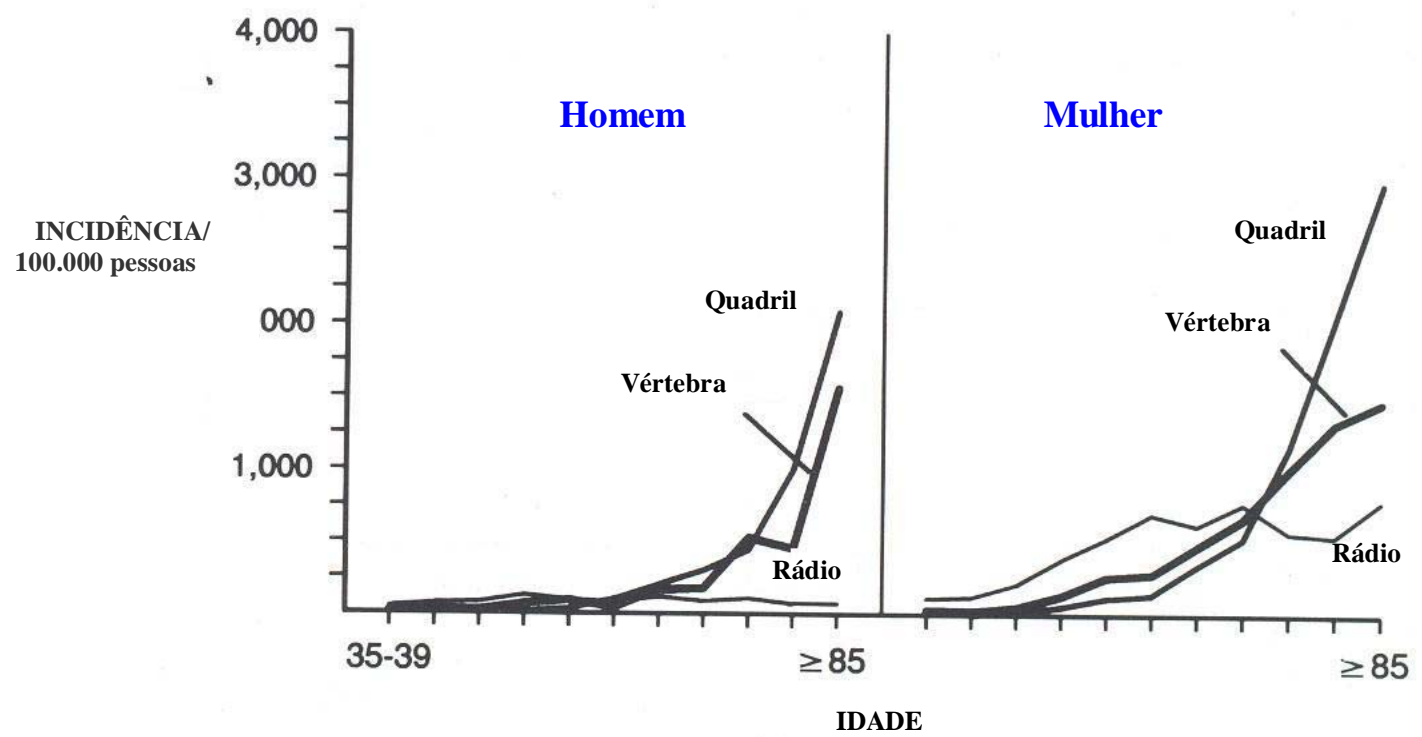

FIGURA 6 - Incidência de fraturas de quadril, vértebra e rádio distal relacionadas com a idade em homens e mulheres. 
Estudos populacionais transversais de distribuição de densidade óssea relacionada com a idade mostram existir um rápido declínio na massa óssea de mulheres entre 40 e 70 anos (AITKEN, 1987).

A prevalência de osteoporose e a incidência de fraturas variam de acordo com o gênero e a raça. As mulheres brancas na pós-menopausa apresentam maior incidência de fraturas. A partir dos 50 anos, $30 \%$ das mulheres e $13 \%$ dos homens poderão sofrer algum tipo de fratura por osteoporose ao longo da vida. Estudos realizados no Brasil evidenciam incidência similar, especialmente na população branca; porém deve-se considerar a grande miscigenação da população brasileira e que a menor incidência de fraturas ocorre entre os negros (PINTO NETO et al., 2002).

Há 200 milhões de pessoas com osteoporose no mundo. No Brasil, mais de 10 milhões de casos culminam em um registro anual de 80.000 casos de fratura de fêmur. Os números mostram que os registros de fraturas osteoporóticas dobraram na última década - são quase 1.700 .000 fraturas de fêmur no mundo, uma a cada 20 segundos - com estimativas de atingir 6 milhões de pessoas em 60 anos. Das mulheres que sofreram fratura de vértebra após a menopausa, 20\% voltaram a sofrer fratura após um ano da ocorrência (LINDSAY et al., 2001). Aproximadamente 25\% dos pacientes faleceram nos primeiros 6 meses após uma fratura e 40\% faleceram nos primeiros 2 anos após uma fratura (FERNANDES et al., 2001). 


\subsubsection{CARACTERÍSTICAS GERAIS DO FEMUR PROXIMAL E SUAS FRATURAS}

O fêmur proximal é o sítio de maior morbidade, mortalidade e perda funcional entre as fraturas osteoporóticas e o de maior impacto socioeconômico.

A maioria dessas fraturas no idoso, indivíduos com idade acima de 60 anos de acordo com a Organização Mundial da Saúde, é resultado de quedas simples. Embora em uma queda a própria altura possa ter energia potencial suficiente para fraturar o fêmur proximal até em pessoas mais jovens, as pessoas de idade avançada são incapazes de dissipar essa energia da mesma forma que as pessoas mais jovens o fazem. Cummings e Nevitt (1989) sugeriram quatro razões para tal fato. Dois desses fatores aumentam a força local aplicada ao grande trocanter do fêmur: primeiro, a velocidade deambulatória fica diminuída na idade avançada e a tendência é cair para o lado em vez de cair para a frente; segundo, suas respostas protetoras ficam diminuídas por causa dos tempos de reação mais lentos, da debilidade e da desorientação, ou pelos efeitos colaterais dos medicamentos. Em adição, os pacientes de idade avançada podem não contar com amortecedores naturais, como gordura ou músculos que absorvem e dissipam a energia aplicada ao quadril numa queda. Finalmente, a resistência óssea diminuída por causa da osteoporose permite a ocorrência de fraturas com quantidades pequenas de energia. Além 
disso, a taxa de ocorrência dessas fraturas aumenta marcadamente com o envelhecimento, bem mais do que o aumento na taxa das quedas (MARKS et al., 2003).

Desde que o paciente com fratura do quadril apresente condições clínicas para ser submetido a tratamento cirúrgico, este é o tratamento de eleição, pois uma fratura desse tipo permite mobilização precoce do paciente e uma rápida recuperação funcional ao ser fixada por meio de uma osteossíntese ou substituída por uma prótese, evitando, assim, que fique acamado, sofrendo conseqüências clínicas indesejáveis que, em muitos casos, podem levar à morte.

Foi realizado um estudo de revisão da literatura, cuja pesquisa foi feita na base de dados Medline (SAKAKI et al., 2004), sobre a mortalidade de idosos por fratura do fêmur proximal, tendo como base as publicações mais relevantes do período compreendido entre 1998 e 2002. Foram incluídos 25 artigos relacionados ao assunto selecionados nos bancos de dados Medline e Cochrane, totalizando 24.062 casos de pacientes com mais de 60 anos de idade que tiveram fratura do fêmur proximal. Quatorze estudos foram prospectivos, oito retrospectivos e três eram revisões sistemáticas. As taxas médias de mortalidade foram de $5,5 \%$ durante a internação hospitalar, de $4,7 \%$ ao fim de um mês de seguimento, $11,9 \%$ aos três meses, $10,8 \%$ aos seis meses, 19,2\% após um ano e $24,9 \%$ após dois anos da fratura.

Os índices de mortalidade dos pacientes geriátricos encontrados por essa revisão mostram que existe realmente uma influência importante da fratura do fêmur proximal na sobrevida desses pacientes, 
principalmente se comparados com os índices encontrados para a população sem fraturas. A taxa de mortalidade nos grupos controle aos seis meses de seguimento é de 3,2\%, ao final de um ano de $5,2 \%$ e aos dois anos de 9,6\% (MEYER et al., 2000), valores bem menores que os encontrados para os pacientes com fratura.

Quanto aos custos financeiros do tratamento dessas fraturas, devem ser considerados os dos procedimentos médicos, de enfermagem, do fornecimento de próteses, além dos custos de reabilitação e os sociais.

A Tabela 1 mostra o custo médio da assistência a um caso de fratura osteoporótica do fêmur em mulheres com idade acima de 50 anos.

Tabela 1

Custos da alternativa tradicional (sem intervençäo específica).

Número estimado de fraturas osteoporóticas

12.750

de fêmur * (mulheres acima 50 anos - Brasil)

Custos **

Hospitalização aguda ***

Longa permanência

Consultas/Fisioterapia

Total

Custo médio de cada fratura de colo de fêmur
$\mathrm{R} \$ 17.319 .478,00$

$\mathrm{R} \$ 4.576 .528,00$

R\$ $126.230,00$

$\mathrm{R} \$ 22.022 .236,00$

$\mathrm{R} \$ 1.727,00$

* Estimativa feita a partir do número de procedimentos pertinentes (DATASUS, 2001), descontando-se os percentuais relativos às retiradas de prótese e a reoperaçōes.

** Valores em reais, derivados de dados obtidos do sistema DATASUS (2001).

*** Primeiro atendimento, reduçäo cirúrgica, artroplastia coxo-fem ural, redução incruenta, assistência conservadora, reoperação e retirada de pino, placa ou prótese. 


\subsubsection{DIAGNÓSTICO DA OSTEOPOROSE}

O diagnóstico da osteoporose deve levar em consideração os seguintes aspectos: a história clínica do paciente, a execução de exames físicos e complementares, como avaliação laboratorial, exames radiológicos e medidas de massa óssea, além da avaliação do risco de fratura. A osteoporose é inicialmente assintomática. As primeiras manifestações clínicas ocorrem quando já houve perda de $30 \%$ a 40\% da massa óssea. Vários métodos têm sido empregados no estudo quantitativo do esqueleto em pacientes com osteoporose. A investigação e o gerenciamento clínico da osteoporose têm sido revolucionados pelo desenvolvimento de novas técnicas não-invasivas para medida de massa óssea, com grande número de aplicações potenciais provadas (COMPSTON, 1995).

Segundo outra revisão da literatura (GENANT et al., 1996), nas últimas décadas tem havido considerável progresso no desenvolvimento de métodos não-invasivos para a avaliação do esqueleto. Atualmente, é possível avaliar-se a densidade mineral óssea dos esqueletos periférico e central, bem como de todo o corpo, além de ser possível a diferenciação entre osso cortical e esponjoso (Tabela 2). Essas técnicas variam em precisão, exatidão e discriminação e diferem substancialmente em metodologia fundamental, utilidade clínica, pesquisa e disponibilidade geral. 
Tabela 2 - Métodos não-invasivos para a avaliação do esqueleto

\begin{tabular}{|l|ll|}
\hline RA & Radiographic Absorptiometry & Radiografia por Absorciometria \\
\hline SPA & $\begin{array}{l}\text { Single Photon Absorptiometry } \\
\text { Single X-ray Absorptiometry }\end{array}$ & $\begin{array}{l}\text { Absorciometria por fóton } \\
\text { Absorciometria por raios X }\end{array}$ \\
\hline DPA & $\begin{array}{l}\text { Dual Photon Absorptiometry } \\
\text { Dual X-ray Absorptiometry (DEXA) }\end{array}$ & $\begin{array}{l}\text { Absorciometria por duplo fóton } \\
\text { Absorciometria por raios X com dupla } \\
\text { energia (DEXA) }\end{array}$ \\
\hline QCT & Quantitative Computed Tomography & $\begin{array}{l}\text { Tomografia Computadorizada } \\
\text { Quantitativa }\end{array}$ \\
\hline PQCT & $\begin{array}{l}\text { Peripheral Quantitative Computed } \\
\text { Tomography }\end{array}$ & $\begin{array}{l}\text { Tomografia Computadorizada } \\
\text { Quantitativa Periférica }\end{array}$ \\
\hline QUS & Quantitative Ultrasound (QUS) & Ultra-Som Quantitativo (Qus) \\
\hline QMR & Quantitative Magnetic Resonance & Ressonância Magnética Quantitativa \\
\hline MMR & Micro Magnetic Resonance & Ressonância Magnética Microscópica \\
\hline
\end{tabular}

Fonte: NJEH et al., 1999.

A RA (Radiografia por Absorciometria) ou Fotodensitometria foi um método muito usado na década de 60, sendo a primeira técnica quantitativa de avaliação da massa óssea integral (trabecular e cortical). Ela faz a estimativa da densidade mineral óssea usando imagens de raios $X$, que são comparadas aos padrões de referência em níveis de cinza, sendo de baixo custo e de fácil acesso. No entanto, esse método mostra pouca reprodutibilidade.

A SPA (Absorciometria por Foton Unico) usa fonte de energia radioativa para realizar medidas do mineral ósseo em sítios periféricos como, por exemplo, punho e calcanhar.

A SXA tem superado o método SPA por ter melhor reprodutibilidade e mais fácil acesso, além de não usar nenhuma fonte radioativa. 
A DPA (Absorciometria por Foton Duplo) realiza medidas em partes do esqueleto que não podem ser medidas pela SXA, como, por exemplo, coluna lombar, quadril e até mesmo todo o corpo.

A DEXA, método desenvolvido na década de 70, é a técnica mais largamente usada e conhecida como densitometria óssea, sendo o exame de referência para o diagnóstico de osteoporose aceito pela OMS. A DEXA realiza medidas de ossos em todo o corpo, além de calcanhar e punho, com alta precisão e exatidão e com uma baixa exposição de radiação para o paciente. Sua disponibilidade e facilidade de uso têm feito com que essa seja a técnica mais usada para medida da densidade óssea em triagens clínicas e em estudos epidemiológicos.

A QCT (Tomografia Computadorizada Quantitativa) é o único método disponível com capacidade para determinar em 3D a densidade volumétrica $\left(\mathrm{mg} / \mathrm{cm}^{3}\right)$ do osso cortical e do esponjoso, por exemplo, o osso trabecular no centro da vértebra, usando uma técnica de raios $X$ tridimensional. A QCT tem uma vantagem sobre as outras técnicas em sua capacidade de avaliar a densidade volumétrica real do osso cortical e do trabecular.

O pQCT é um equipamento de QCT adaptado para medidas de sítios periféricos tais como punho. Ele permite uma medida real do osso apendicular sem superposição de outros tecidos, podendo avaliar separadamente o osso cortical e o trabecular. Essa técnica apresenta as desvantagens de ter um alto custo e uma baixa portabilidade. 
A QUS tem sido usada na predição do risco de fratura pelo fato de a fisiologia da osteoporose incluir diminuição de massa óssea e alteração na microarquitetura do osso trabecular. Essa técnica fornece informações sobre o estado ósseo por meio de ondas ultra-sônicas que atravessam o tecido realizando medidas em vários sítios esqueléticos, incluindo calcanhar, mão, dedos e tíbia. Trata-se de uma técnica alternativa com vantagens como portabilidade, não exposição do paciente à radiação ionizante e baixo custo. A técnica apresenta também algumas desvantagens apontadas pelos especialistas - entre elas pode-se apontar baixa precisão em indivíduos novos e falta de um parâmetro específico para a identificação de indivíduos osteoporóticos e sadios. Atualmente, as medidas de ultra-sonometria baseiam- se no banco de dados da densitometria óssea.

A QMR (Ressonância Magnética Quantitativa), que é uma técnica complexa baseada na aplicação de altos campos magnéticos, tem revolucionado a imagem médica em geral. Estudos experimentais têm confirmado as predições teóricas, sugerindo que essa é uma ferramenta promissora para o estudo da arquitetura do osso trabecular e para a avaliação da osteoporose.

Algumas pesquisas têm indicado que a informação a respeito da densidade óssea de qualquer osso é igualmente valiosa para predizer a osteoporose de modo geral (MELTON III et al., 1993), enquanto outras pesquisas indicam que as medidas obtidas em sítios específicos são melhores informantes a respeito do risco de fratura desse sítio (KANIS; GLUER, 2000), 
Segundo Simões et al. (2000), a escolha do método mais apropriado ou a combinação de técnicas de trabalho são fatores muito importantes, pois, dessa forma, ampliam-se as possibilidades diagnósticas, com conseqüente melhora da abordagem terapêutica. Por exemplo, a medida da porção proximal do rádio oferece uma noção da massa óssea do esqueleto e tem um valor preditivo significativo para a ocorrência de algumas fraturas, sendo, porém, relativamente pouco sensível para a perda precoce que ocorre nos primeiros anos após a menopausa. A medida direta do osso trabecular da coluna permite o diagnóstico precoce de perda de massa óssea após a menopausa, não tendo, entretanto, valor preditivo para fraturas do fêmur. A DEXA e a QCT são as técnicas mais comumente usadas, e a popularidade de outros processos, tais como RA, SXA e QUS, está ganhando terreno.

A escolha do melhor sítio esquelético para a predição da osteoporose é um objeto de grande debate. De qualquer forma, é consenso que os sítios com mais alto conteúdo de osso esponjoso (maior taxa de remodelamento) são mais sensíveis às mudanças osteoporóticas. Estudos longitudinais sugerem que a medida da maioria dos sítios esqueléticos comumente selecionados (coluna, fêmur, rádio e calcâneo) é útil para predizer o risco de fratura em qualquer um deles. A melhor avaliação do risco no sítio específico, de qualquer forma, é a medida da sua densidade mineral óssea (NJEH et al., 1999).

Em estudos epidemiológicos, a avaliação da massa óssea é realizada para estudar determinantes do pico de massa óssea e para determinar o valor de medida da massa óssea de um osso na predição 
do risco de fratura. Em triagens clínicas, as mudanças na massa óssea são comumente usadas como um substituto para o risco de fratura. Na prática clínica, a avaliação de densidade óssea é usada para diagnóstico (osteoporose e osteopenia) e para monitorar a resposta ao tratamento. As Tabelas 3 e 4 mostram as técnicas de medida de massa óssea segundo os sítios medidos e a utilidade clínica. (PINTO NETO et al., 2002)

Tabela 3 - Técnicas de medida de densidade óssea segundo os sítios medidos e a utilidade clínica.

\begin{tabular}{|l|l|l|}
\hline TÉCNICA $^{1}$ & SítTIOS MEDIDOS & UTILIDADE CLÍNICA \\
\hline DEXA & $\begin{array}{l}\text { Coluna AP, } \\
\text { fêmur proximal, } \\
\text { antebraço, } \\
\text { coluna lateral }\end{array}$ & $\begin{array}{l}\text { Diagnóstico, avaliação de risco e } \\
\text { monitoramento } \\
\text { Diagnóstico, avaliação de risco e } \\
\text { monitoramento } \\
\text { Diagnóstico, avaliação de risco } \\
\text { Avaliação de risco e monitoramento }\end{array}$ \\
\hline PDEXA & Calcâneo, antebraço, falange & Avaliação de risco \\
\hline QCT & Coluna, quadril & Avaliação de risco e monitoramento \\
\hline PQCT & Antebraço & Avaliação de risco \\
\hline RA & Falanges & Avaliação de risco \\
\hline SXA & Calcâneo, antebraço & Avaliação de risco \\
\hline
\end{tabular}

FONTE: PINTO NETO et al., 2002

Tabela 4 - Técnica de avaliação quantitativa que não mede a densidade óssea ${ }^{2}$

\begin{tabular}{|l|l|l|}
\hline TÉCNICA & SíTIOS MEDIDOS & UTILIDADE CLÍNICA \\
\hline QUS & $\begin{array}{l}\text { Calcâneo, antebraço, tíbia, } \\
\text { falanges, metatarsos }\end{array}$ & Avaliação de risco \\
\hline
\end{tabular}

FONTE: PINTO NETO et al., 2002

\footnotetext{
${ }^{1}$ DEXA = dual $x$-ray absorptiometry; pDEXA = peripheral dual $x$-ray absorptiometry; $Q C T$ = quantitative computed tomography; $\mathrm{AP}=$ ântero-posterior; $\mathrm{pQCT}$ = peripheral quantitative computed tomography; RA = radiographic absorptiometry; $\mathrm{SXA}=$ Falta; QUS = quantitative ultrasonometry; SOS = speed of sound.

${ }^{2}$ Técnica de avaliação quantitativa que não mede a densidade óssea.
} 


\subsubsection{O EXAME DE DENSITOMETRIA ÓSSEA}

Estudos publicados durante décadas confirmaram a relação entre a massa óssea e as propriedades mecânicas do tecido ósseo. Segundo Faulkner (2000), quando amostras ósseas são investigadas laboratorialmente sob condições controladas, é possível observar que a densidade mineral óssea relaciona-se com $60 \%$ da resistência óssea. Mesmo não sendo resultado coincidente com os de outros autores descritos anteriormente (CRANNEY, 2002), a correlação entre densidade mineral óssea e resistência óssea tem sido confirmada em humanos, nos quais, em vários estudos prospectivos, a densidade mineral óssea tem demonstrado predizer o risco em relação a vários tipos de fraturas.

Conforme citado, a densitometria óssea (DEXA) é o exame de referência para o diagnóstico de osteoporose. Segundo os critérios propostos pela OMS (WHO, 1994), o diagnóstico é realizado pela avaliação da coluna lombar em posição ântero-posterior, do fêmur proximal, do colo femoral e/ou do fêmur total e do antebraço.

A técnica baseia-se na atenuação, pelo corpo do paciente, de um feixe de radiação gerado por uma fonte de raios $X$ com dois níveis de energia. Esse feixe atravessa o indivíduo no sentido antero-posterior e é captado por um detector. O programa calcula a densidade de cada amostra a partir da radiação que alcança o detector em cada pico de energia. O tecido mole (gordura, água, músculos, órgãos viscerais) 
atenua essa energia de forma diferente à do tecido ósseo, permitindo a construção de uma imagem da área de interesse.

O exame fornece o valor absoluto, em g/cm2, da densidade mineral óssea da área estudada. Embora densidade seja uma medida volumétrica e a BMD em posição ântero-posterior, que é a mais comumente utilizada, seja o resultado do conteúdo mineral ósseo dividido pela "área" e não por "volume" de osso, existe uma grande correlação entre a densidade por "área" e a densidade real, volumétrica, medida por tomografia computadorizada.

O laudo também fornece o número de desvios padrão do resultado obtido em relação à média de adultos jovens, população que representa o pico de massa óssea. Esse desvio padrão, ou T-score, é usado para definir o diagnóstico de osteoporose segundo os critérios da Organização Mundial da Saúde: valores até -1 desvios padrão (d.p) da média são considerados normais; valores entre -1,1 e -2,4 d.p. definem osteopenia e valores menores que $-2,5$ d.p. diagnosticam osteoporose. Mais de $90 \%$ dos indivíduos com fraturas a mínimos traumas ou atraumáticos têm valores de densidade mineral óssea além dos $-2,5$ desvios padrão da média de adultos jovens e esta é a razão para que esse valor de corte fosse escolhido para o diagnóstico de osteoporose, mesmo na ausência de fraturas. Para cada desvio padrão abaixo da média, eleva-se uma e meia a três vezes o risco de fraturas osteoporóticas, dependendo do sítio ósseo analisado.

O Z-score ou número de desvios padrão em relação à média esperada para a idade do paciente é outro parâmetro de interesse, 
particularmente nas osteoporoses secundárias a doenças crônicas ou ao uso crônico de medicamentos que afetam a massa óssea.

A densitometria por DEXA pode avaliar a coluna lombar (PA e perfil), o fêmur proximal, o antebraço e o corpo inteiro com sua composição corporal.

O exame da coluna lombar, como demonstrado na Figura 7, em posição ântero-posterior, avalia o segmento de L2 a L4, que é usado para o diagnóstico de osteoporose e que apresenta a melhor sensibilidade para a monitoração terapêutica.

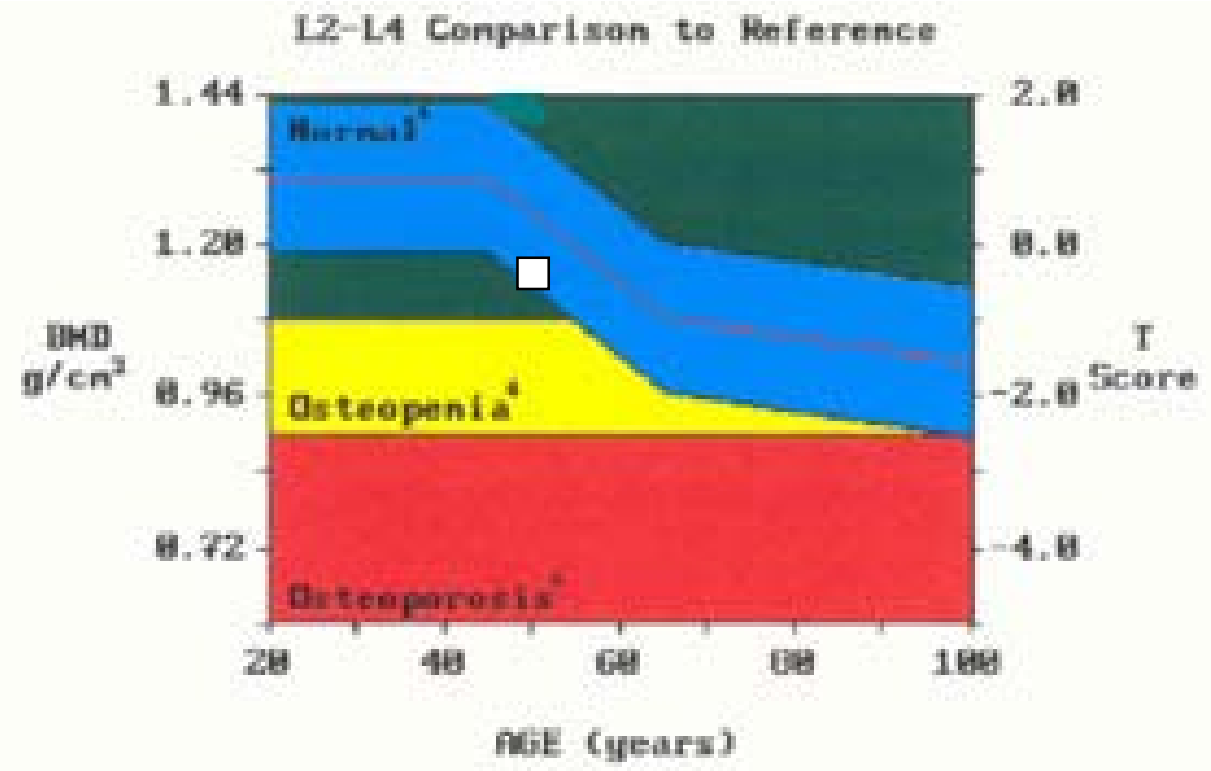

Figura 7 - Gráfico demonstrativo resultante da densitomeria óssea da coluna lombar realizada em aparelho Densitômetro DPX-IQ Lunar, mostrando densidade mineral óssea de $1.30 \mathrm{~g} ; \mathrm{cm} 2$ num individuo de 50 anos.

Manual de Doenças Osteometabólicas - Fleury- Medicina Diagnóstica. 
A análise do exame de fêmur proximal, como mostrado na Figura 8, envolve a medida de BMD em três regiões: colo de fêmur, trocanter maior e região do Triângulo de Wards.

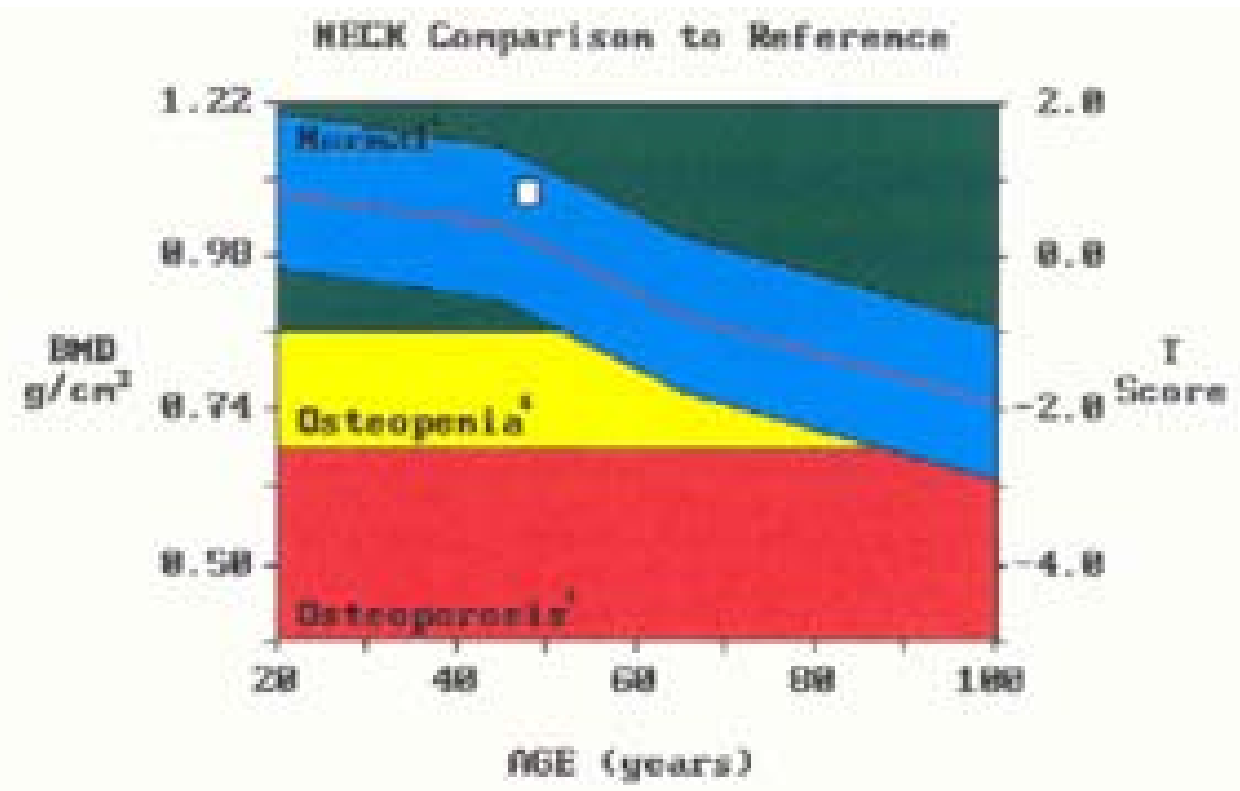

Figura 8 - Gráfico demonstrativo resultante da densitomeria óssea do fêmur proximal realizada em aparelho Densitômetro DPX-IQ Lunar, mostrando densidade mineral óssea de $1.19 \mathrm{~g} / \mathrm{cm} 2$ num individuo de 49 anos.

FONTE: Manual de Doenças Osteometabólicas - Fleury- Medicina Diagnóstica.

A baixa massa óssea usada para definir a osteoporose é fixada em 2,5 desvios padrão ou mais. Abaixo da densidade mineral óssea representativa da mulher na pré-menopausa, alguns pesquisadores (HEANEY, 1987; CUMMINGS et al., 1990) consideraram que, por definição, a osteoporose é um ponto arbitrário na escala. O exame deveria medir não a densidade e sim o remodelamento ósseo. E, além disso, apesar de a densidade mineral óssea estar relacionada com a 
resistência óssea e de as medições da densidade ser capazes de predizer o risco de fratura, nem todos os indivíduos com densidade mineral óssea diminuída chegou a apresentar uma fratura. Ou seja, mesmo que a densidade mineral óssea explique uma porção significativa da resistência óssea, há evidências de que outros aspectos estruturais do osso e a sua qualidade também sejam importantes na determinação do risco de fratura. Os parâmetros de microarquitetura (como a quantidade e espessura das trabéculas) e os fatores de qualidade óssea (como as propriedades materiais da matriz óssea) são aspectos estruturais importantes na avaliação do risco de fratura não considerados pelo exame de densitometria óssea. Entre as desvantagens do uso da densitometria óssea estão:

- não avalia o segmento toráxico, o mais comprometido nos colapsos vertebrais;

- a existência de casos de pacientes com valor de densidade mineral óssea suficiente para a classificação de osteoporose e que nunca sofreram fraturas e também, ao contrário, de pacientes com densidade mineral óssea classificada como normal e que posteriormente têm fratura;

- a existência de erros devidos a variações de resultados de medida de densidade mineral óssea em um mesmo paciente, quando feita por diferentes técnicos ou diferentes equipamentos;

- fraturas por colapso vertebral que reduzem a área vertebral medida, havendo a aproximação das trabéculas ósseas com conseqüente aumento da densidade mineral óssea; 
- alguns pacientes (como aqueles com pinos metálicos na coluna, os submetidos à cirurgia abdominal e suturados com grampos metálicos e os com mais de 126 quilos) não podem realizar o exame;

- o exame não tem padrão definido para classificar a osteoporose em homens.

\subsubsection{RISCO DE FRATURA}

A susceptibilidade da fratura óssea depende de vários fatores como propensão à queda, acuidade visual, resposta à queda e resistência óssea, sendo a ocorrência de fratura determinada pelas propriedades biomecânicas do osso em adição aos fatores relacionados ao estilo de vida e às características das quedas (MAJUNDAR et al., 1998). A princípio, para que uma fratura ocorra, o osso deve ter sido sujeitado a uma força maior do que aquela a que ele poderia resistir.

Segundo Francis (1990), como as propriedades mecânicas dos ossos estão relacionadas ao seu conteúdo mineral e a sua estrutura arquitetônica, uma redução na massa óssea está inevitavelmente associada ao aumento da suscetibilidade de fratura. Melton III e Cooper (1998) realizaram estudos que confirmaram que a perda óssea compromete a integridade biomecânica do esqueleto e aumenta o risco de fratura.

Clinicamente, a evidência de aumentada fragilidade óssea é determinada pela presença de fraturas causadas por quedas ou outras 
lesões que, normalmente, não fraturam os ossos. Isso também inclui fraturas ou características relacionadas com a dor causada por um trauma mínimo. Para se estimar o risco de fratura, considera-se o peso de todas as variáveis das quais ele é dependente (Figura 9). A diferença entre a fratura comum e a provocada por uma doença osteometabólica, como a osteoporose, é a desproporção entre a mesma e o trauma.

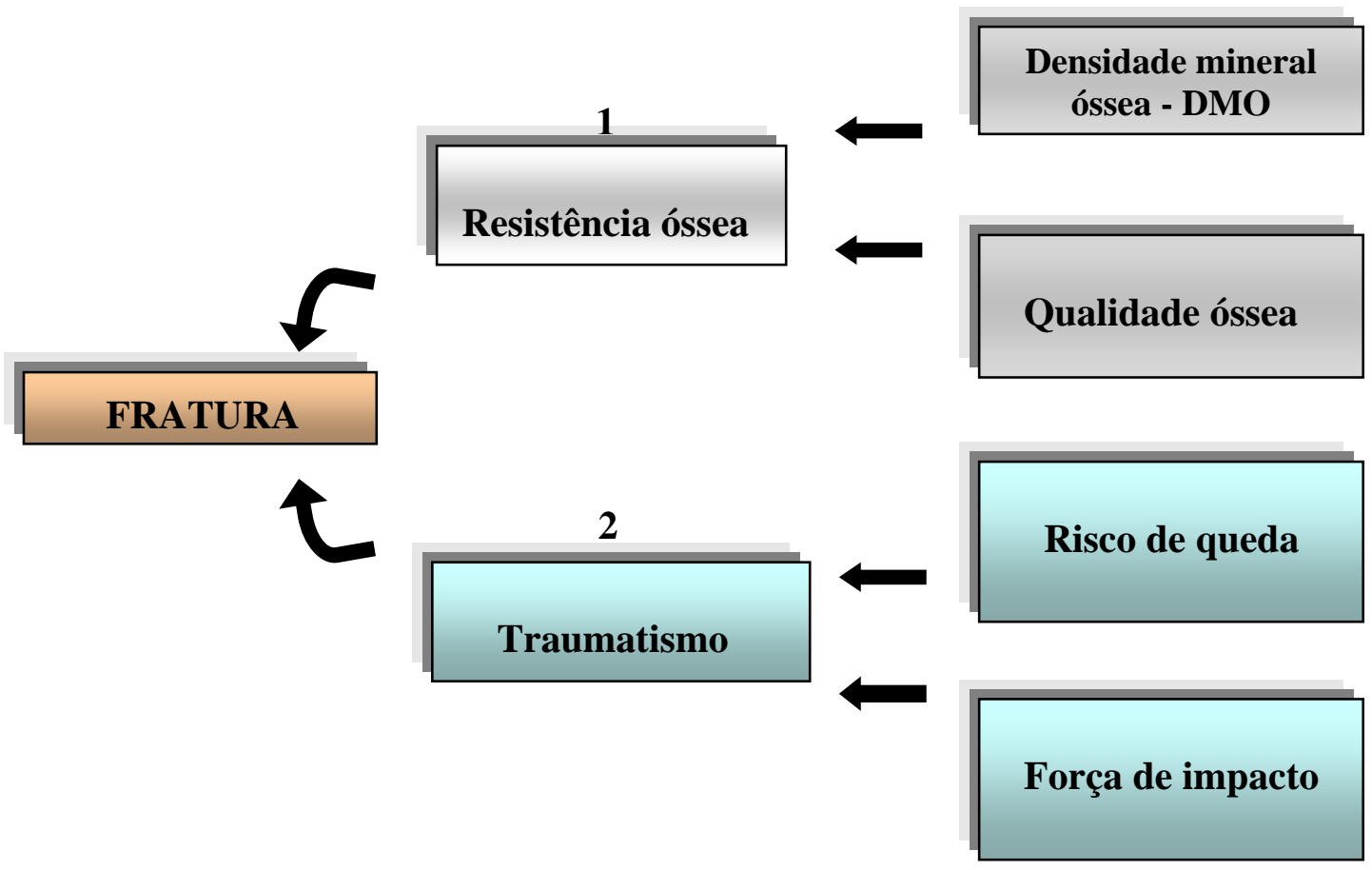

FIGURA 9- Fluxograma mostrando elementosresponsáveis pela fratura.

A fratura é um resultado da diminuição da resist ência e rigidez óssea associada com traumatismos.

1) A resistência óssea depende da densidade e da qualidade óssea.

2) O traumatismo depende de fatores relacionados com a queda e a força de impacto.

Estudos propõem que danos microscópicos no osso podem contribuir de maneira significativa para o aumento da fragilidade óssea, 
levando a complicações tais como fraturas por tensão e osteoporóticas (JOHNSTON; SLEMENDA, 1995). Microtrincas podem afetar as propriedades mecânicas do osso, promovendo a diminuição da rigidez óssea e a resistência à fratura. A acumulação ocasionada por tais danos pode ocorrer devido às atividades diárias normais (SHAFFER et al., 1985).

\subsubsection{CONTRIBUIÇÃO DA RESISTÊNCIA ÓSSEA NA FRATURA}

Segundo Kleerekoper et al. (1985), a resistência dos ossos humanos tem implicações importantes nas doenças do esqueleto, tais como osteoporose e osteomalácia. A resistência óssea depende da densidade mineral óssea e da qualidade óssea, Ross et al. (1990) afirmaram que a massa óssea reduzida é um preditor útil do aumento do risco de fratura. Gerhart (2000) mostrou que a resistência à compressão do osso trabecular é proporcional à sua densidade e diminui com a idade.

A qualidade óssea ou microarquitetura trabecular é responsável por cerca de $30 \%$ a $50 \%$ da resistência mecânica do osso (KLEEREKOPER et al., 1985). Segundo Riggs et al. (1981), a perda concomitante do osso cortical e do trabecular é fisiológica e, após várias décadas, resulta em perda suficiente de osso mineralizado, predispondo às fraturas. Diferentemente da densidade mineral óssea, a 
qualidade óssea é uma variável difícil de quantificar. Torna-se, pois, evidente a necessidade de estudar e compreender essa variável desenvolvendo técnicas que possam quantificá-la com precisão e que permitam estratificar pacientes com maior risco de fraturas (CASTRO; PINHEIRO; SZEJNFELD, 2000).

\subsubsection{CONTRIBUIÇÃO DO TRAUMATISMO NA FRATURA}

Muitas fraturas nos idosos e nas mulheres pós-menopausa resultam de pequenos traumas, freqüentemente ocorrendo sem dor. A osteoporose predispõe às fraturas porque torna os ossos enfraquecidos, as quais podem ocorrer devido a forças de baixa magnitude e à diminuição dos reflexos de proteção no amortecimento do impacto da queda nos idosos (GERHART, 2000). As quedas que causam fraturas ósseas geralmente aplicam, ao mesmo tempo, uma combinação de forças em flexão, torção e compressão para os quais o osso nunca pôde se adaptar (GERHART, 2000). 


\subsection{ULTRA-SONOGRAFIA ÓSSEA}

\subsubsection{ASPECTOS TEÓRICOS DO ULTRA-SOM}

O som é uma forma de energia que consiste da vibração das moléculas de um meio que pode ser gás, líquido, sólido ou tecidos biológicos. A energia se propaga através do meio sob a forma de ondas, sendo o som uma onda mecânica. As características fundamentais de uma onda são a amplitude (distância entre o ponto mais alto e o mais baixo de uma onda) e a freqüência (expressão da quantidade de ciclos que acontecem em uma unidade de tempo), cuja unidade é o Hertz (1Hz = 1 ciclo/segundo).

O ultra-som é uma onda que possui uma freqüência superior à faixa de freqüência do som audível, entre $20 \mathrm{~Hz}$ e $20.000 \mathrm{~Hz}$. Diferentemente das ondas eletromagnéticas, que se propagam no vácuo, o ultra-som, por ser uma onda mecânica, precisa de um meio mecânico para se propagar. Ao atravessar um material, o ultra-som tem suas propriedades alteradas em forma, intensidade e velocidade de propagação. As ondas ultra-sônicas são geradas por transdutores, que são dispositivos que convertem um tipo de energia em outro através do efeito piezoelétrico. Esse efeito foi descoberto por Pierre e Jacques Curie em 1880 e consiste na variação das dimensões físicas de certos materiais quando sujeitos aos potenciais elétricos. O contrário também ocorre, ou seja, a aplicação de pressões acústicas causa variações nas dimensões de materiais piezoelétricos, provocando, neles, o 
aparecimento de campos elétricos (WADE, 2000). Dessa forma, as ondas de ultra-som podem ser produzidas pela aplicação de potenciais elétricos a determinados tipos de cristais (piezoelétricos). Quando uma voltagem é aplicada através do cristal, o realinhamento resultante das moléculas permanentemente polarizadas provoca uma mudança na espessura do cristal. De modo inverso, tensões mecânicas no cristal podem causar a geração de uma voltagem (Figura 10). Desse modo, o transdutor de ultra-som converte energia elétrica em energia ultrasônica e vice-versa. O mesmo transdutor que emite o sinal ultra-sônico pode funcionar como detector, pois os ecos produzem vibração no cristal, fazendo variar suas dimensões físicas que, por sua vez, acarretam o aparecimento de um campo elétrico. Esse campo gera sinais que podem ser amplificados e mostrados em um osciloscópio ou registrador.

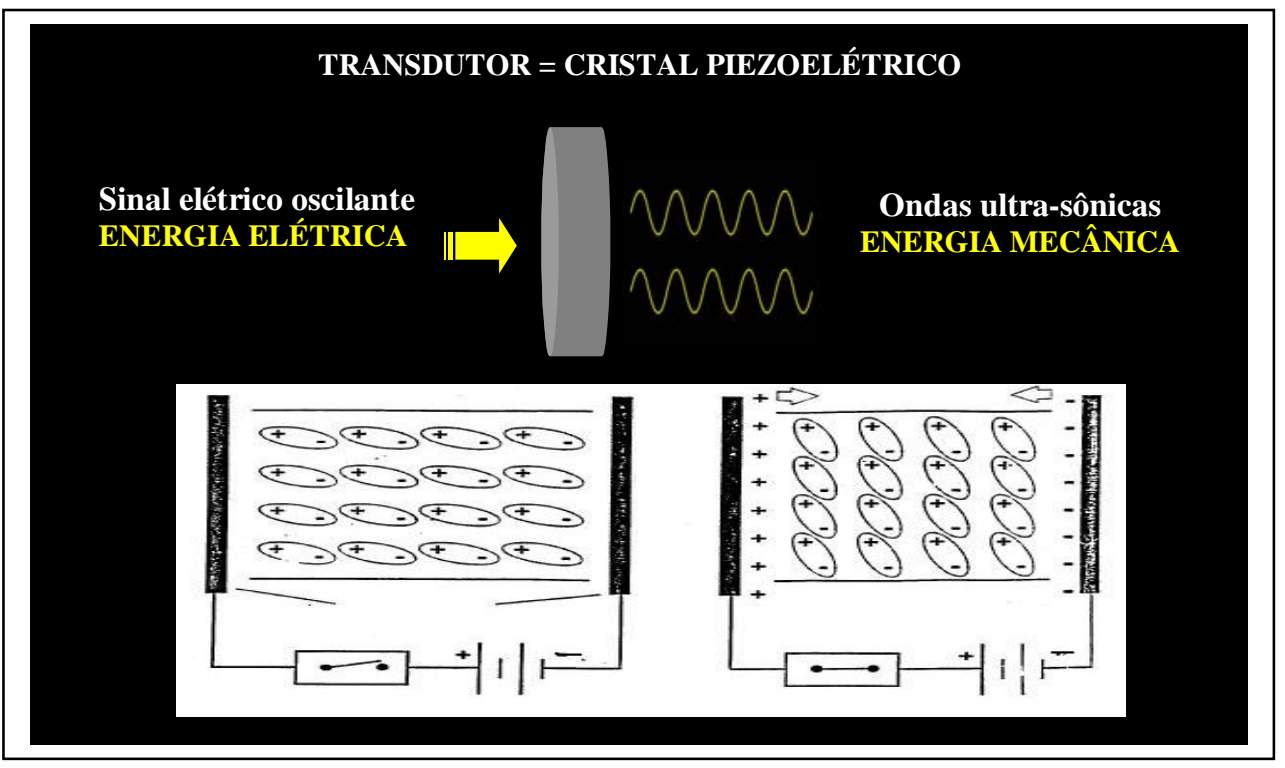

FIGURA 10 - Esquema ilustrativo do mecanismo da piezoeletricidade

As ondas de ultra-som podem ser produzidas pela aplicação de campos elétricos a determinados tipos de cristais (piezoelétricos) que se deformam mecanicamente sob a ação desses campos, gerando ondas acústicas que são transmitidas ao meio onde estão localizados.

FONTE : WADE. 2000 


\subsubsection{PARÂMETROS DO ENSAIO ULTRA-SÔNICO EM OSSO}

O ultra-som tem sido utilizado pela engenharia mecânica e pela engenharia dos materiais desde a década de 50 como uma técnica capaz de avaliar a integridade mecânica dos materiais. O uso do ultrasom na medicina iniciou-se como técnica de terapia e posteriormente, na década de 40, como ferramenta de diagnóstico médico. Currey (1970) foi o primeiro a aplicar essa tecnologia no campo da avaliação da qualidade do tecido ósseo. São dois os parâmetros avaliados pela técnica: a alteração da velocidade ultra-sônica e a atenuação da energia transmitida pela onda ultra-sônica ao atravessar o meio.

\subsubsection{A ALTERAÇÃO DA VELOCIDADE DA ONDA ULTRA-SÔNICA}

O som se propaga em várias velocidades através de diferentes meios. A velocidade na qual o som se propaga em um sólido é uma função de sua densidade, massa e módulo de elasticidade (GRENFIELD et al., 1981). Na prática, quanto mais alta a velocidade do som passando pelo osso, melhor será a qualidade do osso. Uma velocidade baixa revela fragilidade e probabilidade de fratura. Numa pessoa com cerca de 30 anos, a velocidade do som passando pelo osso é de aproximadamente $4.000 \mathrm{~m} / \mathrm{s}$; numa pessoa com 70 anos, essa velocidade cai para $3.800 \mathrm{~m} / \mathrm{s}$.

A velocidade do som pode ser calculada pela medida do tempo requerido para a onda sonora se propagar através da amostra e, então, 
dividindo a largura da amostra pelo intervalo de tempo. A efetividade do uso do ultra-som é manifestada especialmente em medidas no osso esponjoso, porque as ondas com freqüência acima de $2 \mathrm{~Hz}$ se propagam ao longo da trabécula e permitem o cálculo do módulo de elasticidade do material.

\subsubsection{A ATENUAÇÃO DA ENERGIA TRANSMITIDA PELA ONDA ULTRA-SÔNICA}

Além da velocidade do som, a atenuação do sinal ultra-sônico durante sua passagem através do osso pode ser medida pela determinação da redução da amplitude do sinal ultra-sônico. A medida do BUA (Broadband Ultrasound Attenuation) descreve o aumento na atenuação ultra-sônica sobre uma faixa de freqüência particular, tipicamente de 0,2 MHz a 0,6 MHz (BARAN, 1995).

Dois mecanismos produzem a atenuação da onda ultra-sônica pelo meio: o espalhamento e a absorção. A amplitude é reduzida pelo espalhamento porque a energia é direcionada para uma ou mais direções. A intensidade do espalhamento depende do comprimento de onda e das propriedades acústicas do meio de propagação. A absorção é a conversão da energia da onda ultra-sônica em calor e geralmente cresce com o aumento da freqüência ultra-sônica. O espalhamento, devido à densidade e à estrutura óssea, atua como um filtro que diminui os componentes da freqüência pela banda de transmissão, de 
modo que o número, o espaçamento e a orientação dos elementos espalhadores determinam o efeito de filtração no BUA (BARAN, 1995).

\subsection{A ULTRA-SONOMETRIA ÓSSEA}

Várias técnicas não-invasivas de radiodensidade propõem medir o conteúdo mineral ósseo ou a densidade óssea, mas esses métodos não determinam outros aspectos qualitativos da fragilidade óssea (TURNER; EICH, 1991). A diminuição do conteúdo mineral ósseo leva ao aumento da fragilidade óssea, mas inúmeros fatores também levam a esse aumento: danos por fadiga, alterações na arquitetura trabecular, desequilíbrios de mineralização e organização estrutural. Assim, a medida exata da fragilidade óssea deve levar em conta a resistência do tecido e a quantidade de tecido ósseo que compõe o osso. Segundo Rice et al. (1988), a densidade óssea se correlaciona de modo grosseiro com a resistência do osso esponjoso.

Métodos ultra-sônicos medem propriedades intrínsecas da estrutura que não são necessariamente dependentes da massa óssea. Por isso, métodos ultra-sônicos podem ser uma ferramenta útil para diagnosticar fragilidade óssea e osteoporose (TURNER; EICH, 1991). Segundo Gluer et al. (1994), medidas ultra-sônicas fornecem informação não só sobre a densidade mineral óssea, mas também sobre a qualidade óssea. 
Após a pesquisa de Langton, Palmer e Porter (1984), tem havido um interesse crescente no uso de medidas ultra-sônicas por meio dos parâmetros de alteração da velocidade e da atenuação da onda ultrasônica para detecção e monitoramento de osteoporose. A ultrasonometria óssea é uma técnica não-invasiva que envolve a transmissão de ondas sonoras (acima de uma freqüência audível) através do osso, objetivando tirar informações sobre suas propriedades internas. O principal foco para a ultra-sonometria óssea tem sido a osteoporose, mas pesquisadores clínicos estão continuamente ampliando suas aplicações para outras doenças osteometabólicas (DAENS et al., 1999).

Segundo Langton, Palmer e Porter (1984), a aproximadamente 15 anos, a ultra-sonometria óssea surgiu, na pesquisa clínica, com a proposta de fornecer uma medida quantitativa e reprodutível da qualidade óssea.

Em 1990, Porter et al. demonstraram a relação entre os parâmetros da ultra-sonometria óssea e o risco de fraturas em uma população de mulheres idosas.

Turner e Eich (1991) alertaram sobre a importância do desenvolvimento de ferramentas diagnósticas para medir a qualidade física do osso, objetivando detectar fragilidade incipiente, para determinar o risco (desenvolvimento) ou para monitorar o progresso ou a resposta terapêutica de um paciente com osteoporose, dada a ausência de tratamento efetivo para esse mal e a necessidade de prevenção da perda óssea e da fragilidade. 
Segundo Gluer (1997), as vantagens de se utilizar a ultrasonometria óssea na pesquisa médica são: baixo ônus, praticidade, curto tempo de exame e ausência de radiação ionizante. Castro, Pinheiro e Szejnfeld (2000) mostraram que existem controvérsias acerca dessa técnica no que diz respeito à precisão e ao coeficiente de variação. Há uma considerável diversidade tecnológica entre os equipamentos de ultra-sonometria óssea utilizados para avaliar a osteoporose em vários locais do esqueleto: calcâneo, metacarpo, falange, patela, rádio proximal, parte cortical do fêmur e tíbia (GREENFIEL et al., 1981). Nos Estados Unidos, a Food and Drug Administration (FDA) liberou o uso clínico de alguns equipamentos de ultra-sonometria óssea para a avaliação do risco de fratura, em especial dos que utilizam o calcâneo como sítio de medida e sistemas de transmissão de onda sonora (CASTRO, PINHEIRO; SZEJNFELD, 2000).

Turner e Burr (1993) também ressaltaram as principais vantagens do teste do ultra-som: é uma tecnologia mais prática e econômica, pois permite reduzir os custos tanto do equipamento quanto do exame; o ensaio é não-destrutivo; a medida da velocidade pode ser repetida várias vezes para obter um resultado médio e assim reduzir o erro experimental; não apresenta restrição de uso na gestação devido à ausência de radiação; apresenta boa exatidão dos resultados quando usado em pequenas amostras ( $3 \mathrm{~mm}-5 \mathrm{~mm}$ ); proporciona maior rapidez, sendo a medida realizada em, no máximo, 5 minutos. 
Segundo Gluer, Barkmann e Heller (1999), nos últimos anos, a ultra-sonometria óssea tem sido mais pesquisada em relação à avaliação da osteoporose. O desenvolvimento de novas tecnologias tem sido acelerado, e hoje um grande número de diferentes equipamentos está disponível. Para uma avaliação equilibrada desses equipamentos, é necessário reconhecer duas questões: existem diferentes aplicações para a ultra-sonometria óssea e existem diferentes acessos a equipamentos de ultra-sonometria óssea. A respeito das aplicações, a principal área de uso da ultra-sonometria óssea é a avaliação do risco de fratura. Paro o uso no monitoramento e diagnóstico, é necessário mais estudos. Quando usados apropriadamente, os equipamentos atuais podem desempenhar um importante papel na avaliação da osteoporose.

\subsubsection{A ULTRA-SONOMETRIA ÓSSEA E O RISCO DE FRATURA.}

\subsubsection{A ULTRA-SONOMETRIA ÓSSEA E A DENSIDADE MINERAL ÓSSEA}

Diversos estudos fazem a comparação entre esses dois fatores, tanto in vitro (ALVES et al., 1996b) como in vivo (ROUX et al., 1996), porém os resultados, algumas vezes, são conflitantes (CASTRO; PINHEIRO; SZEJNFELD, 2000). Índices de correlação significativos são mostrados $(r=0,75-0,90)$ quando ambas as técnicas são aplicadas a um mesmo sítio esquelético (ROUX et al., 1996 
Um estudo com 123 pacientes estabeleceu a capacidade do ultrasom de identificar pacientes osteoporóticos e osteopênicos (por densitometria óssea), concluindo que os parâmetros do ultra-som não predizem os casos de osteopenia. Esses dados mostram que a ultrasonometria óssea não é preditiva da densidade óssea, principalmente para locais com maior prevalência de fraturas associadas à osteoporose, como a coluna vertebral, o colo do fêmur e o punho (CASTRO; PINHEIRO; SZEJNFELD, 2000).

Estudos in vitro usando calcâneo têm demonstrado uma boa correlação entre a atenuação ultra-sônica e as medidas de densidade óssea por tomografia computadorizada quantitativa (MCKELVIE et al., 1989).

\subsubsection{A ULTRA-SONOMETRIA ÓSSEA E A QUALIDADE ÓSSEA}

A qualidade óssea possui um conceito complexo que envolve diversos fatores. Ela depende da mineralização óssea, do turnover e da microarquitetura. É um dos parâmetros envolvidos na determinação da resistência mecânica do tecido ósseo. Estudos in vitro (GLUER et al., 1994) mostraram a validade do uso do ultra-som devido à correlação com a organização e a orientação trabecular. Gluer, Wu e Genant (1993), ao estudarem cubos de osso trabecular de fêmur bovino, observaram que os valores de atenuação ultra-sônica e a velocidade do som se alteravam linearmente de acordo com o alinhamento trabecular e com a conectividade do tecido ósseo, concluindo que a ultra- 
sonometria óssea oferece uma medida indireta da anisotropia e da qualidade óssea.

Heaney et al., (1989) foram os primeiros a demonstrar, na década de 80, o valor da ultra-sonometria óssea na predição de fraturas de estresse em cavalos de corrida. A partir dessa observação, confirmouse a validade do exame na avaliação do risco de fraturas. A ultrasonometria óssea discrimina pacientes com fraturas de coluna e/ou de quadril daqueles sem fratura (CASTRO; PINHEIRO; SZEJNFELD, 2000)

Bauer et al. (1995) e Hans et al. (1996) avaliaram, por 2 anos, cerca de 6 mil mulheres nos períodos da pré e pós-menopausa, utilizando a ultra-sonometria óssea de calcâneo. O risco relativo de fratura medido nesses estudos variava de 1,6 a 2,8. Ross (1995) mostrou que esses valores são semelhantes aos observados para a densitometria óssea de coluna lombar e quadril, sugerindo que, nesses casos, a técnica avalia o risco de fratura com a mesma eficiência que a densitometria óssea (CASTRO; PINHEIRO; SZEJNFELD, 2000).

O risco relativo de fraturas avaliado pela ultra-sonometria óssea não variou com o peso, a altura, a idade, o tempo de menopausa e com a densidade, sendo uma informação a mais na avaliação de pacientes com osteoporose, independentemente da massa óssea (KANIS; WHO, 1994). Como os riscos avaliados pela ultra-sonometria óssea e pela densitometria óssea são independentes, confirma-se a idéia inicial de que os dois exames (ultra-sonometria óssea e densitometria óssea) avaliam diferentes propriedades do tecido ósseo. Alguns autores 
sugerem o uso combinado das técnicas em pacientes com osteoporose para aperfeiçoar a predição de fratura (HANS EY AL., 1995).

\subsubsection{A ULTRA-SONOMETRIA ÓSSEA DO CALCÂNEO}

Devido a sua maior relação superfície/volume, o osso trabecular possui uma taxa de remodelamento aproximadamente oito vezes maior que a do osso compacto, respondendo mais rapidamente a estímulos metabólicos. Por esse motivo, o osso trabecular é o sítio primário para a detecção de perdas ósseas precoces, assim como para o monitoramento da eficácia dos diferentes tratamentos (BIANCO, 1991).

A escolha do melhor local do esqueleto para a predição da osteoporose é objeto de muito debate. É consenso que as regiões com maior conteúdo de osso esponjoso (alto remodelamento) são mais sensíveis às mudanças causadas pela osteoporose (NJEH et al., 1999).

O calcâneo é o local mais utilizado pelo fato de a sua constituição ser predominantemente de osso trabecular, metabolicamente mais ativo, mais acessível, por possuir superfícies de trabéculas paralelas (reduzindo os erros no posicionamento do pé durante a realização do exame) e por conter baixa quantidade de tecido mole ao seu redor (GLUER; WU; GENANT, 1993). O calcâneo é um dos ossos que formam o tarso; trata-se de um osso plano, que forma a base do calcanhar, e faz parte do esqueleto apendicular, que possui superfícies paralelas, 
sendo $90 \%$ composto de osso do tipo trabecular e que é circundado por pouco tecido mole, mesmo em obesos (Figura 11).
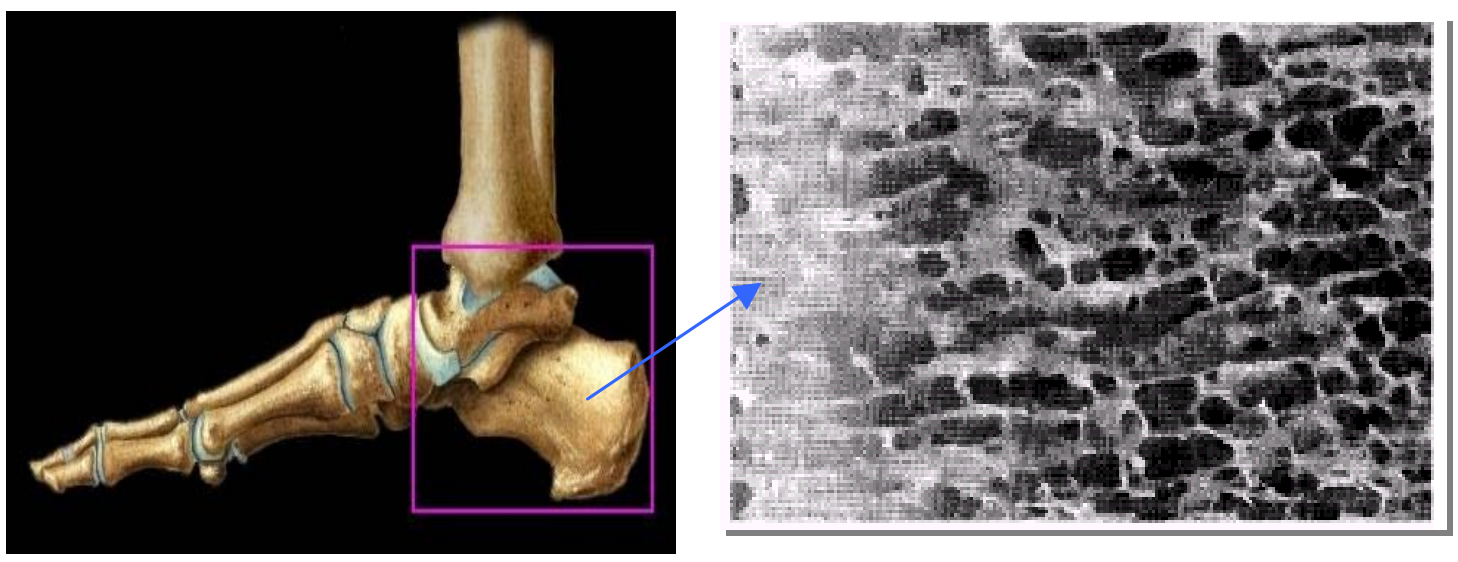

FIGURA 11 - Fotografia localizando o osso calcâneo com ampliação da área mostrando as características estruturais do tecido ósseo esponjoso.

LANGTON, 1996.

As propriedades do tecido ósseo podem ser estudadas pela ultrasonometria óssea através de medidas de reflexão ou de transmissão da onda sonora, as mais utilizadas comercialmente.

As variáveis determinadas pelo aparelho são: velocidade(SOS) e atenuação (BUA) do som (Figura 12) e stiffness. 

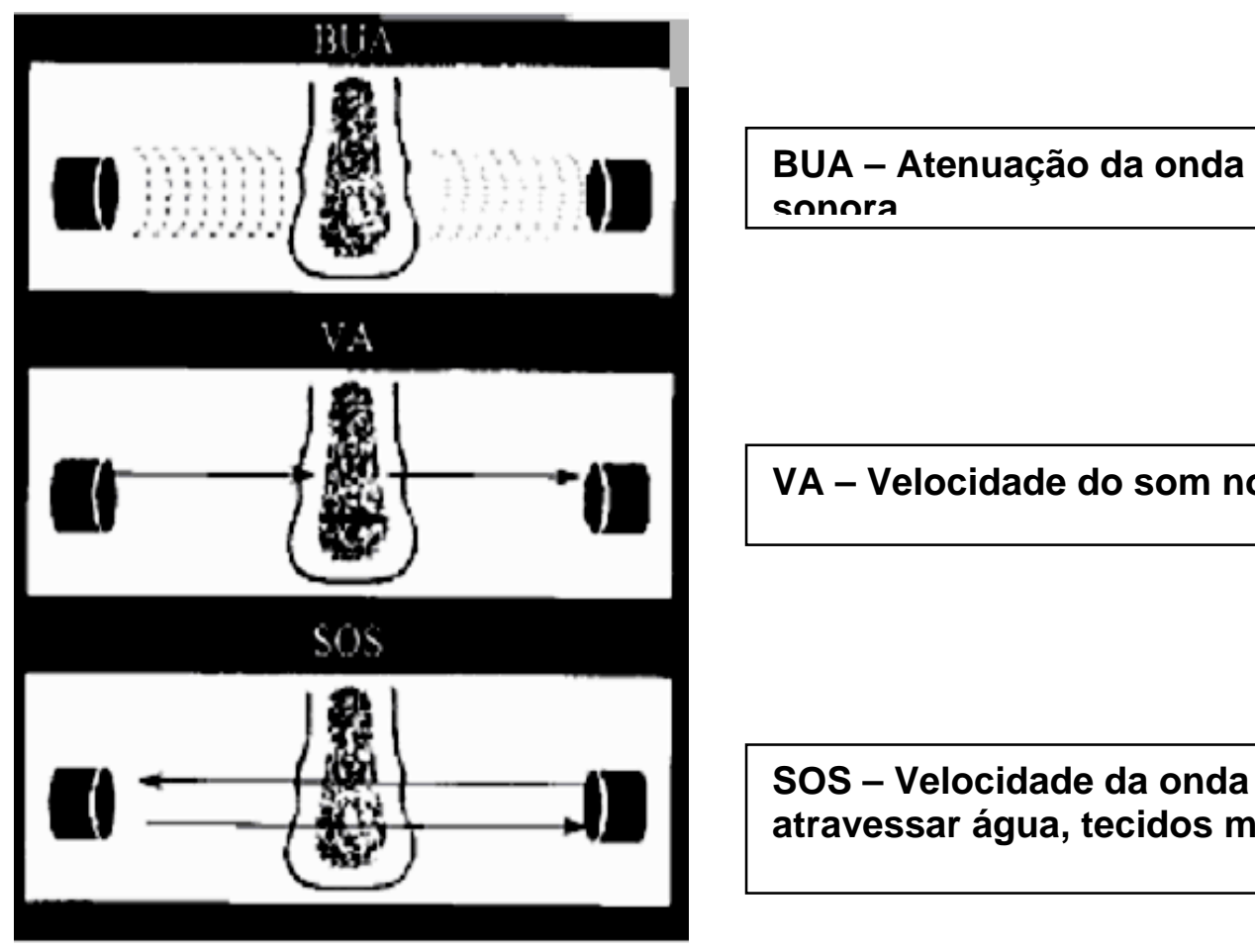

Figura 12 - Parâmetros determinados pela ultra-sonometria do calcâneo

O método baseia-se nas alterações que a onda sonora apresenta na sua velocidade e na amplitude ao atravessar o tecido ósseo. Utilizase um recipiente com dois transdutores alinhados (emissão e recepção), em que o pé (calcanhar) é colocado entre duas campânulas contendo água que se acoplam perfeitamente sobre as superfícies lateral e medial do calcanhar (Figura 13). Antes de colocar o pé no recipiente, recomenda-se limpar o tornozelo com álcool para remover o excesso de gordura presente na pele. Os transdutores são conectados a um computador que emite ondas sonoras em freqüência preestabelecida. As medidas são realizadas automaticamente por meio de equações matemáticas presentes no programa utilizado. 


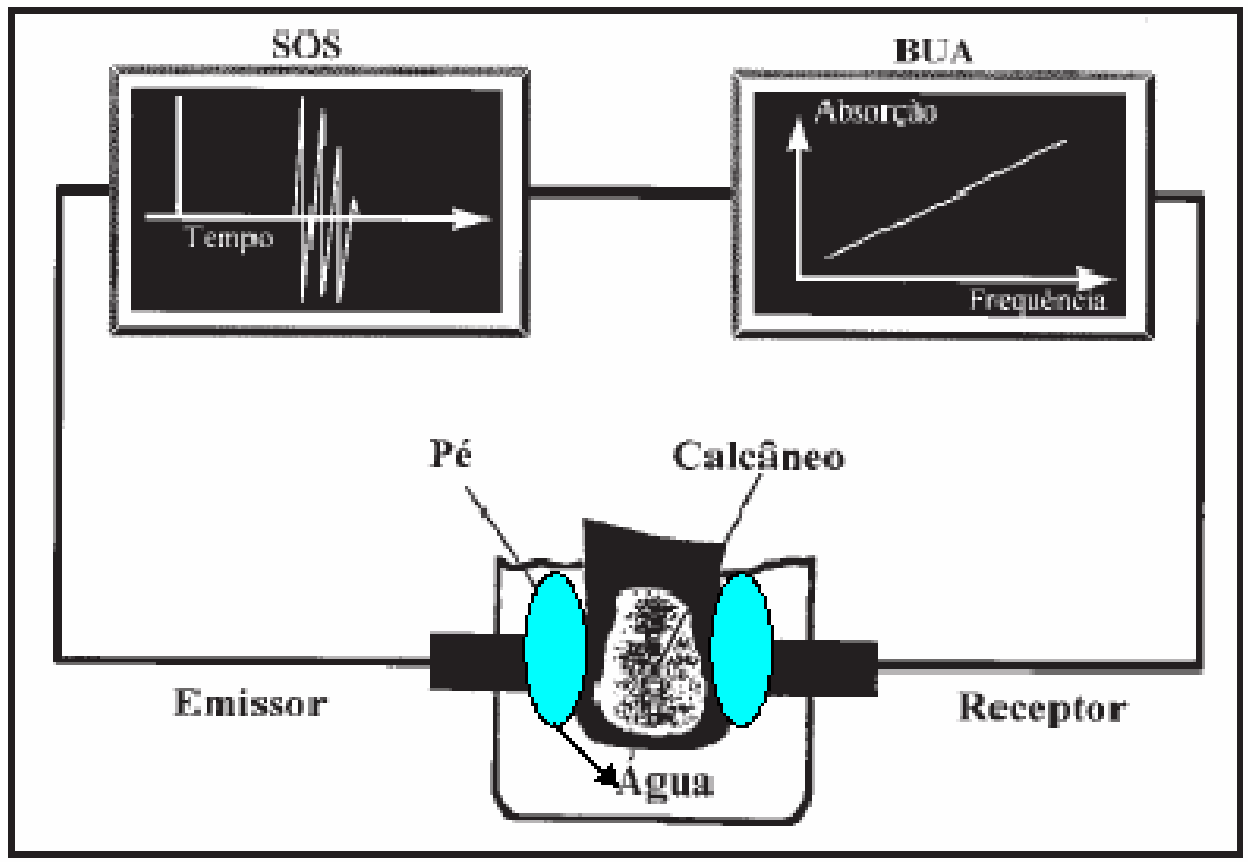

Fiq.-13- llustr ação esquemática das medidas da USO. O pé é colocaco em um recipiente com água aquecida e a feixe de ultra-som é transmitida lateralmente ao nível do calcâneo. $O$ primeiro dos múltiplos ecas é o que é det erminado. O BUA é determinado pela inclinação da curva interaçāo/abs orçâa, proporcional à freqüência emitida, sendo expresso em dB/ $/ \mathrm{MHz}^{-} \mathrm{O}$ SOS ế calculado através da razäo entre a distâneia percorrida (tr ansdutor emissor ao r eceptor) e o tempo gasto pela onda s:onora ao atravessar a calcâneo.

Velocidade do som (SOS): é a velocidade medida da transmissão da onda sonora ao atravessar o tecido ósseo em freqüência de $150 \mathrm{kHz}$ a $300 \mathrm{kHz}$. É determinada pelo quociente entre o tempo de transmissão do som e a largura do sítio ósseo analisado (tempo/largura) e expressa em m/s. A largura do calcâneo é padronizada pelo aparelho em $40 \mathrm{~mm}$; portanto, a presença de excesso de partes moles ou qualquer outro fator que aumente a distância percorrida pela onda sonora pode diminuir o valor do SOS. A velocidade da onda sonora é relacionada ao tecido estudado, sendo, em média, de $1.450 \mathrm{~m} / \mathrm{s}$ na gordura, $1.480 \mathrm{~m} / \mathrm{s}$ 
na água, $1.500-1.600 \mathrm{~m} / \mathrm{s}$ nos tecidos moles, $1.600-2.000 \mathrm{~m} / \mathrm{s}$ no osso trabecular e 3.500 a 4.000 m/s no osso cortical. Assim, não se pode comparar os valores encontrados entre sítios diferentes. Por exemplo, no calcâneo, a velocidade pode variar de $1.400 \mathrm{~m} / \mathrm{s}$ a $1.900 \mathrm{~m} / \mathrm{s}$, enquanto, na patela, os valores podem ser de $1.600 \mathrm{~m} / \mathrm{s}$ a $2.000 \mathrm{~m} / \mathrm{s}$, mesmo sendo ambos os sítios representantes de osso trabecular preferencialmente. A velocidade (V) é a mais representativa das propriedades materiais do osso, como a densidade ( $p$ ) e a elasticidade $(E)$, em que $V=E / p$, isto é, quanto mais compacto o objeto, maior a velocidade do som ao atravessá-lo.

Atenuação do som (BUA): é a taxa de energia perdida pela onda sonora ao passar pelo tecido ósseo em freqüência entre 300 kHz e $600 \mathrm{kHz}$. Seu resultado é expresso como a inclinação da curva interação/absorção, proporcionalmente à amplitude e à freqüência de onda, em dB/MHz (Figura 13). Até o momento, há poucas evidências de que exista correlação forte entre o BUA e a densidade óssea. Da mesma forma, poucos trabalhos demonstraram boa correlação entre o BUA e o SOS, provavelmente por medirem propriedades diferentes do tecido ósseo.

Um fator de erro possível existe pela dificuldade em definir uma região de interesse para a medida. Por isso, alguns autores têm proposto a imagem como forma de determinar a melhor área dentro do osso, ou seja, o BUA scan (área de $1 \mathrm{~cm}^{2}$ situada na metade posterior do calcâneo). 
Velocidade aparente (velocity): é a medida da velocidade do som apenas no osso, desprezando a velocidade ao atravessar a água e os tecidos moles.

Stiffness: medida desenvolvida pela Lunar e definida por uma fórmula matemática - Stiffness $=(0,67 \times$ BUA $)+(0,28 \times$ SOS $)-420)$ - pela combinação de valores normalizados de SOS e BUA, com o objetivo de melhorar os coeficientes de variação entre eles. Embora esse valor seja traduzido como "rigidez", ele não reflete necessariamente a rigidez mecânica do osso e, até o momento, não tem tradução definitiva para a língua portuguesa.

A Figura 14 mostra o gráfico que resulta de um exame de ultrasonometria óssea do calcâneo em que a relação entre o stifness, a idade e o T-score é mostrada com a finalidade de situar o examinando dentro desses parâmetros. Este T-Score e o mesmo parâmetro utilizado pela densitometria óssea e que é referência para a ultra-sonometria óssea. 


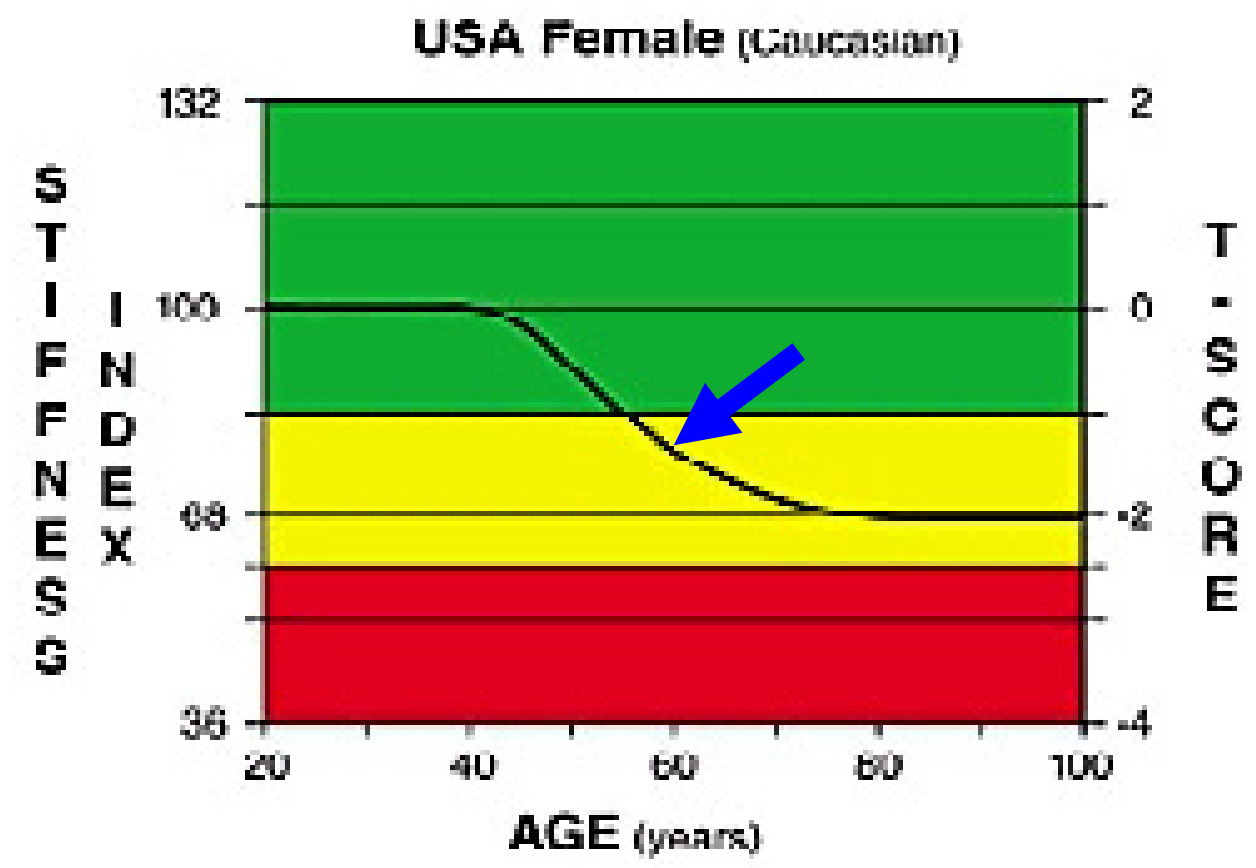

FIGURA 14 - Gráfico exibido no resultado da ultra-sonometria óssea do calcâneo do aparelho GE-Aquilles, mostrando a correlação do stiffness e do t-score com a idade do examinado em anos. 


\section{OBJETIVOS}

ropôs-se, neste estudo, a utilização de uma

ferramenta de baixo custo e de fácil acesso e aplicação - a ultrasonometria óssea do calcâneo - para identificar mulheres idosas com maior risco de fratura do fêmur proximal numa população de baixa renda cadastrada em serviços públicos de saúde e instituir, baseados principalmente nesse rastreamento, um programa de prevenção dessas fraturas e da osteoporose. 


\section{MATERIAL E MÉTODO}

\subsection{SUJEITOS}

Um grupo de 757 mulheres com idade acima de 60 anos, extraídas aleatoriamente, no período de novembro de 2002 a outubro de 2003, de uma população de 5.000 indivíduos cadastrados no Programa de Saúde do Idoso da Prefeitura de Araraquara-SP, foi submetido à avaliação da ultra-sonometria óssea do calcâneo e a um questionário.

\subsection{MATERIAL E EQUIPAMENTO}

A ultra-sonometria em osso do calcâneo desses indivíduos foi realizada em um aparelho de fabricação norte-americana da empresa General Eletric, no seu modelo Achilles Express, com as características expressas em catálogo anexo (Anexo C), tendo sido disponibilizado mediante locação. 
Foi consultado o Ministério da Saúde com a finalidade de se obter o Protocolo Clínico e as Diretrizes Terapêuticas para a Osteoporose com seus respectivos critérios de inclusão e exclusão de pacientes em protocolo terapêutico (Anexo A).

Um questionário de 11 questões de múltipla escolha (Anexo B) foi desenvolvido para ser respondido pelos examinados. Seus resultados foram informatizados em planilha Microsoft Excel.

\subsection{PROCEDIMENTO}

O procedimento foi aprovado pelo Comitê de Ética em Pesquisa da Faculdade de Odontologia da Universidade Estadual Paulista em seu campus de Araraquara.

A seleção dos indivíduos foi feita aleatoriamente após convite por contato telefônico para comparecer ao local do exame e se submeter à avaliação da ultra-sonometria do calcâneo e ao questionário após assinarem o termo de consentimento proposto pelo referido Comitê de Ética.

Esses indivíduos, em sua maioria, apresentavam doenças concomitantes como a Hipertensão Arterial Sistêmica e/ou o Diabete Mellitus, entre outras, com avaliações clínicas e exames complementares periódicos para essas patologias, porém sem nunca 
terem sido avaliados formalmente pelo Programa em relação à osteoporose ou ao seu risco de fratura.

Todas as avaliações foram realizadas pelas mesmas duas agentes de saúde do Programa de Saúde do Idoso da Prefeitura Municipal de Araraquara, supervisionadas pelo médico responsável pela pesquisa.

Dos dados fornecidos pelo dispositivo, a idade do indivíduo e o $T$ - score foram os utilizados para os propósitos desta pesquisa.

As 757 mulheres, todas assessoradas por uma mesma agente de saúde do Programa especialmente treinada, foram submetidas, também, a um questionário impresso, cujas perguntas de múltipla escolha estão descritas a seguir. Esse questionário tinha como proposta obter informações sobre o conhecimento das examinadas a respeito de osteoporose, alguns fatores de risco, ocorrência de fraturas potencialmente osteoporóticas, doenças concomitantes e sobre se tiveram acesso ao tratamento médico e a medicações para osteoporose. Para esta pesquisa foram utilizados os dados sobre o conhecimento e o diagnóstico da patologia, obtidos pelo acesso a médico, sobre terem tomado ou não medicação para osteoporose receitada por médico, o significado do termo osteoporose e a freqüência de fraturas na população investigada.

Os resultados dos questionários respondidos, juntamente com os da análise das ultra-sonometrias dos calcâneos, foram colocados numa planilha eletrônica Microsoft-Excel para que se pudesse arquivar 
resultados, distribuir freqüências e cruzar informações por meio de software específico.

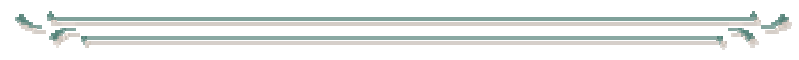




\section{RESULTADO}

ma população de 757 mulheres idosas, de idade entre 60 a 95 anos, cuja média de idade era 75 anos, foi submetida ao exame de ultra-sonometria do calcâneo e ao questionário proposto. Os parâmetros de idade e de T-score fornecidos pelo aparelho foram avaliados de acordo com os critérios da OMS instituídos para o DEXA, e que são utilizados também para o QUS, obtendo a seguinte classificação: osso normal, com resultado até -1,0 desvio padrão; osso osteopênico, quando o resultado foi situado entre $-1,0$ e $-2,5$ desvios padrão; osso osteoporótico, com resultado abaixo de $-2,5$ desvios padrão. Assim, 178 mulheres, 24\% do total, foram classificadas como osteoporóticas; 362 mulheres, 47\%, como osteopênicas e 217, 29\%, com osso normal (Figura 15). Considerando-se os resultados da osteopenia e da osteoporose como sendo os de indivíduos de maior risco de fratura, tem-se $71 \%$ deles nesta condição (Figura 16). 


\section{ULTRA-SONOMETRIAS DE CALCÂNEO}

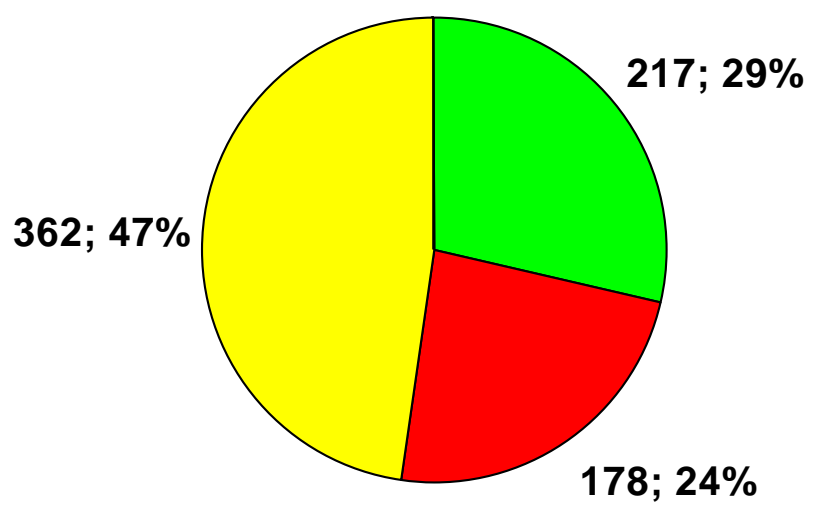

$\square$ NORMAL

$\square$ OSTEOPOROSE $\square$ OSTEOPENIA

Figura 15 - Número e porcentagem de mulheres examinadas em função do resultado obtido.

757 ULTRA-SONOMETRIA DE CALCANEO (100\%)

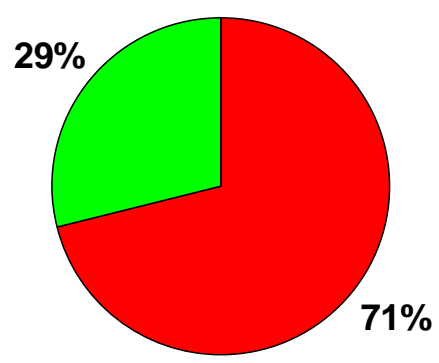

$\square$ RISCO AUMENTADO

$\square$ RISCO NORMAL

Figura 16 - Porcentagem de examinados com maior risco de fratura. 
Ao analisar os dados relativos ao questionário anexo, verificouse a concomitância de doenças, tendo sido observado que $14,5 \%$ das pesquisadas eram diabéticas e 47,7\% hipertensas (Figura 17).

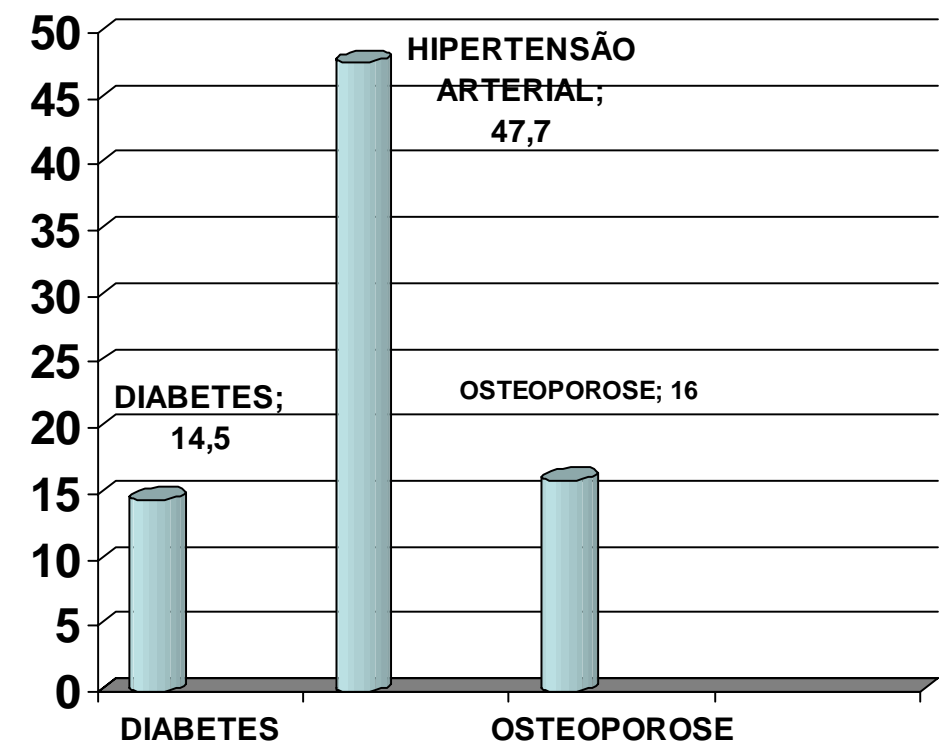

Figura 17 - Porcentagem de doenças concomitantes entre as mulheres examinadas de acordo com questionário respondido.

Neste estudo, encontrou-se, quanto ao conhecimento da patologia, que $49 \%$ tinham alguma informação sobre a moléstia e que $51 \%$ a desconheciam (Figura 18). Em relação ao conhecimento da osteoporose pelo acesso ao médico e ao DEXA, 16\% afirmaram ter obtido seu diagnóstico por esse método e $84 \%$ não ter tido acesso (Figura 19). 


\section{CONHECIMENTO SOBRE A OSTEOPOROSE}

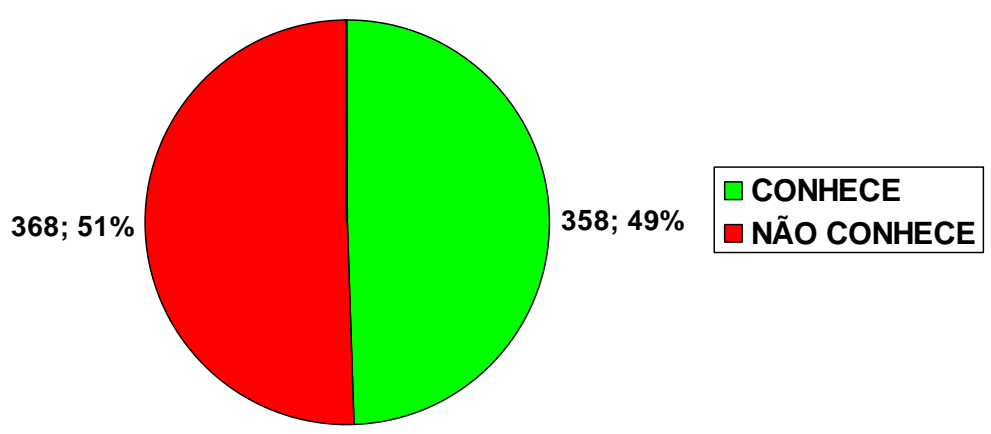

Figura 18 - Porcentagem de mulheres examinadas que afirmaram ter algum conhecimento sobre osteoporose através de qualquer método citado no questionário.

\section{PORCENTAGEM DE MULHERES COM ACESSO À DENSITOMETRIA ÓSSEA}

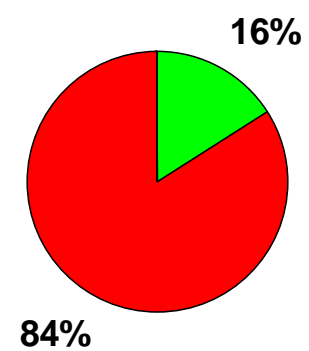

COM ACESSO

$\square$ SEM ACESSO

Figura 19 - Porcentagem de mulheres examinadas que tiveram acesso à densitometria óssea.

Das mulheres entrevistadas, 188 (26\%) tomaram, em algum momento, medicação para osteoporose receitada por médico e $74 \%$ nunca tomaram medicação para essa finalidade (Figura 20). Isto pode 
ter ocorrido por falta de diagnóstico da moléstia ou por impossibilidade de aquisição do medicamento, Além disso, das mulheres entrevistadas que tomaram tal medicação, 39,1\% interromperam o tratamento pelo alto custo da medicação e 2,9\% por desconhecimento da posologia e forma de administração. Todas as mulheres já medicadas estavam no grupo de maior risco.

\section{PORCENTAGEM DE MULHERES MEDICADAS PELO MENOS UMA VEZ PARA OSTEOPOROSE}

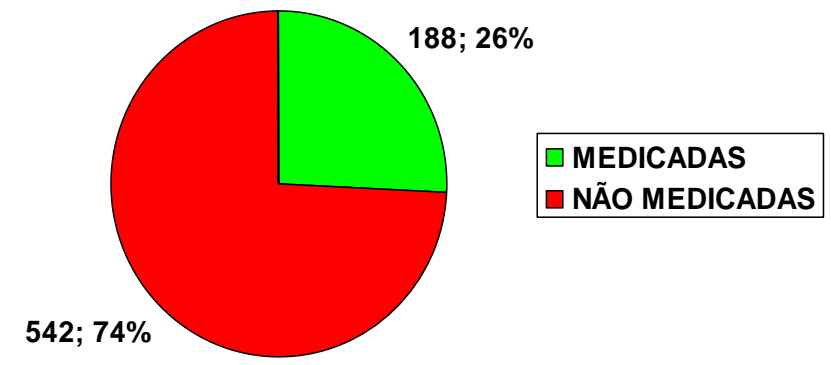

Figura 20 - Porcentagem de mulheres medicadas pelo menos uma vez para osteoporose.

Em relação às mulheres que afirmaram já ter tido fratura do fêmur proximal, em número de $11(1,4 \%)$, apenas duas tinham tido acesso ao DEXA e diagnóstico de osteoporose (Figura 21). Todas essas mulheres estavam no grupo considerado de maior risco pela ultra-sonometria óssea. 

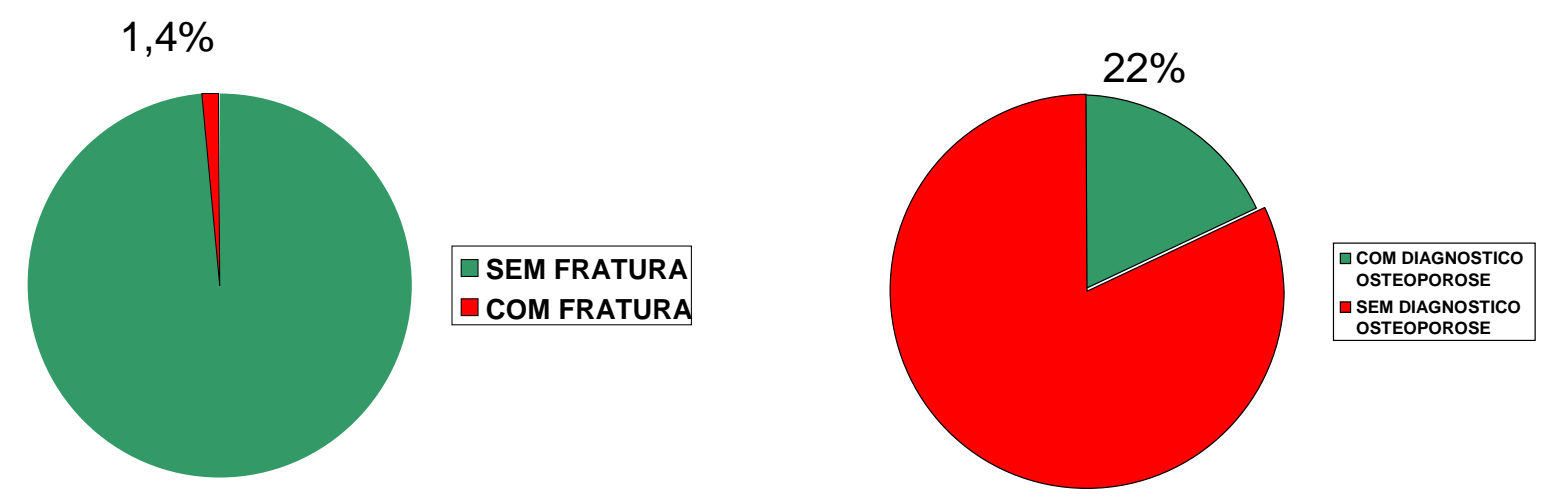

Figura 21 - Porcentagem das mulheres que tiveram fratura do quadril em função do conhecimento e do diagnóstico de osteoporose.

Ao se cruzar os dados da ultra-sonometria dos calcâneos com as respostas obtidas pelo questionário aplicado, foram obtidas correlações que, na maior parte, mantiveram as porcentagens dos resultados relacionando número de eventos com amostragem. Assim, das mulheres que se situavam no grupo de maior risco de fraturas, a maioria não teve acesso ao DEXA, não teve diagnóstico de osteoporose e nem tomou medicação para esse fim. Observou-se que tanto as mulheres osteopênicas quanto as osteoporóticas eram pouco informadas a respeito da osteoporose.

Quanto às mulheres classificadas como normais em relação ao risco de fraturas medido pela ultra-sonometria do calcâneo, tem-se que, também na maioria, eram mal-informadas sobre a patologia; porém, que o acesso ao DEXA tinha sido maior que o do outro grupo.

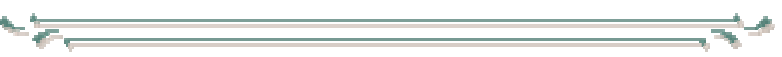




\section{DISCUSSÃO}

\section{A}

possibilidade de as pessoas morrerem no auge de sua idade produtiva no século $X X$ era um fato bastante concreto. O cenário atual mostra-se diferente, pois, conforme a região do mundo, a probabilidade de sobrevivência a partir dos 60 anos vem aumentando progressivamente. A iniqüidade das políticas locais, em diversas regiões do mundo, ganha visibilidade, pois as possibilidades de envelhecimento estão estreitamente relacionadas ao acesso a condições dignas de vida e renda. Esse acesso, inclusive, poderá ser um fator determinante da qualidade com que se vai envelhecer. Sabese que o processo de envelhecimento é marcado por profundas mudanças biológicas e de comportamento. Entretanto, essa fase não tem de estar, necessariamente, acompanhada de doenças, de limitações para o desempenho de atividades cotidianas e de incapacidades definitivas (VERAS, 1995; PASCHOAL, 1996)

Se, por um lado, o envelhecimento populacional trouxe os benefícios de uma maior longevidade, por outro trouxe um novo perfil 
de morbi-mortalidade caracterizado por um aumento (acúmulo) de doenças crônico-degenerativas.

Neste trabalho, uma população de 757 mulheres idosas, de 60 a 95 anos, com idade média de 71 anos, foi submetida ao exame de ultra-sonometria do calcâneo e ao questionário proposto (Anexo B). Os parâmetros de idade e de $T$-score fornecidos pelo aparelho $G E$ Aquilles Express (Anexo C) foram avaliados de acordo com os critérios da OMS instituídos para o DEXA, e que são utilizados também para o QUS, obtendo a seguinte classificação: osso normal, com resultado até -1,0 desvio padrão; osso osteopênico, quando o resultado foi situado entre -1,0 e -2,5 desvios padrão; osso osteoporótico, com resultado abaixo de $-2,5$ desvios padrão. Assim, 178 mulheres, 24\% do total, foram classificadas como osteoporóticas; 362 mulheres, 47\%, como osteopênicas e 217, 29\%, com osso normal. Ao obtermos esses dados e observarmos que praticamente $2 / 3$ da população estudada possui risco de fratura do fêmur proximal aumentado e que essa amostragem de 730 mulheres representa uma população de mais de 10 mil mulheres na cidade de Araraquara, tornam-se sugestivas medidas de prevenção dessas fraturas, instituídas em diferentes níveis de complexidade de acordo com o rastreamento efetuado, aumentando a chance de eficácia dos vários métodos, em vez de se utilizar apenas métodos gerais que certamente não contemplariam os casos de maior risco. Esses métodos incluiriam desde medidas de prevenção de quedas por causas ambientais, medicamentosas e de hábitos, passando por utilização de órteses e equipamentos especiais de proteção a quedas, até medidas 
de distribuição de medicamentos anti-osteoporose preventivos e terapêuticos por parte do poder público de forma eficiente. Isto, no entanto, é motivo de investigação e atuação de outra natureza. Comparando-se com a literatura e em especial com o Programa Nacional de Prevenção de Osteoporose do Ministério da Saúde, em seu segundo estágio, os resultados não são compatíveis. No programa, 32.500 mulheres de todo o Brasil foram avaliadas para obter o perfil ultra-sonométrico de amostras populacionais nas cinco macrorregiões geográficas do país onde $13,3 \%$ das mulheres examinadas foram classificadas como osteopênicas ou osteoporóticas. Tal diferença entre as duas pesquisas pode ser explicada pelo fato de, apesar de as duas amostras terem sido escolhidas aleatoriamente, as populações alvo serem diferentes. Em uma, foi a população em geral, e o objeto deste trabalho foi uma população de mulheres idosas já registradas em serviço de saúde, isto é, uma população já considerada doente com ou sem concomitância de patologias.

Ao analisarmos os dados relativos ao questionário com modelo anexo (anexo B), verificamos a concomitância de doenças, tendo $14,5 \%$ das pesquisadas relatado ser diabéticas, $47,7 \%$ hipertensas e, infelizmente, $84 \%$ não sabendo dizer se tinham osteoporose por absoluta falta de diagnóstico. Encontramos, também, quanto ao conhecimento e diagnóstico da osteoporose pelo acesso ao médico e ao DEXA, dados demonstrativos de que 358 mulheres $(47,2 \%)$ teriam tido esse acesso e que $368(52,8 \%)$ responderam não saber ou não ter tido acesso. Das mulheres entrevistadas, 188 (24,8\%) tomaram, em 
algum momento, medicação para osteoporose receitada por médico e $75,2 \%$ nunca tomaram medicação para essa finalidade. Isto pode ter ocorrido por falta de diagnóstico da moléstia ou por impossibilidade de aquisição do medicamento, Além disso, das mulheres entrevistadas que tomaram tal medicação, 39,1\% interromperam o tratamento pelo alto custo da medicação e 2,9\% por desconhecimento da posologia e da forma de administração. Estes dados mostram a precariedade da assistência pública à moléstia osteoporose comparada com outras patologias crônico-degenerativas para as quais o diagnóstico é de fácil acesso e a utilização de medicamentos é mais regular, inclusive pelo fato de existirem programas para sua distribuição regulamentados pelo Ministério da Saúde, como o existente para osteoporose (VERAS 1995). Essas informações podem ser comparadas aos resultados de uma pesquisa realizada na cidade de São Carlos-SP, em 2004 (FELICIANO et al., 2004), num extenso levantamento de dados realizado sobre a população idosa de baixa renda local. A população do estudo $(n=523)$ foi constituída pelo universo de pessoas com 60 anos ou mais cadastradas no Programa Saúde da Família e no Cartão Nacional de Saúde. Nele, um dos aspectos abordados foi o acesso aos serviços de saúde. Entre os idosos estudados, 22,4\% precisaram passar por algum tipo de internação nos últimos dois anos anteriores à pesquisa. Nesse caso, a necessidade das mulheres foi maior que a dos homens, com $24,0 \%$ e $21,0 \%$ respectivamente. Quanto ao acesso ou à procura por serviços de saúde, $87,0 \%$ dos idosos relataram ter procurado algum serviço de saúde nos últimos seis meses anteriores à pesquisa. Quanto 
à utilização de medicamentos, 67,0\% dos participantes informaram seu uso de forma regular. Na comparação por gênero, as distribuições de tal uso foram $74,0 \%$ para o feminino e $60,0 \%$ para o masculino.

Entretanto, como o critério principal para essa distribuição é o resultado da densitometria óssea, recurso inacessível para uma grande parte da população de baixa renda, o processo se torna ineficaz, inclusive contemplando muitos pacientes que obtiveram esse resultado por meio de planos de saúde complementares e que não se enquadram no perfil da população considerada de baixa renda.

Como mais da metade das mulheres entrevistadas não tiveram informações sobre a moléstia e a grande maioria não teve acesso ao seu diagnóstico, não se pode determinar se as consideradas normais eram mais bem instruídas a respeito da doença do que as osteopênicas ou as osteoporóticas. Também não se pode relacionar as de maior risco de fratura com as menos informadas. Isso deve ter acontecido pelo fato de as informações acontecerem por iniciativa dos profissionais de saúde e não pela procura espontânea dos pacientes.

Quanto à fratura osteoporótica do fêmur proximal, das mulheres examinadas e entrevistadas, 1,4\% (11 casos) relataram já ter sofrido esse tipo de fratura, a maioria após os 70 anos de idade. Destas, apenas duas tinham conhecimento a respeito da osteoporose e todas tinham doenças associadas. Estes dados são comparáveis com os da literatura e, em especial, com o Estudo PRONAFF-Programa Multicêntrico de Avaliação de Fraturas de Fêmur ( MARQUES NETO et al., 2002) realizado sobre 532 fraturas de fêmur em todo o Brasil. Nele, 
$65 \%$ das fraturas aconteceram em mulheres, e, destas, $71 \%$ acima dos 70 anos de idade, a maioria fazendo tratamentos concomitantes. Esse estudo foi complementado pelo PROJETO PROMED - PENECDOR: Programa de avaliação epidemiológica, educação continuada e assistência à osteoporose no Brasil, com avaliação sobre a freqüência de fraturas de fêmur registradas pelo SUS, em população acima de 60 anos, entre 2001 e 2005, e seus custos. Nele, quase 23 milhões de reais foram gastos para tratar de pouco mais de 12 mil fraturas de fêmur proximal em mulheres idosas. Certamente a importância desse dado é tida como um dos motivos de preocupação da saúde pública em razão do aumento dos casos de osteoporose e dos custos que podem representar. Porém, deve-se analisar a situação dos fêmures proximais em idosos com uma abordagem mais abrangente, isto é, contemplandose, além do tratamento de suas fraturas, o diagnóstico de sua densidade óssea e a prevenção e o tratamento da osteoporose que for constatada. Com isso, pode-se observar como a saúde pública pode agir perante evidências constatadas.

Em revisão sistemática da literatura (SILVA, 2003), o custo e a efetividade de intervenções na assistência à fratura osteoporótica do fêmur contemplando o diagnóstico da osteoporose e as formas de tratamento foram avaliados de acordo com a realidade da assistência pública pelo Sistema Único de Saúde (SUS). O processo de avaliação deu-se por meio da Avaliação Tecnológica em Saúde, que pode ser definida como um tipo de pesquisa que sintetiza as evidências científicas disponíveis sobre as implicações da utilização da tecnologia 
médica. O seu objetivo primeiro é fornecer aos formuladores de políticas subsídios relativos às alternativas tecnológicas disponíveis, contribuindo para a definição de políticas de regulação do uso das tecnologias. Outro objetivo importante da avaliação tecnológica, paralelo ao primeiro, é subsidiar a elaboração de protocolos ou diretrizes de condutas clínicas e de instrumentos para avaliação e melhoria da qualidade da atenção à saúde (BANTA; LUCE, 1993). Foram apresentdos, de forma sucinta, os fatores considerados e as metodologias de síntese empregadas (revisões sistemáticas/ metanálises, análise de decisão e análise custo-efetividade) em uma avaliação tecnológica (parcial) e a lógica subjacente à sua elaboração e utilização no campo da saúde pública. O exemplo utilizado focalizava o problema osteoporose na pós-menopausa, analisando a oportunidade da incorporação, no momento atual, da densitometria óssea e de tecnologias anti-osteoporoses em nosso país. Nesse sentido, introduzse inicialmente o problema osteoporose, aspectos clínicos e epidemiológicos, apresentando as questões a serem resolvidas para a tomada de decisão sobre a incorporação de tecnologias, tentando aproximá-las da realidade brasileira. Tais evidências foram sintetizadas com base na revisão da literatura e na análise de avaliações tecnológicas e de metanálises de efeitos de tecnologias, já produzidas acerca do assunto, e de ensaios antigos e recentes. Esses estudos foram examinados quanto à sua qualidade, utilizando a metodologia recomendada por Clarke e Oxman (2000), e à sua pertinência ao SUS/Brasil, procurando conhecimento mais atualizado e aplicado ao 
país. Os custos das alternativas analisadas foram estimados do ponto de vista do SUS, assumindo-se que os reembolsos efetuados atualmente para os procedimentos considerados sejam correspondentes aos custos. Uma análise custo-efetividade preliminar das alternativas de intervenção ante as de não-intervenção (alternativa tradicional), com o cálculo da razão dos diferenciais de custo e de efetividade, é apresentada com o objetivo de suscitar a reflexão sobre a tomada de decisão. As questões a serem respondidas seriam: (a) quantas fraturas de fêmur (entre outros danos) poderiam ser evitadas, ou quantos anos de vida com qualidade poderiam ser ganhos, por diferentes intervenções anti-osteoporose? (b) Estas deveriam atualmente incluir procedimentos diagnósticos (prognósticos), como a densitometria óssea? (c) Qual o custo de cada alternativa antiosteoporose por fratura evitada? (d) O que seria mais vantajoso para a sociedade/governo: adotar os procedimentos anti-osteoporose atuais ou apenas cuidar das fraturas osteoporóticas?

Análises de custo-efetividade preliminares de alternativas de intervenção ante a assistência tradicional foram apresentadas considerando mulheres na perimenopausa e com 65 anos de idade. A despeito das hipóteses otimistas assumidas, as estimativas de custo incremental por fratura evitada foram elevadas, todas acima de $\mathrm{R} \$ 10.000,00$ para quaisquer das alternativas de intervenção examinadas, sendo o custo médio estimado das fraturas assistidas dentro da alternativa tradicional inferior a $\mathrm{R} \$ 2.000,00$ (dois mil reais), o que indica que a implementação no SUS de qualquer uma das 
alternativas em pauta seria questionável segundo critérios de eficiência no uso de recursos e de eqüidade.

Esses dados nos incentivam a procurar alternativas, mesmo que parciais, para melhorar a assistência ao paciente com osteoporose e, em particular, com maior risco de fratura osteoporótica do fêmur.

O que traria racionalidade para o uso da densitometria óssea ou outro instrumento diagnóstico, como, por exemplo, a ultra-sonometria óssea do calcâneo, em uma estratégia de intervenção para o problema da osteoporose, seria a identificação de um subgrupo de mulheres com baixa densidade óssea ou com risco aumentado de fraturas servindo de base para uma terapia efetiva (prevenção secundária), o que resultaria menos fraturas no futuro. Enquanto não existirem dados sobre ensaios de programas de rastreamento (incluindo procedimentos diagnósticos e terapêuticos) e não rastreamento (sem procedimento diagnóstico/prognóstico) para osteoporose, a longo prazo, a alternativa é analisar as evidências parciais disponíveis, a saber, as relativas a cada uma das etapas do processo de screening, e combiná-las de forma a nos aproximarmos da evidência desejada. Assim, será possível ter uma indicação do impacto de um programa de rastreamento compreendendo, por exemplo, ultra-sonometria óssea do calcâneo e medidas de prevenção de quedas e de fraturas osteoporóticas do fêmur.

Considerando-se que a estruturação das políticas públicas de saúde deve estar fundamentada no diagnóstico de problemas específicos e que o problema osteoporose não está, de fato, 
contemplado, apesar de existirem protocolos bem definidos para essa finalidade (VERAS; 1995), o médico-ortopedista, que tem a oportunidade de participar de todo o processo evolutivo da patologia, desde seu diagnóstico em recém-nascidos com patologias osteometabólicas osteoporóticas, como a osteogênese imperfeita, até a identificação de fraturas osteoporóticas do idoso, encontra-se na situação angustiante de se ver, muitas vezes, impossibilitado de atuar na prevenção e no tratamento da osteoporose da população de baixa renda pela falta de acesso ao diagnóstico preconizado atualmente pela OMS. Há de se comentar, também, a falta de estímulo dos profissionais envolvidos e de suas sociedades de classe para desenvolver programas de reciclagem no aprendizado e nas condutas por meio de diretrizes. Isto pode ser verificado nos resultados do Estudo PRONAFF (MARQUES NETO et al., 2002), no qual quase sempre não há orientação para tratamento clínico da doença de base (osteoporose) no pósoperatório imediato e tardio das fraturas do fêmur em idosos, e também nas conclusões dos trabalhos do Programa Nacional de Assistência à Osteoporose do Ministério da Saúde, que tem a recomendação de capacitar melhor o médico e a rede assistencial, promover educação continuada do paciente e do médico e instituir tratamentos eficazes, seguros e economicamente mais acessíveis à população.

Em relação aos pacientes de risco, trabalho recente (CARVALHO, 2006) concluiu que as mulheres desse grupo devem ser informadas dessa situação pelos médicos ou profissionais de saúde em todas as oportunidades. 
Portanto, para que essas oportunidades sejam criadas para a população de baixa renda, é que propomos um método alternativo de avaliação do risco de fratura osteoporótica do fêmur proximal através da ultra-sonometria do calcâneo.

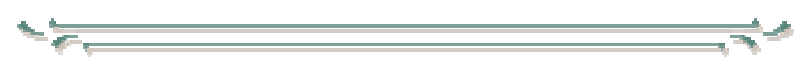




\section{CONCLUSÕES}

1 revisão bibliográfica associada aos resultados das pesquisas efetuadas permite concluir que:

- mesmo sendo a densitometria óssea o atual critério para diagnóstico de osteoporose, sua credibilidade é questionável e seu acesso é restrito;

- a população feminina e idosa de baixa renda está exposta aos riscos de fratura osteoporótica do fêmur proximal sem conhecer os riscos próprios da sua estrutura óssea;

- a ultra-sonometria óssea do calcâneo é um método preditivo de risco de fratura, principalmente do fêmur proximal, de baixo custo, que contribuiria para a identificação de mulheres com maior risco de fraturar o fêmur proximal por osteoporose e, com isso, incrementar programas para sua prevenção a um menor custo financeiro e social.

- Os sujeitos examinados formaram uma amostra de pacientes, e não somente de indivíduos, pois foram aleatóriamente escolhidos de um universo de pacientes já cadastrados em serviço de tratamento de saúde, o que torna os resultados da pesquisa especialmente importante para contemplar esse tipo de assistência publica.

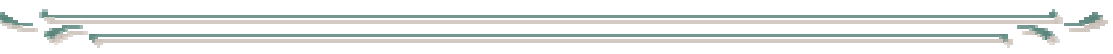




\section{REFERÊNCIAS}

AITKEN, J.M. Relationship between mortality after femoral neck fracture and osteoporisis. Osteoporosis. p. 45-8, 1987.

ALVES, J.M. et al. Caracterização de tecido ósseo por ultra-som para o diagnóstico de osteoporose. Tese de Doutoramento, Universidade de São Paulo, Instituto de Física de São Carlos, 1996b..

ATHANASIOU, K.A.; ZHU, C.F.; LANCTOR, D.R.; AGRAWAL, G.M.; WANG, X. Tissue Engineering. Mary nn Liebert, Inc., 2000.

SILVA L.K. Avaliação tecnológica em saúde: densitometria óssea e terapêuticas alternativas na osteoporose pós-menopausa. Cad. Saúde Pública, Rio de Janeiro, 19(4):987-1003, jul-ago, 2003.

BARAN et al. Quantitative ultrasound : a techniqueto target womenwith low bone mass for preventive therapy. Am j Med 1995 ;48S-51S.

BAUER, D.C. et al. Quantitative ultrasound and vertebral fracture in postmenopausal women. J. Bone Miner. Res., v.10, p.353-8, 1995. BEERS, M.H.; BERKOW, R. The Merck Manual of Geriatrics, 2000. Internet Edition Provided by Medical Services. USMEDSA, USHH. Disponível em <http://www.merck.com/pubs/>. Acesso em: 10 jan 2004 
BIANCO, A.C. Regulação endócrina da homeostase do cálcio. In: AIRES, M. M. Fisiologia Humana. Rio de Janeiro: Guanabara-Koogan. p.1525-53, 1991.

BLACK, D.M, CUMMINGS, S.R, KARPF, D.B, CAULEY, J.A., THOMPSON, D.E, NEVITT, M.C et al. Randomized trial of effect of alendronate on risk of fracture in women with existing vertebral fractures. Lancet, 348:1535-1541, 1996

BORAH, B, DUfRESNE, T.E, CHMIELEWSKI, P.A. et al.: Risedronate preserves trabecular architecture and increases bone strength in vertebra of ovariectomized minipigs as measured by three-dimensional microcomputed tomography. J Bone Miner Res 17:1139-1147, 2002.

BRUNDTLAND, G.H. The Burden of Musculoskeletal Conditions at the Start of the New Millennium. Word Health Organization and The Bone and Joint Decade 2000-2010. Geneva, 2000.

CARVALHO MI. 92. Osteoporose - visão do ortopedista. Rev Bras Ortop. 2006;41(4):91-7

CASTRO, C.H.M.; PINHEIRO, M.M.; SZEJNFELD, V.L. Prós e contras da ultrasonometria óssea de calcâneo (artigo de revisão). Rev. Ass. Med. Brasil. São Paulo, jan/mar,.p.63, 2000.

CHESNUT, C.H., ROSEN, C.J. Reconsidering the effects of antiresorptive therapies in reducing osteoporotic fracture. $J$ Bone Miner Res.;16: S193-2172, 2001.

CHESNUT, C.H. III, SILVERMAN, S., ANDRIANO, K. et al. A randomized trial of nasal spray salmon calcitonin in postmenopausal women with established osteoporosis: the Prevent Recurrence of Osteoporotic Fractures study. Am J Med.; 109: 267-276, 2000. 
CLARKE, M.J.; OXMAN, A.D. Cochrane Reviewers' Handbook 4.0 [update July 1999]. In: Review Manager (RevMan).Version 4.1. Oxford: The Cochrane Collaboration, 2000.

COMPSTON, J.E. Bone density; BMD, or corrected BMD? Bone, v. 16, n. 1, p. 5-7 1995.

CONSENSUS DEVELOPMENT CONFERENCE. Prophylaxis and treatment of osteoporosis. Am J Med, 90:107-110, 1991.

COOPER, C.; MELTON III, L. J. Epidemiology of osteoporosis. Trends Endocrinol. Metab. , 3, 224-29, 1992.

COOPER, C.; CAMPION, G.; MELTON III, L.J. Hip Fractures in the Elderly: A world-Wide Projection. Osteoporosis International, v.2, p.285-9, 1992.

COWIN. S.C. BONE MECHANICS. BOCA RATION, FL: CRC PRESS, 1989.

CUMMINGS, S.R. Epidemiology of rip fractures. Osteoporisis, p.40-3, 1987.

CUMMINGS, S.R., NEVITT, M.C. The causes of hip fractures: a hypothesis. J Gerontol Med Sci; 44: M107-111, 1989.

CUMMINGS, S.R. et al. Am J Méd; 112: 281-289, 2002.

CUMMINGS, S.R.; BLACK, D.M.; NEVITT, M.C.; BROWNER, W.S.; CAULEY. J.A.; GENANT, H.K.; MASCIOLI, S.; SCOTT, J.C.; SEELEY. D.G.; STEIGER. P.; VOGT,. T.M. The Study of Osteoporotic Fractures 
Research Group. Appendicular bone density and age predict hip fracture in women. JAMA, n.263, p. 665-8, 1990.

CURREY, J.D: Three analogies to explain the mechanical properties of bone. Biortheology, 2:1-10, 1964.

CURREY, J.D. The mechanical properties of bone. Clin.Orthop. Rel. Res., v.73, p.210-31, 1970.

DAENS, S. et al. Efficiency of quantitative ultrasound measurements as compared with dual-energy x-ray absorptiometry in the assessment of corticosteroid-induced bone impairment. Osteoporosis International, v.10, p.278-283, 1999.

DEMPSTER, D.W.; FERGUSON, P.M.W.; MELLISH, R.W.E.; COCHRAN, G.V.B.; XIE, F.; FEY, C.; HOBERT, W.; PARISIEN, M.; LINDSAY, R. Relationships between bone structure in the iliac crest and bone structure and strength in the lumbar spine. Osteoporosis Int., v.3, p.90$6,1993$.

DIETER, M; LINDSKOG, M.D., MICHAEL, R.; BAUMGAERTNER, M.D. Unstable Intertrochanteric Hip Fractures in the Elderly. J Am Acad Orthop Surg; 12:179-190, 2004.

EINHORN, T. A. The Bone Organ System: Form and Function. In: MARCUS, R.; FELDMAN, D.; KELSEY, J. Osteoporosis. San Diego: Academic Press, 1996.

FAULKNER, K. Bone Matters: are density increases necessary to reduce fracture risk? J. Bone Miner Research, n. 15 (2), p.183-6, 2000. 
FAULKNER, K.G., POCOCK, N: Future methods in the assessment of bone mass and structure. Best Practice \& Research Clinical Rheumatology, 15 (3): 359-383, July 2001.

FELICIANO A.B. et AI. O perfil do idoso de baixa renda no município de São Carlos, são Paulo, Brasil - um estudo epidemiológico.Cad. Saúde Pública, Rio de Janeiro, 20(6):1575-1585, nov-dez, 2004.

FAULKNER, K.G., CANN, C.E., HASEGAWA, B.H: Effect of bone distribution on vertebral strength: assessment with patient-specific nonlinear finite element analysis. Radiology,179 (3): 669-674, June 1991.

FERNANDES, I.C.; SILVA, A.M.S.P.; FREIRE, C.R.S.; PEREIRA, G.M.A.; PERES, M.C.M.; ALMEIDA, M.L.; CAVALCANTE, P.F.; DinK, S.M.F.; BORGES, Z.M.; MACHADO, M.S.; ALENCAR, V.M.R. Osteoporose fatores de risco e tratamento. JBM, v.80-92, 2001.

FDA - FOOD AND DRUG ADMINISTRATION The National Osteoporosis Risk Assessment (NORA) Study, published December 12, 2001 in the Journal of the Americal Medical Association (JAMA); Projeto Diretrizes - AMB. TURNER, C.H.; BURR, A.B. Basic biomechanical measurements of bone: A tutorial. Bone. v.14. p.595-608, 1993.

FRANCIS, R. M.; SUTCLIFFE, A. M.; SCANE, A. C. Pathogenesis of osteoporosis. In: STEVENSON, J.C.; LINDSAY, R. Osteoporosis. Chapman \& Hall Medical, 1998.

FREITAS et al. HCFMUSP-Rev Med, 77(1): 31-44, 1998.

FYRIE, D.P.; KIMURA, J.H. Cancellous Bone Biomechanics. J Biomech. n.32, p.1139-48, 1999. 
GASPERINO, J. Androgenic regulation of bone mass in women. Clin. Orthop. p.311-278, 1995. In: BAGNOLI, V. R. et al. Síndrome do Climatério, osteoporose: como diagnosticar e tratar. Revista Brasileira de Medicina (Grupo Editorial Moreira Jr.) São Paulo, v.55, n.12, Dez. 1998. Disponível em: <http://www.cibersaude.com.br/ revistas.asp?fase=r003\&id_materia=1529>. Acesso em: 24 jun. 2001.

GERHART, T. N. (Contributors) Fractures. Basics of Geriatric Care. In: BEERS, M. H.; BERKOW, R. (Editors).The Merck Manual of Geriatrics, Internet Edition Provided by Medical Services, $3^{\text {th }}$ ed. New Jersey: Merck \& Co., 2000.

GIBSON. L.J. The mechanical behavior of cancelous bone. J. Biomech, v.18, p.317-28, 1985.

GIBSON; L.J.; ASHBY, M.F. Solids celular. Cambridge Solid State Science Series. 2a ed. Cambridge University Press, p.429-52, 1997.

GLUER, C.C. Quantitative ultrasound techniques for the assessment of osteoporosis: expert agreement on current status. J. Bone Miner. Res. n.12, p.1288, 1997.

GLUER, C.C.; WU, C.Y.; GENANT, H.K. Broadband Ultrasoun Attenuation signals depend on trabecular orientation: a in vitro study. Osteoporosis International, v.3, p.185-91, 1993.

GLUER, C.C. et al. Three quantitative ultrasound parameters reflects bone structure. Calcif. Tissue Int., v.55, p.46-52, 1994.

GLÜER, C.C. et al. Quantitative Ultrasound Techniques for the Assessment of Osteoporosis. Expert Agreement on Current Status. J Bone Min Res, 8: 1280-1288, 1997.

GLUER, C.C.; BARKMANN, R.; HELLER, M. Quantitative ultrasound: Status 1999. Der radiologie, v.39, p.213-21, 1999. 
GOLDSTEIN, S.A; GOUlET, R.; MCCUBBREY, D. Measurement and significance of three dimensional architetecture to the mechanical integrity bone. Calcif Tissue Int. n.53 (SUPPL 1), p.1132-133, 1993.

GURALNIK, J.; HAVLIK, R. (Contributors) Demographics. Section 1. Basics of Geriatric Care. In: BEERS, M. H.; BERKOW, R.(Editors).The Merck Manual of Geriatrics, Internet Edition Provided by Medical Services, $3^{\text {th }}$ ed. New Jersey: Merck \& Co., (C) 2000.

HANS, S. et al. Ultrasound velocity and broadband attenuation over a wide range of bone mineral density. Osteoporos Int, v.6, p.291-6, 1996.

HANS, D, DARGENT, P, SCHOTT, A.M. et al. Ultrasound parameters predict hip fracture independently of hip bone density: the EPIDOS prospective study. J Bone Miner Res, 1995; 10 (Suppl): S169.

HEANEY, R.P. Qualitative factors in osteoporotic fractures: the state of the question. Osteoporosis. p.281-87, 1987.

HEANEY, R.P. Is the paradigm shifting? Bone, 33: 457-465, 2003.

HELMINEN, H.J.; KIVIRANTA, I.; TAMMI, M.; SAAMANEN, A.M.; PAUKKONENK, K.; JURVELIN, J. Joint loading - biology and health of articular structures. In: WRIGHT. Adaptation and remodelling of articular cartilage and bone tissue. $4^{\mathrm{a}}$ ed. Bristol: Cap.10,1987.

HEMERT, A.M.; VANDERBROUCK, J.P.; BIRIKENHAGER, J.C.; VALKENBURG, H.A. Osteoporotic fractures in the general population. Osteoporosis. p.38-9, 1987.

HOLLINGER, J.O.; BUCK, D.C.; BRUDER, S.P. Biology of Bone Healing: Its Impact on Clinical Therapy. In: LYNCH, S.E.; GENCO, R.J.; 
MARX, R.E. Tissue Engineering. Quintessence Publishing Co, Inc. , 1999.

IBGE, Censo Demográfico 2000. Disponível em: http://www.ibge.gov.br/. Acesso em: 12 jun. 2004

JOHNSTON, C.C.; SLEMENDA, C.W. Pathgenesis of vascularized and nonvascularized autografts. Clin. Orthop. n.197, p.32-43, 1985.

JUNQUEIRA, L. C.; CARNEIRO, J. Histologia Básica. $9^{\circ}$ ed. Rio de Janeiro: Guanabara Koogan,. p. 111-28, 1999.

KANIS J. A.; the WHO study group. Assessment of fracture risk and its implication to screening for postmenopausal osteoporosis: synopsis of a WHO report. Osteoporos. Int., v.4, p.368-81, 1994.

KAPLAN, S.J.; HAYES, W.C.; STONE, J.C.; BEAUPRE, G.S. Tensie strength of bovine trabecular bone. J. Biomech., v.18, p.723-27, 1985.

KATZ, J. L. Hard tissue as a composite material: I. Bounds on the elastic behavior. J Biomech, 4: 455-473, 1971.

KATZ, J.L.; YOON, H.S. The structure and anisotropic mechanical properties of bone. IEEE Trans Biomed Eng, 12: 878-884, 1984.

KEAVENY, T.M.; GUO, X.E.; WACHTEL, E.F. Trabecular bone is linearly elastic up to yelaing and vields by cracking. Trans. 39th ors, v.18, p.586, 1993.

KLEEREKOPER, $M$. et al. The role of three dimensional trabecular microstrusture in pathogenesis of vertebral compression fractures. Calcif. Tissue Int., v.37, p.594-97, 1985. 
KRANE et al., 1996

LANGTON, C.M.; PALMER, S.B.; PORTER, R.W. The measurement of broadband ultrasonic attenuation in cancellous bone. Engl. Med. Local, v.13, p.89-91, 1984.

LIAN, J. B.; STEIN, G. S. Osteoblast Biology. In: MARCUS, R.; FELDMAN, D.; KELSEY, J. Osteoporosis. San Diego: Academic Press. p.23-59, 1996.

LINDSAY, B. et al. Risk of new vertebral fracture in the year following a fracture, JAMA, n.285, p.320-23, 2001.

LOTZ, J.C, CHEAL, E.J, HAYES, W. C. Fracture prediction for the proximal fêmur using finit element models: Part I- linear analysis. J Biomech Eng, 113:353-360, 1991.

LUCAS, T.S, EINHORN, T.A: Osteoporosis: The role of the orthopaedist. J Am Acad Orthop Surg , 1:48-56,1993.

MAJUNDAR, S.J.; KOTHARI, M.; AUGAT, P.; NEWITT, T.M.; LIND. C.; LANG, T.; LUY, I.; GENAMT, H.K. High-resolution magnetic resonace imaging: three-dimensional trabecular bone architecture and biomechanical properties. Bone, v. 22, p. 445-54, 1998.

MARKS, R., ALLEGRANTE, J.P., RONALD MACKENZIE, C., LANE, J.M. Hip fractures among the elderly: causes, consequences and control. Ageing Res Rev. Jan; 2(1):57-93. 2003. Review.

MARQUES NETO, J. F. ; PINA, F P ; PAIVA, N A. Projeto multicêntrico de avaliação de fraturas de fêmur (PROMAFF).. Revista Brasileira de Reumatologia, São Paulo, v. 42, n. 1, p. 38-38, 2002. 
MARQUES NETO, J. F. Programa Nacional de Prevenção de Osteoporose - estagio II. Perfil uiltrassonometrico MARSHALL, D.; JOHUELL, O.; WEDEL, H. Meta-analysis of how well measures of bone mineral density predict ocurrence of osteoporotic fractures. BMJ, 1996.

MARTIN, T.J.; DEMPSTER, D.W. Bone structure and Cellular Activity. In: STEVENSON, J. C.; LINDSAY, R. Osteoporosis. Chapman \& Hall Medical, p.1-28, 1998.

MCKELVIE, M.L; FORDHAM, J.; CLIFFORD, C.; PALMER, S.B. In vitro comparison of quantitative computed tomography and broadband ultrasonic attenuation of trabecular bone. Bone, v.10, p.101-4.

MELTON III, L.J.; COOPER, C. Epidemiology. In: STEVENSON, J. C.; LINDSAY, R. Osteoporosis. Chapman \& Hall Medical. p.65-84, 1998.

MEUNIER at al. Ultrasound Parameters Predict Hip Fracture Independently of Hip Bone Density: The EPIDOS Prospective Study. J Bone Min Res 10 (Suppl 1): S169, 1995.

MEYER, H.E., TVERDAL, A, FALCH, J.Á., PEDERSEN, J.I. Factors associated with mortality aft.er hip fracture. Osteoporos Int. 11:228$232,2000$.

MERCK - The 18th Edition of The Merck Manual of Diagnosis and Therapy.- 2006

MINAKUSH, Y., INOUE, N., LEVIN, R. et al: Ultrasound velocity in human calcaneus and its relations to mechanical properties and trabecular structure. Trans Orthop Res Soc 22:207, 1997. 
MOSEKILDE, L. Sex difference in age-related losso of vertebral trabecular bone mass and structure - biomechanical consequences. Bone, n.10, p.425-32, 1889.

MUNDY 1993

NEER, R.M., ARNAUD, C.D., ZANCHETTA, J.R. et al. Effect of parathyroid hormone (1-34) on fractures and bone mineral density in postmenopausal women with osteoporosis. $N$ Engl J Med.; 344:1434$1441,2001$.

NJEH, C.F.; LANGTON, C.M. The effect of cortical endplates on ultrasound velocity through the calcaneaus an in vitro study. The british journal of radiology, n.70, p.504-10, 1997.

NJEH, C.F. et al. Radiation exposure in bone mineral density assessment. Applied Radiation and Isotopes. n.50, p.215-36, 1999.

$\mathrm{NIH}$ consensus statement. Osteoporosis prevention, diagnosys and therapy. March 27-29;17(1): 1-45, 2000.

PARFITT. A.M. Age-related structural changes in trabecular and cortical bone: cellular mechanisms and biochemical consequences. Calcif Tissue Int. n.36 (supll), p.123-28, 1984.

PASCHOAL, S.M.P. Epidemiologia do envelhecimento. In: Papaléo Netto M, organizador. Gerontologia.São Paulo: Atheneu; p. 26-43, 1996.

PINTO NETO, A.M. et al,. Consenso brasileiro de osteoporose 2002. Revista Brasileira de Reumatologia, v.42, n.6, p.343-53, 2002. 
PORTER, R., MILleR, C., GRANIGER, D., PALMER, S. Prediction of hip fracture in elderly women: a prospective study. $\mathrm{Br}$ Med J, 301: 638$641,1990$.

PROMED PENECDOR - Programa de avaliação epidemiológica, educação continuada e assistência à osteoporose no Brasil. Ministério da Saúde. 2000.

CRANNEY A, GUYATT G, GRIFFITH L, et al. Meta-analyses of therapies forpostmenopausal osteoporosis. IX: Summary of metaanalyses of therapies for postmenopausal osteoporosis. Endocr Rev. $2002 ; 23(4): 570-578$.

REGINSTER, J.Y, MINNE, H.W, SORENSEN, O.H. et al. Randomized trial of the effects of risedronate on vertebral fractures in women with established postmenopausal osteoporosis. Osteoporos Int.; 11:83-91, 2000.

RODRIGUES, M. E. SOUZA. Análise do risco de fratura óssea por ultrasonometria e ensaio mecânico de compressão. Dissertação de Mestrado. Bioengenharia. USP, 2003.

ROSSMAN et al., 1989

ROUX, C. et al. Broadband ultrasound attenuation imaging: A new imaging method in osteoporosis. J. Bone Miner. Res., v.11, p.1112-18, 1996.

SAKAKI, M.H., OLIVEIRA, A R., COELHO, F.F et al. Study of the proximal femoral fractures mortatlity in elderly patients. Acta ortop. bras., Oct./Dec. 2004, vol.12, no.4, p.242-249. ISSN 1413-7852. 
SIMÕES, R. D. et al. Diagnóstico e tratamento da osteoporose. Fascículos de Atualização em Climatério- FAC. Disponível em: <http://www.dr-online.com.br>. Acesso em: 12 mai 2000.

TURNER, C.H.; BURR, A B. Basic biomechanical measurements of bone: A tutorial. Bone, 14, p. 595-608, 1993.

TURNER, C.H.; EICH, M. Ultrasonic Velocity as a predictor of strength in bovino cancellous bone. Calcif. Tissue Int., v.49, p.116-19, 1991.

VERAS, R.P. A população idosa no Brasil: considerações acerca do uso de indicadores de saúde. In: Minayo MC, organizador. Os muitos brasis: saúde e população na década de oitenta. São Paulo: Editora Hucitec/Rio de Janeiro: ABRASCO; 1995. p. 320-37.

WEINSTEIN, R.S. et al. J Boné Miner Res; 15: 621-625, 2000.

WHO Study Group. Assesment of fracture risk and its application to screening for postmenopausal osteoporosis. Geneva: World Health Organisation, 1994. 


\section{ANEXO A}

\section{Portaria ${ }^{0} 470$ de 24 de Julho de 2002.}

O Secretário de Assistência à Saúde, no uso de suas atribuições legais,

Considerando a Portaria GM/MS no 1.318, de 23 de julho de 2002, que define o Grupo 36 Medicamentos, da Tabela Descritiva do Sistema de Informações Ambulatoriais do Sistema Único de Saúde;

Considerando a necessidade de estabelecer Protocolo Clínico e Diretrizes Terapêuticas para 0 tratamento da Osteoporose, que contenha critérios de diagnóstico e tratamento, observando ética e tecnicamente a prescrição médica, racionalize a dispensação dos medicamentos preconizados para 0 tratamento, regulamente suas indicações e seus esquemas terapêuticos e estabeleça mecanismos de acompanhamento de uso e de avaliação de resultados garantindo assim a prescrição segura e eficaz;

Considerando a Consulta Pública a que foi submetido o Protocolo Clínico e Diretrizes Terapêuticas - Osteoporose por meio da Portaria SAS no 286, de 14 de agosto de 2000 - Anexo II, que promoveu sua ampla discussão e possibilitou a participação efetiva da comunidade técnico científica, sociedades médicas, profissionais de saúde e gestores do Sistema Único de Saúde na sua formulação, e

Considerando as sugestões apresentadas ao Departamento de Sistemas e Redes Assistenciais no processo de Consulta Pública acima referido, resolve:

Art. $1^{0}$ - Aprovar, na forma do Anexo desta Portaria, o PROTOCOLO CLÍNICO E DIRETRIZES TERAPÊUTICAS - OSTEOPOROSE -, Bisfosfonados, Calcitonina, Carbonato de Cálcio, Vitamina D, Estrógenos e Raloxifeno.

$\S 1^{0}$ - Este Protocolo, que contém o conceito geral da doença, critérios de diagnóstico, critérios de inclusão/exclusão de pacientes no protocolo de tratamento, esquemas terapêuticos preconizados para 0 tratamento da Osteoporose e mecanismos de acompanhamento e avaliação deste tratamento, é de caráter nacional, devendo ser utilizado pelas Secretarias de Saúde dos estados, do Distrito Federal e dos municípios, na regulação da dispensação dos medicamentos nele previstos.

$\S 2^{0}$ - As Secretarias de Saúde que já tenham definido Protocolo próprio com a mesma finalidade, deverão adequá-lo de forma a observar a totalidade dos critérios técnicos estabelecidos no Protocolo aprovado pela presente Portaria.

$\S 3^{0}$ - É obrigatória a observância deste Protocolo para fins de dispensação dos medicamentos nele previstos.

$\S 4^{0}$ - É obrigatória a cientificação do paciente ou de seu responsável legal, dos potenciais riscos e efeitos colaterais relacionados ao uso dos medicamentos preconizados para o tratamento da Osteoporose, 0 que deverá ser formalizado através da assinatura do respectivo Termo de Consentimento Informado, conforme modelo constante do Protocolo. contrário.

Art. $2^{0}$ - Esta Portaria entra em vigor na data de sua publicação, revogadas as disposições em

\section{JPROTOCOLO CLÍNICO E DIRETRIZES TERAPÊUTICAS - OSTEOPOROSE}

Portaria SAS/MS no 470, de 23 de julho de 2002.

\section{CRITÉRIO DE INCLUSÃO}

Osteoporose definida por escore $\mathrm{T}$ igual ou inferior a $-2,5$ desvios padrão, com

ou

sem fraturaprévia.

4.1. Exames Complementares Exigidos

- Densitometria óssea recente (realizada há, no máximo, 1 ano)

- Calcemia

- Calciúria de 24 horas 
ANEXO B

\section{QUESTIONÁRIO}

PESQUISA:

DETERMINAÇÃO ULTRA-SONOMÉTRICA DA DENSIDADE ÓSSEA EM MULHERES ACIMA DE 60 ANOS

PESQUISADOR:

Dr. LUIZ TADEU DE MOURA FACHINE

INSTITUIÇÕES:

CENTRO REGIONAL DE REABILITAÇÃO DE ARARAQUARA-

PROGRAMA DE SAÚDE DO IDOSO

ORTOTRAUMA - ARARAQUARA

IDENTIFICAÇÃO:

NOME:

ANOS

PRONTUÁRIO : 


\section{RESPONDA ÀS QUESTÕES ESCOLHENDO UMA DAS RESPOSTAS}

1. Logo após a menopausa você tomou hormônio do ginecologista por pelo menos 5 anos?

$$
\text { SIM NÃO NÃO SEI }
$$

2- Durante sua vida tomou medicação corticóide ou para convulsão e Epilepsia ?

$$
\text { SIM NÃO NÃO SEI }
$$

3- Você é ou foi fumante por longo tempo ?

$$
\text { SIM NÃO NÃO SEI }
$$

4- Você está ficando mais baixa (menor estatura) ou com corcunda-(costas encurvadas) ?

$$
\text { SIM NÃO NÃO SEI }
$$

5- Você já teve alguma dessas fraturas ?
COLUNA
QUADRIL
PUNHO
NÃO TIVE

6- Pessoas de sua família tiveram alguma dessas fraturas?

$$
\text { SIM NÃO NÃO SEI }
$$

7- O que você sabe sobre osteoporose você aprendeu com:
MÉDICO
TELEVISÃO
REVISTA
RÁDIO
AMIGOS NÃO SABE

8- Para você, osteoporose significa:

DOR NAS JUNTAS

9-Você tem alguma dessas doenças crônicas:
DIABETES
PRESSÃO ALTA
REUMATISMO
OSTEOPOROSE NÃO TENHO

10- Você já tomou algum remédio RECEITADO POR MÉDICO para tratar osteoporose ? SIM NÃO NÃO SEI

11- Se foi receitado e você não tomou corretamente, foi porque

PREÇO É ALTO NÃO ENTENDEU COMO TOMAR NÃO SABE 


\section{ANEXO C}

Achilles Express ${ }^{\mathrm{TM}}$

\section{Precision in vivo}

2.0\% CV in osteoporotic patients

\section{Patient Throughput}

1-minute measurement

\section{Signal Analysis}

Real-time, Fourier transform analysis with bi-directional

measurement and convergence algorithms

\section{UItrasonometry Transducers}

Fluid-coupled, through-transmission

Quarter wave-matched, broadband single element (25 mm diameter) Center frequency $500 \mathrm{KHz}$ 


\section{Results}

STIFFNESS Index

T-score and \% Young Adult

Z-score and \% Age-Matched

\section{Display}

LCD "touch" screen

Swivels to multiple positions

\section{Printer}

Thermal printer

Batch printing

Results can be attached to preprinted report form

\section{Fluid Coupling System}

Fully automated and self-contained

Heated to $33^{\circ} \mathrm{C}\left(92^{\circ} \mathrm{F}\right)$

Replaceable silicon membranes

Water-soluble ultrasonic gel

\section{Electrical Requirements}


95-240 volts, 50/60 Hz@4A

\section{Physical Factors}

Integrated transportable design

Dimensions (WxHxD): $25 \times 31 \times 61 \mathrm{~cm}(10 \times 12 \times 24$ in)

Operating range temperature: $15^{\circ}-35^{\circ} \mathrm{C}\left(59^{\circ}-95^{\circ} \mathrm{F}\right)$

Humidity: $20-80 \%$

Weight: $10 \mathrm{~kg}$ (22 lbs)

\section{GE LUNAR Support}

Achilles Express is supported by GE LUNAR.

Training and technical service are available worldwide.

\section{Fast and Comfortable}

- 1-minute measurement

- Fully automated

- No x-rays

\section{T-Scores}

- Fracture risk assessment

- Comparable to axial 
BMD

\section{Precise Measurement}

- $2 \%$ in vivo

- Fixed transducers

- Reduced operator dependency

\section{Fully Self-Contained}

- LCD touch-screen menu

- Built-in microcomputer and printer

- 100-measurement memory

\section{Cost-Effective}

- Ideal for physicians' offices

- No special training

- Proven reliability

\section{Compact Design}

- Occupies less than 2 square feet of office space

- Weighs only 22 pounds

- Fits on front seat or in trunk of car

- Built-in ergonomic carrying handle 